\title{
COMPUTATIONAL METHODOLOGY FOR BLEED AIR ICE PROTECTION SYSTEM PARAMETRIC ANALYSIS
}

\author{
A Thesis by \\ Rodrigo Hoffmann Domingos \\ Bachelor of Science, Universidade Federal de Santa Catarina, 2001
}

Submitted to the Department of Aerospace Engineering and the faculty of the Graduate School of

Wichita State University in partial fulfillment of the requirements for the degree of Master of Science 
(C) Copyright 2010 by Rodrigo Hoffmann Domingos

All Rights Reserved 


\section{COMPUTATIONAL METHODOLOGY FOR BLEED AIR ICE PROTECTION SYSTEM PARAMETRIC ANALYSIS}

The following faculty members have examined the final copy of this thesis for form and content, and recommend that it be accepted in partial fulfillment of the requirement for the Master of Science with a major in Aerospace Engineering.

Michael Papadakis, Committee Chair

Scott Miller, Committee Member

Ikram Ahmed, Committee Member 


\section{ACKNOWLEDGMENTS}

I would like to acknowledge the advice and guidance of Dr. Michael Papadakis, and to thank him for the opportunity to work in the Aircraft Icing Lab at WSU on the development of this thesis. I am grateful to the researchers and students in the Aircraft Icing Lab for their help and fellowship, and to Hsiung-Wei Yeong and Alonso Oscar Zamora Rodriguez for their support on the execution of the present work.

I am thankful to Luis Carlos de Castro Santos and Roberto Petrucci, my supervisors at EMBRAER. The accomplishment of this thesis would have been extremely difficult without their support.

I am immensely grateful to my wife and daughter for their lovely companionship throughout these years. 


\begin{abstract}
Aircraft in-flight icing is a major safety issue for civil aviation, having already caused hundreds of accidents and incidents related to aerodynamic degradation due to post takeoff ice accretion.

Airplane makers have to protect the airframe critical surfaces against ice build up in order to ensure continued safe flight. Ice protection is typically performed by mechanical, chemical, or thermal systems. One of the most traditional and still used techniques is the one known as hot-air anti-icing, which heats the interior of the affected surfaces with an array of small hot-air jets generated by a piccolo tube. In some cases, the thermal energy provided by hot-air ice protection systems is high enough to fully evaporate the impinging supercooled droplets (fully evaporative systems), while in other cases, it is only sufficient to maintain most of the protected region free of ice (running wet systems). In the latter case, runback ice formations are often observed downstream of the wing leading edge depending on hot-air, icing, and flight conditions.

The design process of hot-air anti-icing systems is traditionally based on icing wind tunnel experiments, which can be very costly. The experimental effort can be significantly reduced with the use of accurate three-dimensional computational fluid dynamic (CFD) simulation tools. Nevertheless, such type of simulation requires extensive CPU time for exploring all the design variables. This thesis deals with the development of an efficient hot-air anti-icing system simulation tool that can reduce the computational time to identify the critical design parameters by at least two orders of magnitude, as compared to 3-d CFD tools, therefore narrowing down the use of more sophisticated tools to just a small subset of the entire design space.
\end{abstract}

The hot-air anti-icing simulation tool is based on a combination of available CFD 
software and a thermodynamic model developed in the present work. The computation of the external flow properties is performed with FLUENT (in a 2-d domain) by assuming an isothermal condition to the airfoil external wall. The internal skin heat transfer is computed with the use of local Nusselt number correlations developed through calibrations with CFD data. The internal and external flow properties on the airfoil skin are provided as inputs to a steady state thermodynamic model, which is composed of a 2-d heat diffusion model and a 1-d uniform film model for the runback water flow.

The performance of the numerical tool was tested against 3-d CFD simulation and experimental data obtained for a wing equipped with a representative piccolo tube anti-icing system. The results demonstrate that the simplifications do not affect significantly the fidelity of the predictions, suggesting that the numerical tool can be used to support parametric and optimization studies during the development of hot-air anti-icing systems. 


\section{TABLE OF CONTENTS}

Chapter

Page

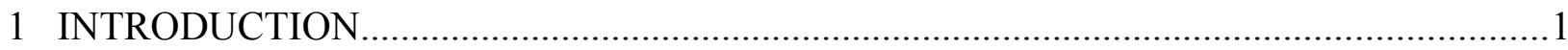

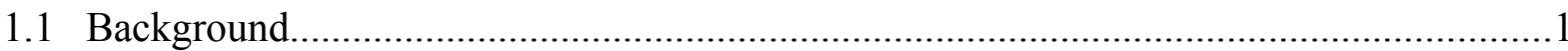

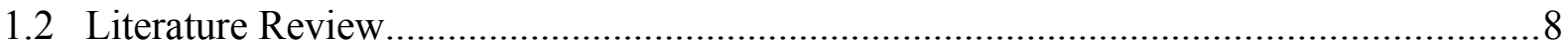

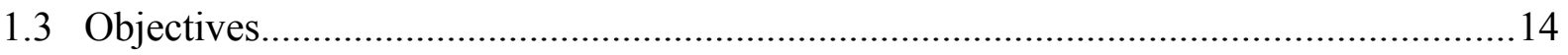

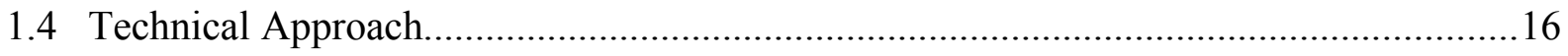

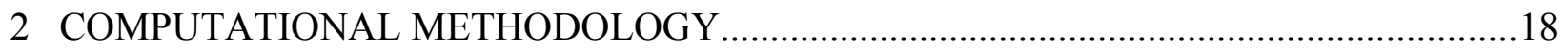

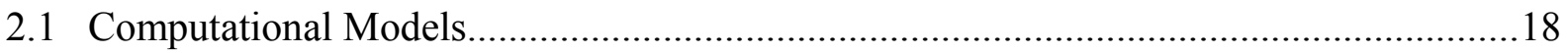

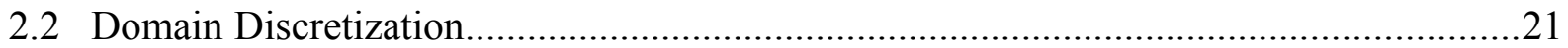

2.2.1 External Flow Computational Grid..................................................................22

2.2.2 Thin Passage Computational Grid........................................................................23

2.2.3 Solid Wall Computational Grid.....................................................................25

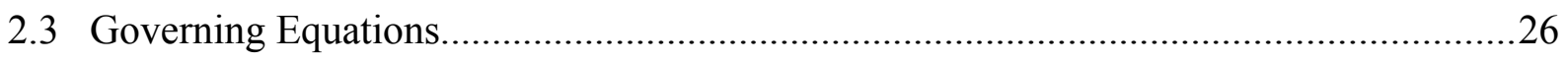

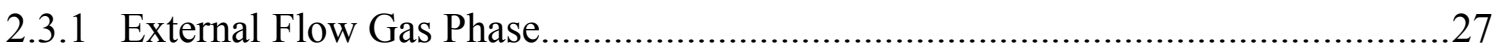

2.3.2 External Flow Liquid Phase (Water Catch Efficiency).....................................31

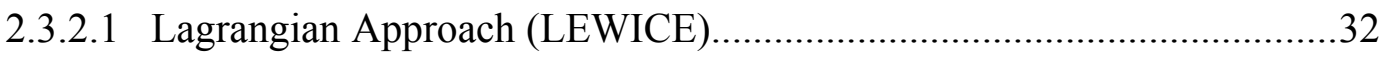

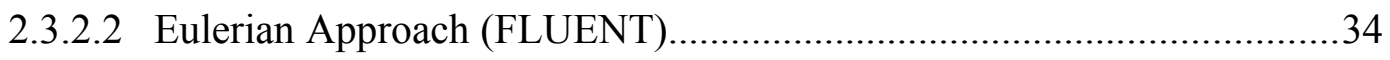

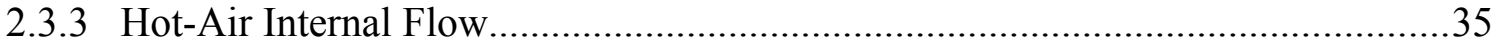

2.3.3.1 Heat Transfer Correlation for Hot-Air Impinging Jet...........................36

2.3.3.2 Heat Transfer Correlation for Thin Passages.....................................41

2.3.3.3 Thin Passage Laminar Flow Simulation.............................................43

2.3.4 Hot-Air Anti-icing Thermodynamic Model........................................................44

2.3.4.1 Water Film Flow (Runback)........................................................47

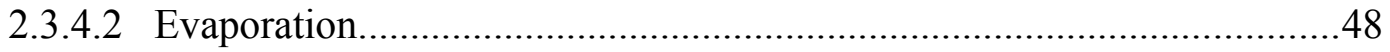

2.3.4.3 Convective Heat Transfer.................................................................50

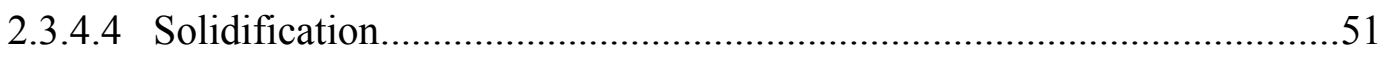

2.3.4.5 Heat Diffusion in the Solid Wall......................................................51

2.3.4.6 Sensible Heat Exchange ..................................................................56 


\section{TABLE OF CONTENTS (Cont.)}

Chapter $\quad$ Page

2.3.4.7 Kinetic Heating from Impinging Droplets...........................................57

2.3.4.8 Energy and Mass balances................................................................58

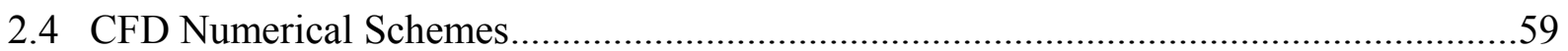

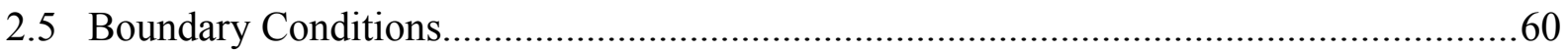

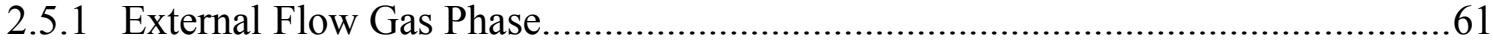

2.5.2 External Flow Liquid Phase (Water Collection Efficiency)...............................62

2.5.3 Thin Passage Laminar Flow Simulation......................................................62

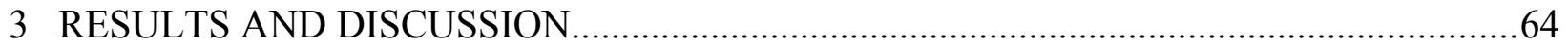

3.1 External Flow Gas Phase.........................................................................................66

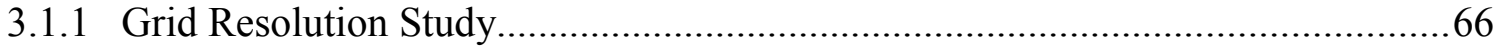

3.1.2 Assessment of the Isothermal Boundary Condition...................................... 70

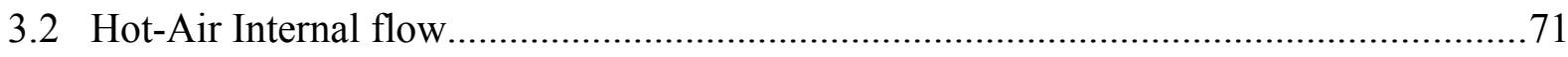

3.2.1 Calibration of Heat Transfer Correlation for Hot-Air Impinging Jet..................71

3.2.2 Calibration of Heat Transfer Correlation for the Thin Passage Flow....................78

3.3 Thermodynamic Model for Hot-air Anti-icing Systems................................................ 81

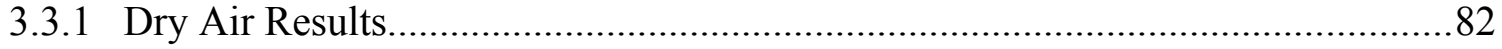

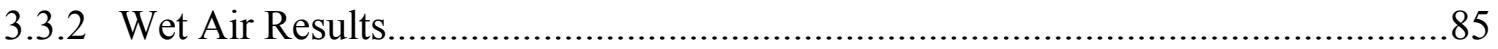

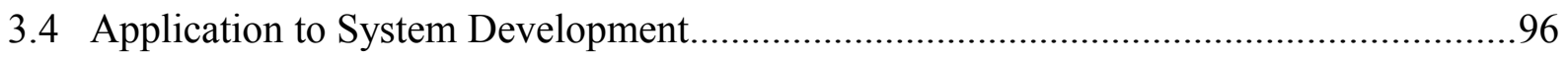

4 CONCLUSIONS AND RECOMMENDATIONS ....................................................... 99

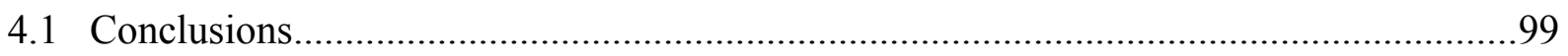

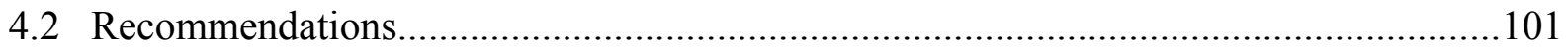




\section{LIST OF ABBREVIATIONS}

$\begin{array}{ll}\text { 2-d } & \text { Two-dimensional } \\ \text { 3-d } & \text { Three-dimensional } \\ \text { CFD } & \text { Computational Fluid Dynamics } \\ \text { CV } & \text { Control Volume } \\ \text { FAA } & \text { Federal Aviation Administration } \\ \text { FAR } & \text { Federal Aviation Regulations } \\ \text { IRT } & \text { Icing Research Tunnel (at NASA Glenn Research Center) } \\ \text { LE } & \text { Leading Edge } \\ \text { LS } & \text { Lower Surface (airfoil) } \\ \text { NASA } & \text { National Aeronautics and Space Administration } \\ \text { N-S } & \text { Navier-Stokes } \\ \text { ONERA } & \text { Office National D'études Et de Recherches Aérospatiales } \\ \text { RANS } & \text { Reynolds-Averaged Navier-Stokes } \\ \text { SLD } & \text { Supercooled Large Droplets } \\ \text { US } & \text { Upper Surface (airfoil) } \\ \text { WSU } & \text { Wichita State University }\end{array}$




\section{LIST OF SYMBOLS}

\begin{tabular}{|c|c|c|}
\hline$\alpha$ & Angle of attack & {$\left[{ }^{\circ}\right]$} \\
\hline$\beta$ & Local water collection (or catch) efficiency & \\
\hline$\mu$ & Absolute viscosity & {$[\mathrm{Pa}-\mathrm{s}]$} \\
\hline$\rho$ & Fluid density & {$\left[\mathrm{kg} / \mathrm{m}^{3}\right]$} \\
\hline$A$ & Surface area & {$\left[\mathrm{m}^{2}\right]$} \\
\hline$c$ & $\begin{array}{l}\text { Curvilinear coordinate (surface distance over upper and lower } \\
\text { airfoil surfaces from highlight) }\end{array}$ & {$[\mathrm{m}]$} \\
\hline$C$ & Airfoil chord & {$[\mathrm{m}]$} \\
\hline$C_{i c e}$ & Specific heat of ice & {$[\mathrm{J} / \mathrm{kg}-\mathrm{K}]$} \\
\hline$c_{n}$ & Piccolo hole pitch in spanwise direction & {$[\mathrm{m}]$} \\
\hline$C_{p}$ & Specific heat at constant pressure & {$[\mathrm{J} / \mathrm{kg}-\mathrm{K}]$} \\
\hline$C_{w}$ & Specific heat of water & {$[\mathrm{J} / \mathrm{kg}-\mathrm{K}]$} \\
\hline$d$ & Diameter of hot-air jet orifice on piccolo tube & {$[\mathrm{m}]$} \\
\hline$D$ & Piccolo tube diameter & {$[\mathrm{m}]$} \\
\hline$D_{a w}$ & Binary mass diffusion coefficient for air-water vapor mixtures & {$\left[\mathrm{m}^{2} / \mathrm{s}\right]$} \\
\hline$D P$ & Impinging jet heat transfer correlation parameter & \\
\hline$e_{e}$ & $\begin{array}{l}\text { Saturated evaporative pressure of water at the external skin } \\
\text { temperature }\end{array}$ & {$[\mathrm{Pa}]$} \\
\hline$e_{e d g}$ & $\begin{array}{l}\text { Saturated evaporative pressure of water at the static temperature } \\
\text { of the boundary layer edge }\end{array}$ & {$[\mathrm{Pa}]$} \\
\hline$h_{e}$ & Convective heat transfer coefficient on the airfoil external skin & {$\left[\mathrm{W} / \mathrm{m}^{2}-\mathrm{K}\right]$} \\
\hline$h_{i}$ & Convective heat transfer coefficient on the airfoil internal skin & {$\left[\mathrm{W} / \mathrm{m}^{2}-\mathrm{K}\right]$} \\
\hline $\bar{h}_{i}$ & Span-weighted average of internal heat transfer coefficient & {$\left[\mathrm{W} / \mathrm{m}^{2}-\mathrm{K}\right]$} \\
\hline
\end{tabular}




\section{LIST OF SYMBOLS (Cont.)}

\begin{tabular}{|c|c|c|}
\hline$h_{m}$ & Mass transfer coefficient & {$[\mathrm{m} / \mathrm{s}]$} \\
\hline HCONST & Impinging jet heat transfer correlation parameter & \\
\hline$k$ & Thermal conductivity & {$[\mathrm{W} / \mathrm{m}-\mathrm{K}]$} \\
\hline$L$ & Lewis number & \\
\hline$L_{f r}$ & Latent heat of solidification of water & {$[\mathrm{J} / \mathrm{kg}]$} \\
\hline$L_{v}$ & Latent heat of evaporation of water & {$[\mathrm{J} / \mathrm{kg}]$} \\
\hline LWC & Liquid Water Content & {$\left[\mathrm{g} / \mathrm{m}^{3}\right]$} \\
\hline$M_{e d g}$ & Mach number at the edge of boundary layer in the external flow & \\
\hline$\dot{m}^{\prime}$ & Hot-air mass flow rate per unit span & {$[\mathrm{kg} / \mathrm{s}-\mathrm{m}]$} \\
\hline$\overline{\dot{m}^{\prime}}$ & $\begin{array}{l}\text { Hot-air mass flow rate normalized by piccolo tube effective } \\
\text { length }\end{array}$ & {$[\mathrm{kg} / \mathrm{s}-\mathrm{m}]$} \\
\hline$\dot{m}_{\text {evap }}$ & Evaporation rate & {$[\mathrm{kg} / \mathrm{s}]$} \\
\hline$\dot{m}_{i m p}$ & Impingement rate (water catch rate) & {$[\mathrm{kg} / \mathrm{s}]$} \\
\hline$\dot{m}_{f r}$ & Freezing rate & {$[\mathrm{kg} / \mathrm{s}]$} \\
\hline MVD & Median Volumetric Diameter & {$[\mu \mathrm{m}]$} \\
\hline$(M W)_{w}$ & Molecular weight of water & {$[\mathrm{kg} / \mathrm{kg}-\mathrm{mol}]$} \\
\hline$n$ & Normal direction with respect to the airfoil wall & \\
\hline$N_{f r}$ & Freezing fraction & \\
\hline$N u_{d}$ & $\begin{array}{l}\text { Local Nusselt number over internal skin on impinging jets region, } \\
\text { based on hot-air jet orifice diameter }\end{array}$ & \\
\hline$N u_{t}$ & $\begin{array}{l}\text { Local Nusselt number due to thin passage flow, based on passage } \\
\text { thickness }\end{array}$ & \\
\hline$N_{w}$ & Wetness factor of external skin & \\
\hline
\end{tabular}




\section{LIST OF SYMBOLS (Cont.)}

\begin{tabular}{|c|c|c|}
\hline$P$ & Air static pressure & {$[\mathrm{Pa}]$} \\
\hline$P_{0}$ & Ambient total pressure & {$[\mathrm{Pa}]$} \\
\hline $\operatorname{Pr}$ & Prandtl Number & \\
\hline$q_{c}$ & $\begin{array}{l}\text { Heat diffusion within the airfoil wall in the direction of the } \\
\text { curvilinear coordinate } c\end{array}$ & {$[\mathrm{~W}]$} \\
\hline$q_{e}$ & Net convective heat flux on the external skin & {$[\mathrm{W}]$} \\
\hline$q_{\text {evap }}$ & Latent heat flux due to evaporation & {$[\mathrm{W}]$} \\
\hline$q_{f r}$ & Latent heat flux due to freezing & {$[\mathrm{W}]$} \\
\hline$q_{i}$ & Convective heat flux on the external skin & {$[\mathrm{W}]$} \\
\hline$q_{i}^{\prime \prime}$ & Heat flux per unit surface area on the internal skin & {$\left[\mathrm{W} / \mathrm{m}^{2}\right]$} \\
\hline$q_{k e}$ & Droplets kinetic energy release rate & {$[\mathrm{W}]$} \\
\hline$q_{n}$ & Heat diffusion in the airfoil wall normal direction & \\
\hline$q_{s}$ & Spanwise heat diffusion in the solid domain & {$[\mathrm{W}]$} \\
\hline$q_{\text {sens }}$ & Rate of sensible heat exchange with incoming water & {$[\mathrm{W}]$} \\
\hline$r$ & $\begin{array}{l}\text { Surface (curvilinear) distance from a given point on the internal } \\
\text { skin to the stagnation point of the nearest hot-air jet, as defined in } \\
\text { Fig. } 2.11 \mathrm{c}\end{array}$ & {$[\mathrm{m}]$} \\
\hline$\hat{R}$ & Molar ideal gas constant & {$[\mathrm{J} / \mathrm{kg}-\mathrm{mol}-\mathrm{K}]$} \\
\hline rec & Recovery factor & \\
\hline $\operatorname{Re}_{d}$ & Reynolds number based on hot-air jet orifice diameter, $d$ & \\
\hline$R e_{t}$ & $\begin{array}{l}\text { Reynolds number at inlet of the thin passage, based on the inlet } \\
\text { thickness, } t\end{array}$ & \\
\hline$R E P$ & Impinging jet heat transfer correlation parameter & \\
\hline
\end{tabular}




\section{LIST OF SYMBOLS (Cont.)}

$R P \quad$ Impinging jet heat transfer correlation parameter

$R R P \quad$ Impinging jet heat transfer correlation parameter

$t \quad$ Thin passage thickness

[m]

$s$

Surface distance in the spanwise direction

[m]

$T_{e} \quad$ External surface temperature

$T_{\text {edg }} \quad$ Air static temperature on the edge of the boundary layer

$T_{f r} \quad$ Freezing point temperature for water

$T_{h} \quad$ Bulk (or mixture) temperature of air at the inlet of thin passage flow computational domain

$T_{i} \quad$ Internal surface temperature

$T_{p} \quad$ Total temperature of air in a piccolo tube cross section

$\bar{T}_{p} \quad$ Average of total temperature of air $T_{p}$ along piccolo tube

$T_{\text {rec }} \quad$ Recovery temperature at the airfoil external surface

$T_{0} \quad$ Ambient total temperature

$T_{\infty} \quad$ Freestream static temperature

$V_{\infty} \quad$ Freestream speed

$z \quad$ Distance from the piccolo orifice exit plane to the impingement point at the leading edge wall

[m]

$Z P \quad$ Impinging jet heat transfer correlation parameter 


\section{CHAPTER 1 \\ INTRODUCTION}

\subsection{Background}

Aircraft in-flight icing is caused by supercooled water droplets, ice crystals, and mixed phase particles suspended in the atmosphere. Despite being below the freezing point, these particles can be in liquid phase [1]. When there is enough evaporative and convective cooling, the super cooled liquid droplets tend to freeze upon impact on unheated solid surfaces [2]. The Federal Aviation Administration (FAA), according to its Federal Airworthiness Regulations (FAR) Part 25, classifies the particles in suspension as [3]:

$\rightarrow$ Appendix C: Small Supercooled Droplet, with median volumetric diameters (MVD) spanning from 15 to $40 \mu \mathrm{m}$

$\rightarrow$ Appendix D (proposed): Ice crystals, happening typically near convective weather; and mixed phase

$\rightarrow$ Appendix X (proposed): Large Supercooled Droplet, representative of freezing rain \& freezing drizzle, with MVD up to $2000 \mu \mathrm{m}$

The forward facing surfaces of airplanes are the most susceptible to impact with suspended droplets, specially the leading edges (LE) of engine inlets, tail planes, wings, rotors, and instrumentation probes $[4,5]$. Ice accreted on the airframe can shed and be ingested by rearmounted engines, damaging compressor blades and even causing combustors to flame-out. On aerodynamic surfaces, icing generally decreases lift and increases drag. Iced probes can produce false instrument readings, which in turn can lead to pilot confusion and sometimes to fatal mistakes [1]. The amount of water that can be collected by the airframe in flight depends on the 
water impingement efficiency (or catch efficiency). The impingement efficiency is determined by the trajectory of the droplets with respect to exposed surface, which depends on the airplane speed, surface shape and angle of attack; droplet size, shape, and density; air temperature, density, and viscosity.

Different sizes and shapes of ice can form depending on the cloud and flight conditions [1]. For very cold weather, most droplets freeze entirely upon impact, entrapping small quantities of air and forming rime ice. This kind of ice shape normally has a single horn, a relatively smooth surface, and tends to conform somewhat to the airfoil shape. Conversely, in warmer conditions part of the collected water does not freeze. Instead, the residual liquid phase can shed into the airstream or flow over the surface and freeze at another location. The result is a rough ice shape with sometimes double horns and/or a lobster tail aspect, named glaze ice. Intermediary ice shapes can also form, being classified as mixed ice. An illustration of rime and glaze icing regimes is provided in Fig 1.1.

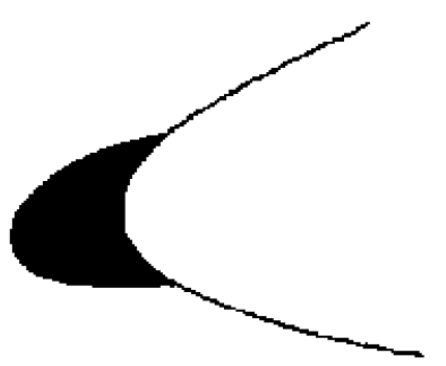

1.1a. Rime ice shape [6].

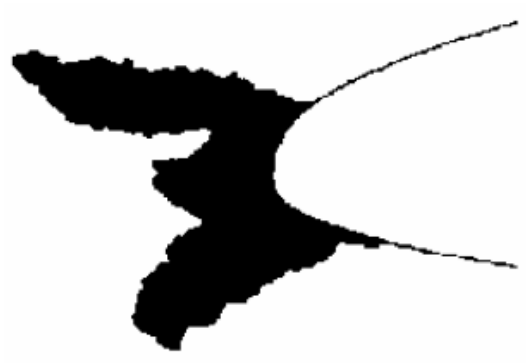

1.1b. Glaze ice shape, double horns [6].

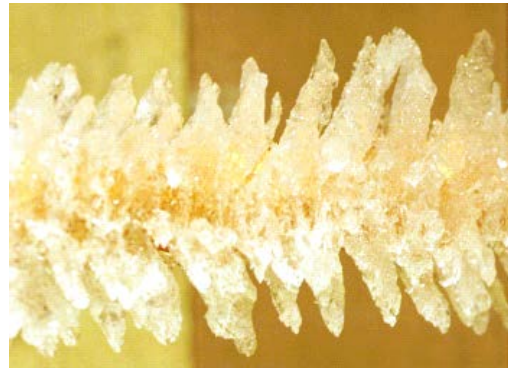

1.1c. Glaze ice shape, lobster tail [8].

Figure 1.1: Different types of ice shapes.

The time of exposure to the icing cloud is an important parameter that affects the amount of ice build up. On the experiments performed in [7], for instance, a general aviation airfoil (NLF-0414) showed a reduction of 35\% in the maximum lift coefficient for a 6-minutes glaze ice 
shape and a reduction of $45 \%$ for a 22.5 -minutes glaze ice shape. Similarly, stall angles were reduced by $35 \%$ and $65 \%$ respectively.

The phenomenon of in-flight icing is a major safety issue for general aviation and small commuter aircraft. In the USA, from 1978 to 2002, according to the information extracted from the public databases of NTSB, FAA and NASA, at least 645 accidents and incidents involving purely aerodynamic degradation took place at some point after the completion of the takeoff phase [9].

Many aircraft ice protection techniques have been developed to either prevent ice accretion or cyclically remove the accumulated ice. Ice protection systems can be divided into two main categories named anti-icing and de-icing systems.

Anti-icing systems prevent the impinging droplets from turning into ice on critical surfaces, and can be further divided into two types:

$\rightarrow$ Thermal anti-icing: removes completely or partially the incoming water by heating the affected surfaces

$\rightarrow$ Chemical anti-icing: spreads a layer of fluid that depresses the water freezing temperature

De-icing systems repeatedly remove the accreted ice by weakening the adhesive forces at the ice-airfoil interface, either by thermal or mechanical means. De-icing systems usually have lower energy consumption, but on the other hand allow a small cyclic ice build-up and hence some residual aerodynamic degradation. Some examples of technologies applied for de-icing and anti-icing systems are:

$\rightarrow$ Hot-air removal from engine compressor (piccolo tube, swirl)

$\rightarrow$ Electrothermal 
$\rightarrow$ Weeping wing (coats the surface with a low freezing point fluid)

$\rightarrow$ High frequency microwave

$\rightarrow$ Electro-expulsive

$\rightarrow$ Pneumatic rubber boots

The hot-air anti-icing technique, in particular, is one of the most used in aviation because of its simplicity, efficiency, and reliability. This method consists of extracting (or bleeding) air at high temperature and pressure from the engine compressor to distribute via perforated feeder tubes (also known as piccolo tubes - Fig. 1.2) to the internal side of the protected surfaces. Due to the high pressure of the bleed air, the piccolo tube generates an array of air jets that impinge on the protected surface with a high heat transfer coefficient, and therefore can keep the LE at temperatures high enough to evaporate the incoming water or to allow the incoming water to flow downstream over the airfoil to a less critical region.

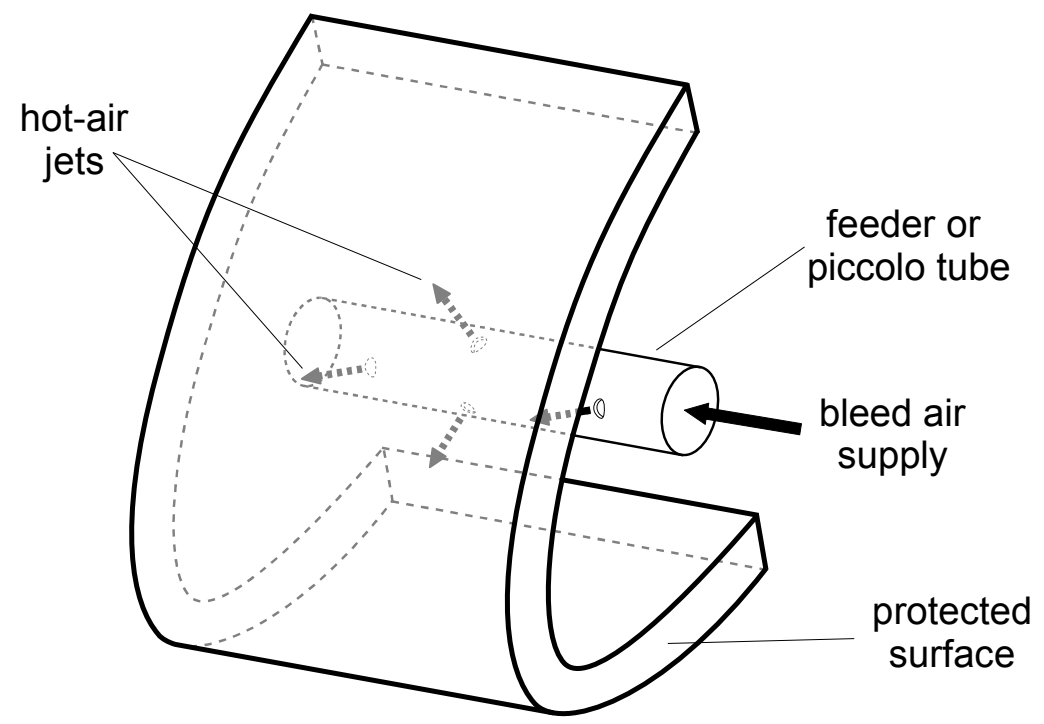

Figure 1.2. Schematic of the piccolo tube in a bleed air anti-ice system.

For anti-icing systems using piccolo tubes, the thermally protected region can be extended beyond the impingement region of the hot-air jets through the installation of an inner 
liner that drives the hot-air through thin passages, as illustrated in Fig. 1.3. The constriction in the airflow caused by these thin passages increases the flow speed and intensifies the heat transfer to the airfoil wall.

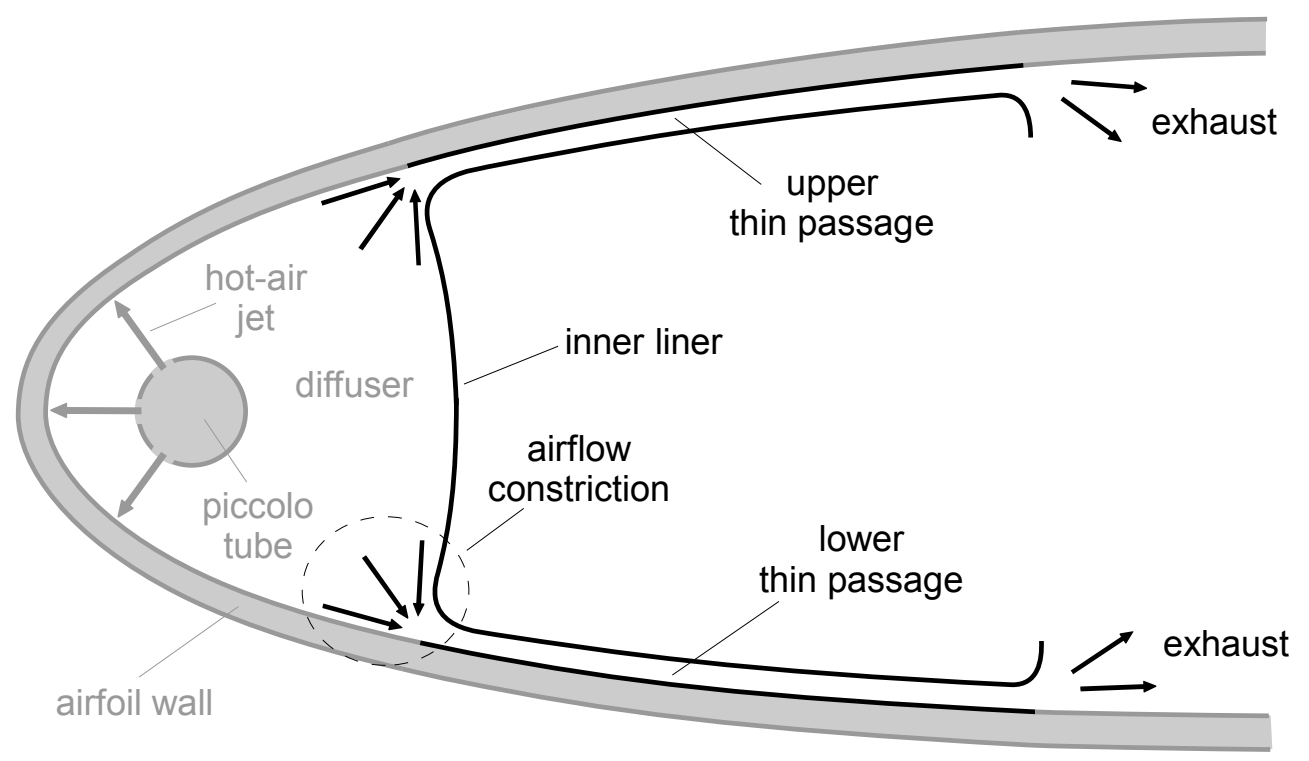

Figure 1.3. Schematic of thin passages in a bleed air anti-ice system.

The design of anti-icing systems is based on numerical tools and laboratory tests performed with scaled models in icing wind tunnels. For certification purposes, the manufacturer is required to perform flight tests to demonstrate the ability for continued safe flight in icing conditions.

To reduce the need for expensive laboratory and flight tests, simulation tools have been developed for computing the icing characteristics of aircraft and the performance of ice protection systems. Traditionally, icing codes apply the model proposed by Messinger [25] (or variations of it) to solve the thermodynamic balance involving: (a) water phase change through solidification, evaporation, and sublimation; and (b) conductive and convective heat transfer. Moreover, the discrete impingement of the droplets in the Messinger model is treated as a 
continuous liquid phase of impinging water.

Several ice accretion codes based on the Messinger model have been developed over the years such as: LEWICE (USA), ONERA code (France), TRAJICE2 (UK), CANICE (Canada), CIRAMIL (Italy \& Canada), and AEROICING (Brazil). A quantitative method for assessing the agreement between experimental and calculated ice shapes can be found at $[19,20,21]$. Figure 1.4 illustrates the simulation results obtained with two different icing codes for a GLC305 airfoil with a $0.9144[\mathrm{~m}]$ chord, for an ambient temperature of 257 [K], a freestream speed of $59.9[\mathrm{~m} / \mathrm{s}]$, a liquid water content of $1.16\left[\mathrm{~g} / \mathrm{m}^{3}\right]$, a droplet median volumetric diameter of $50[\mu \mathrm{m}]$, and an icing exposure of 259 seconds.

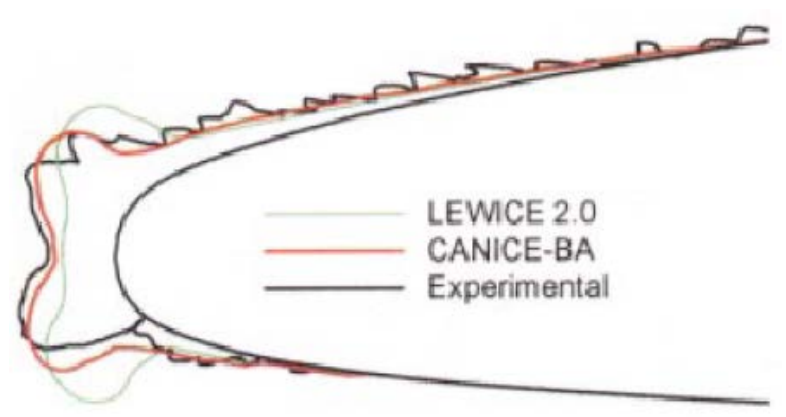

Figure 1.4. Comparison of computer codes prediction and experimental ice shape [4].

Besides the continuous water inflow model, a different technique was presented in [8], where a morphogenetic method is used to track the discrete fluid elements, which are allowed to impact randomly on a surface or on an existing ice structure. The result is an ice shape with more realistic features (Fig. 1.5), showing that the randomness present in this model might be a key factor in the prediction of complex 3-d ice structures. 


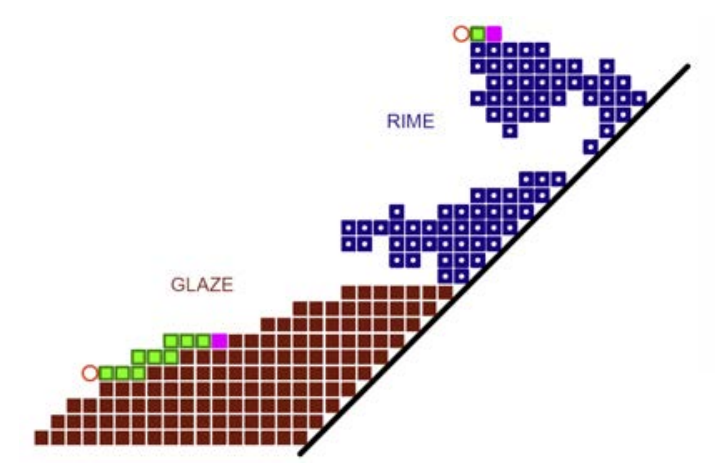

1.5a. Discrete droplet impingement model.

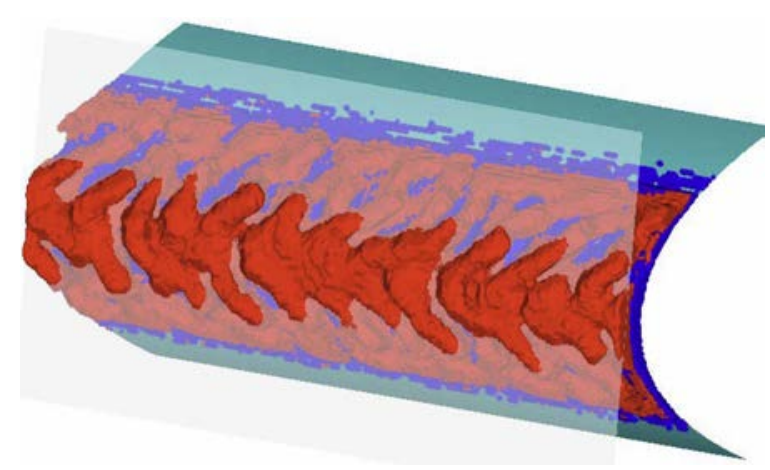

1.5b. Simulated ice shape with lobster tail structure.

Figure 1.5. Morphogenetic model for 3-d ice shape prediction [8].

In hot-air anti-icing system simulation, besides dealing with the external two-phase flow, analysis codes must be able to handle the internal hot-air flow so that the convective heat transfer from the piccolo tube jets to the airfoil skin can be quantified. This problem has been studied using methods of varying complexity. The simple methods use empirical correlations based on the Nusselt number [14], while more sophisticated techniques rely on viscous flow analysis using Navier-Stokes solvers $[15,44]$.

This thesis is focused on the development of a low computational cost hybrid method for assessing the performance of hot-air anti-icing systems. The simulation methodology developed combines 2-d commercial CFD software with empirical formulations and specially designed computer codes to predict the LE temperature distribution and the initial location of runback ice accretions (if any), of a wing with a hot-air ice protection system. Inputs to the simulation tool developed include the 2-d airfoil profile, flight and icing conditions, and the hot-air anti-icing configuration. The methodology developed solves the gas and liquid phases of the external flow separately with commercial codes. The internal surface heat-transfer is modeled with Nusselt number correlations, and the thermodynamic balance at the airfoil wall is computed with a steady state model based on the Messinger model. 
The new simulation methodology was applied to evaluate the performance of a representative piccolo tube anti-icing system that was tested by WSU at the NASA Glenn Icing Research Tunnel [24]. The simulation data obtained were compared with the icing tunnel data and with 3-d CFD analysis results [15] obtained at WSU.

The main outcome of the present effort was an efficient 2-d analysis methodology and a computer code suitable for performing parametric design studies in support of hot-air anti-icing system development and performance evaluation.

\subsection{Literature Review}

The first step in the simulation of ice accretion, de-icing and anti-icing processes is the computation of the local rate of water impingement over the external surfaces. Two techniques for computing the trajectories of the droplets in the two-phase external flow are widely used: Lagrangian $[11]$ and Eulerian $[12,13]$. The Lagrangian method obtains the collection efficiency by solving the motion equation of droplets and tracking the trajectories individually. In the Eulerian method, the water phase is treated as a pseudo continuous fluid that interpenetrates with the air and the collection efficiency is obtained through solving the velocity and apparent density distribution of the droplets [10]. The Eulerian method is usually faster for complex 3-d geometries, although grid type and level of refinement must be carefully selected $[16,17]$. The Lagrangian approach is in general more precise for prediction of impingement limits and faster for simple geometries, although the optimal combination of quantity of trajectories and particle sowing location for complex 3-d geometries may not be an easy task [18].

For freezing, evaporation, and sublimation of the water film over the impingement region, one of the first and still most used thermodynamic model was formulated by Messinger 
in 1953 [25]. The discretization of the airfoil surface is done with control volumes that use as boundary conditions the properties of the surrounding external flow and the condition of no heating at the interior of the airfoil. A mass and energy balance is used to compute the local equilibrium stage, which includes the determination of skin temperature and the associated rates of evaporation, freezing, and sublimation for each control volume.

In the LEWICE code developed by NASA [29], capable of ice prediction and anti-icing simulation, the Messinger model is implemented with the addition of some features such as the heat conduction at the airfoil wall. The solid domain can be treated as either a semi-infinite body or a finite thickness wall composed of distinct solid layers that can have internal heat generation and a prescribed convective heat transfer on the internal surface. The 2-d heat equation is solved in two domains, the metallic layers and the water/ice layer. An empirical model based on stagnation freezing fraction is used to estimate the ice roughness. Furthermore, the code accounts for water loss due to splashing when intercepting the body, water and ice shedding, standing water, and running back water [30]. The external 2-d flowfield and boundary layer are computed with a panel method associated to a momentum integral equation. External flowfield solutions computed with CFD or other analysis tools can also be imported into LEWICE [31]. For a 3-d configuration (with the simulated ice growing in 2-d cuts) the external flow must be provided as input [32]. The trajectory of the droplets, both for 2- and 3-d cases, are solved with the Lagrangian approach. A pneumatic boot de-icing model and a semi-empiric model for supercooled large droplets (SLD) impingement are also available in the code [36]. Studies comparing LEWICE ice shape predictions with experimental data can be found in $[33,34,36]$, and validation of the electrothermal de-icing and anti-icing model against icing wind tunnel data is provided in [26, 27, 29]. 
Also based on the Messinger model, ONERA and DERA developed their ice accretion codes, called ONERA [37] and TRAJICE2 [38] respectively. In a more recent version of the first, the model was converted from 2-d to 3-d, with the external flowfield being calculated with the Euler method. The 3-d boundary layer is calculated using a mixing length formulation to model the wall roughness influence on convective heat transfer, and the runback flow is guided by the near wall stream direction [39].

The performance of the 2-d computer codes developed by DERA, NASA, and ONERA were compared in a joint study described in [40, 41, 42]. Droplet trajectory, ice shape, and electrothermal de-icing system simulation data were compared with each other and with experimental results. Considerable differences between predicted and experimental shapes were often encountered in the comparisons. None of the assessed codes stood out as being distinctly consistent with respect to the experimental ice shapes. The experimental data cases used in this workshop were mainly glaze or mixed icing cases, the most difficult to predict. Better results would have been naturally achieved for rime ice regime simulations.

A major development in anti-icing system simulation was achieved by Al-Khalil [43] in 1991. In his work, the solid wall was represented by a two-dimensional multi-layer model, capable of simulating electrical and convective heating. The water runback flow can breakup from a uniform liquid film into individual streams or rivulets separated by dry spaces, based on a criterion of minimum energy state of the physical system, allowing the prediction of wetness factor distribution over the surface. The temperature field inside the water runback flow was computed with the energy equation, taking into account the temperature gradient across the water film thickness and in the film flow direction.

CANICE [49] is another 2-d ice accretion and anti-icing simulation code currently used 
for icing analysis in the aviation industry that follows the Messinger approach. In this code, three simplifications are imposed to the water film: continuous, two dimensional, and no perturbation waves due to droplet impact. As opposed to most codes where the water film velocity is driven by shear stress only, additional physical aspects such as the tangential pressure gradient and the momentum of the impinging droplets are included in the formulation, resulting in a parabolic velocity profile. The heat conduction within the solid domain is treated with a 1-d scheme that neglects the thermal resistance across the airfoil wall thickness. The external boundary layer is computed with an integral method, and the rate at which heat enters the water film is assumed to change slowly for the integration of the energy equation inside the liquid domain. For the simulation of the hot-air impinging jets flow (see Fig. 1.2), either a local internal convection coefficient or a heat flux boundary condition can be specified. In 2001, CANICE was modified to include a film model where the runback flow starts only when the height of the coalescing water beads reaches a threshold where the shear force on the air-water interface, which drives the water downstream, overcomes the opposite force resulting from the surface tension effect at the metal-water interface [50]. The height of the beads is also used to determine the roughness of the ice. The incompressible potential flow solution for the external flow is corrected with the Karman-Tsien compressibility method, and, finally, smoothed curves for the velocity profile near the stagnation region are used to overcome the problem of multiple stagnation points due to the incremental ice growth.

A 3-d version of CANICE was presented in 1992 [51]. This version employs a 3-d panel method for the solution of the potential flow and solves the droplet tracking problem with a 3-d Lagrangian approach. The water accumulated on the body is treated by the continuity and energy equations, which are solved on 3-d control volumes placed over the surface. The water film is 
considered uniform and moves along the streamline direction of the near wall airflow, and the heat transfer coefficient is obtained from an integral 2-d boundary layer model.

In 1998, Croce et al. [44] introduced FENSAP-ICE, a 2-d/3-d finite-element based Navier-Stokes solver that simulates the external flow, droplets impingement, ice accretion, and the hot-air impinging jets flow. The energy exchange between the internal and external domains is accomplished by heat conduction through the solid skin, exchanging temperature and heat flux boundary conditions iteratively. The ice accretion solver was derived from the Messinger model, using a 3-d partial differential equation equilibrium method [46]. The water film is handled by a 2-d control volume mesh disposed over the airfoil surface. A linear velocity profile with no slip condition at the wall is imposed to the water film, with the flow direction being dictated by the wall shear stress [48]. In 2009 [65], a numerical approach for the prediction of roughness evolution was implemented. The code uses a Lagrangian model that is run separately to identify the main statistical features of the stochastic process of bead nucleation, growth, and coalescence under glaze ice conditions. The results are then used to provide information on beads average parameters to FENSAP-ICE.

AEROICING is an icing prediction tool that was proposed by Silveira [52] in 2001. As in LEWICE and in other icing codes, the external flow can be solved with a panel method and the boundary layer with an integral formulation, or it can be provided by any viscous flow solver. In AEROICING, the thermal domain is divided in 1-d control volumes, and the incoming liquid water can evaporate, freeze, sublimate, shed, or flow to the adjacent downstream element. The temperature variation inside the liquid film is neglected in the direction normal to the airfoil surface. Moreover, it is assumed that the shallow water layer is at the same temperature as the external skin. The energy and mass balances are always performed at the outer surface, located 
either on the airfoil or on the accreted ice. The heat can be diffused to the interior of the airfoil, normal to the wall, with a formulation for semi-infinite bodies. In the second version of AEROICING, a convective boundary condition was incorporated on the internal surface to allow the simulation of anti-icing systems. In addition, heat conduction along the airfoil wall was enabled. An example of the application of AEROICING to the design of a piccolo tube anti-icing system for an engine inlet and comparisons with experimental data is given in [53]. The third version of AEROICING has a roughness model for the ice surface. A detailed description of the model and comparisons of the predicted ice shapes in glaze, rime, and mixed icing regimes against experimental data and other numerical results are provided in [54].

In the simulation of hot-air anti-icing systems, a common practice for computing the convective heat transfer coefficient on the internal skin is the use of Nusselt number correlations. Brown et al. [68] performed an experimental investigation of heat transfer in an aircraft nacelle inlet equipped with a piccolo tube and compared the results with existing Nusselt number correlations. Martin [69] discussed the hydrodynamics of impinging flow and presented empirical equations for the prediction of heat and mass transfer coefficients within a large range of variables, such as: nozzles spatial arrangement, jet cross section (slot/round), jet Reynolds number, nozzle-to-impinged surface distance, etc. Fregeau et al. [70] used numerical simulation to conduct a parametric study of heat transfer coefficient distribution from an array of hot-air jets impinging on a 3-d curved surface. The goal was to create a numerical database for numerical correlations. Pellissier et al. [71] studied the optimization of piccolo tubes using 3-d computational fluid dynamics, reduced order models (Proper Orthogonal Decomposition), and genetic algorithms to determine the optimal configuration (jet angles, spacing of holes, and position from leading edge). In this study, a Nusselt number correlation for heat transfer in the 
internal skin was calibrated using CFD data to reduce computational time and cost. A review of empirical Nusselt number correlations for hot-air anti-icing system applications is presented in [14].

An extensive investigation of CFD procedures for the simulation of bleed air anti-icing system in dry air condition was performed by Wong, Papadakis, and Zamora in 2007 [15, 78]. A wing segment equipped with a hot-air ice protection system was simulated simultaneously in a single computational domain that included the external airflow, the heat conducting anti-icing system structure, and the internal hot-airflow. The effects of turbulence model, grid refinement, and spatial discretization scheme on the computational results were thoroughly investigated. The numerical results were compared to experimental data from icing tunnel tests and good agreement was achieved for a wide range of external and internal flow conditions.

An experimental investigation by Papadakis et al. [24] with a highly instrumented wing model equipped with a wing hot-air anti-icing system representative of a modern business jet was conducted at the NASA IRT facility. Measurements of wing LE temperatures, heat fluxes, and internal flow properties at several wing spanwise stations were performed. Temperature sensors were embedded in the airfoil skin to avoid interference with the hot-air internal flow.

Other studies of icing accretion model and anti-icing systems can be found in the literature, such as in $[66,67]$. Despite the abundance of publications related to the validation of ice shape simulation, public data involving detailed validation of hot-air anti-icing simulation codes against experimental data is still limited.

\subsection{Objectives}

During the development of bleed air ice protection systems, designers must assess 
the effect of a large number of variables on system performance and need to identify critical flight, icing, and engine conditions that may compromise bleed air system effectiveness. These design studies require evaluation of hundreds or even thousands of variables and need to be performed in a short time with limited computational resources. The time required to accomplish such a task with sophisticated 3-d CFD analysis tools is prohibitive. Thus there is a need for an accurate and cost efficient design tool to help narrow down the design space. More sophisticated simulation tools can then be applied to examine promising configurations prior to selecting a very small number of designs for icing tunnel or flight testing.

The main objective of this thesis was to develop an efficient 2-d bleed air anti-icing simulation methodology for ice protection system parametric design studies and performance evaluation. The methodology developed was based on available analysis tools as well as numerical models developed during the course of this research. Another objective of the present effort was to validate the simulation tool developed by comparing analysis results for a representative piccolo tube anti-icing system against experimental data from [24] and related 3-d CFD data obtained from previous research performed at WSU [15].

The main work tasks performed were as follows:

$\rightarrow$ Development of a 2 -d thermodynamic model with low computational cost for simulation of hot-air anti-icing systems

$\rightarrow$ Development and calibration of a Nusselt number correlation for thin passages formed between the airfoil wall and the inner liner

$\rightarrow$ Selection and calibration of a heat transfer correlation for an array of hot-air jets impinging on the airfoil internal surface, and illustrate the correlation calibration process 
$\rightarrow$ Adaptation of the 3-d methodology developed in [15] to a 2-d geometry, keeping the capability of representing an actual anti-icing system with good accuracy

$\rightarrow$ Development of a cohesive 2-d anti-icing simulation tool by assembling several computational modules in a fully automated process, including an anti-icing thermodynamic model, heat transfer correlations for the internal flow, automatic mesh generator for the external flow domain, N-S solver for the external flow, and Lagrangian/Eulerian solver for the droplets impingement.

\subsection{Technical Approach}

The development of a computational methodology for bleed air ice protection systems involved the selection of the appropriate governing equations, numerical schemes, and boundary conditions. A viscous flow analysis using FLUENT was adapted from the procedure developed in [15] for 2-d external flow and convective heat transfer analysis along the external surface of the airfoil. The droplet impingement efficiency problem was solved with either an Eulerian (FLUENT) or a Lagrangian (LEWICE) formulation.

A study was performed to explore the use of heat transfer correlations in place of the RANS equations for simulating the impinging jet and thin passage internal flows. The temperature related problem of water evaporation and freezing over the airfoil external skin was solved with a steady state thermodynamic model developed in this work, capable of modeling the heat diffusion inside the airfoil wall, water evaporation over the external surface of the airfoil wall, and starting location of runback ice. Comparisons of simulation results from the anti-icing code developed with representative experimental and numerical data were performed to validate the simulation methodology. 
Three computational grids were used in this work to model the regions of the twodimensional physical domain: the first grid was used for simulating the external flow, the second, for solving the 1-d water film model and the 2-d heat conduction in the airfoil wall, and the third for computing the flow in the thin passages to generate heat transfer data for calibrating the thin passage Nusselt number correlation. 


\section{CHAPTER 2}

\section{COMPUTATIONAL METHODOLOGY}

\subsection{Computational Models}

The hot-air anti-icing problem was treated with a modular approach where the physical domain was divided into three regions: (1) the external two-phase flow, composed of the gas phase (air) and the liquid phase (water droplets); (2) the hot-air internal flow, including the diffuser bay and thin upper and lower passages; and (3) the airfoil wall, which conducts heat from the interior of the leading edge to the runback flow on the external surface. These three regions are illustrated i2.1 Fig. 2.1. The external and internal flows were decoupled and used to provide boundary conditions to a steady state thermodynamic model, which computes the temperature distribution in the airfoil wall and the energy and mass balances on the water film over the external skin.

In the methodology developed, the two-dimensional external airflow is computed with the RANS equations and the SST $k$ - $\omega$ turbulence model. The RANS, continuity, energy and state equations are solved with the commercial program FLUENT. An isothermal boundary condition is applied at the airfoil wall, and the resulting distributions of heat transfer coefficient and pressure are then used as boundary conditions in the thermodynamic model. For dry air cases, the external flow domain is divided in laminar and turbulent regions, following the approach used in [15]; while for wet cases, due to the presence of water beads over the airfoil, specially close to the stagnation point, the external flow is assumed as fully turbulent. 


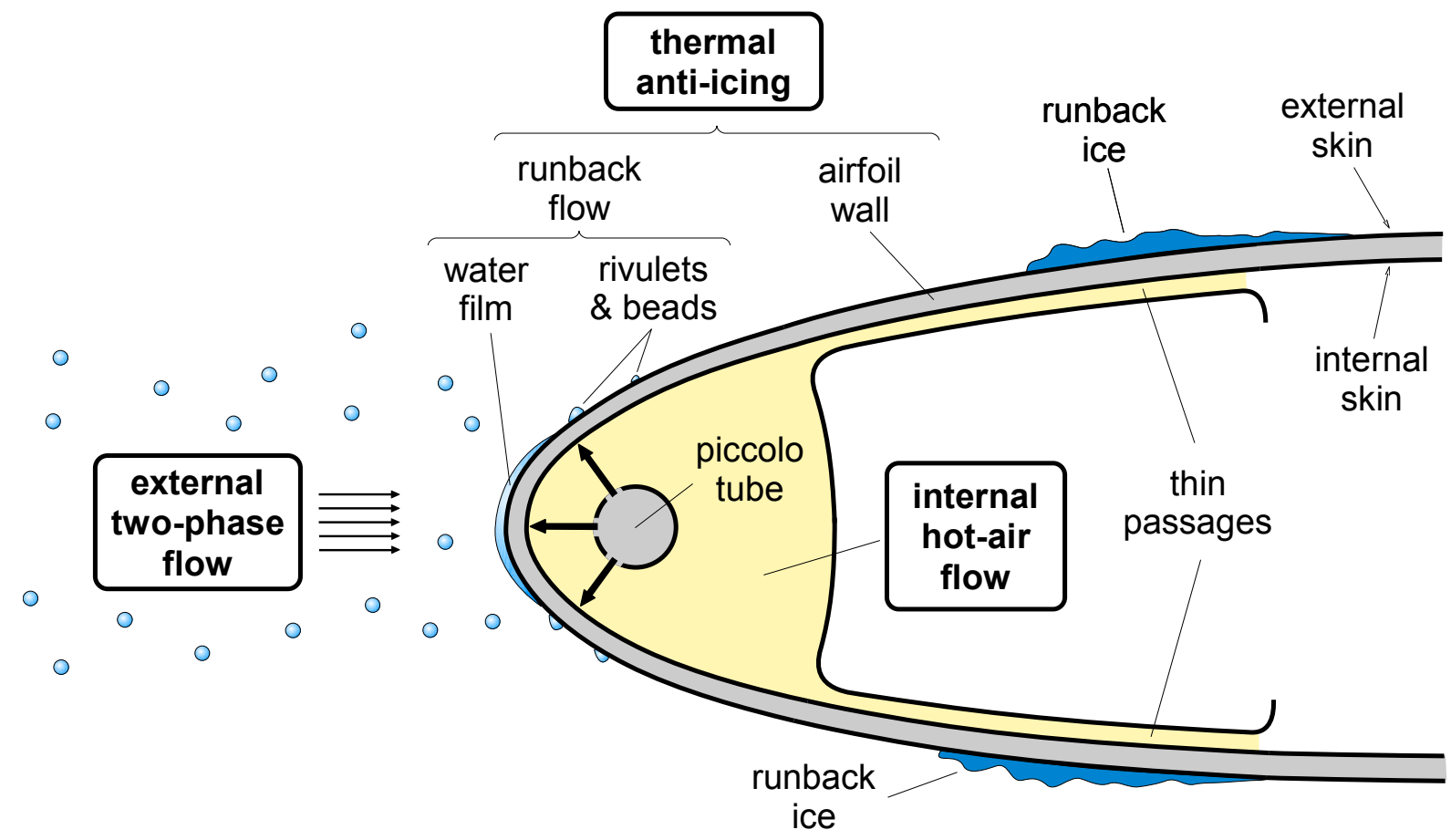

Figure 2.1. Schematic of bleed air anti-ice system.

In the water phase of the external flow, the computation of local water catch efficiency (b) is performed either with FLUENT, by solving Eulerian equations; or with LEWICE, by solving a Lagrangian formulation for the droplets trajectory. For 2-d airfoils, the latter allows faster computations with negligible loss of accuracy, and therefore is the preferred one for parametric studies.

The solution of the 3-d diffuser flow (array of hot-air jets) via finite volumes method requires a fine grid resolution to correctly capture the free jet development and the heat transfer over the impingement and wall jet zones. A computation grid with tens of millions of elements is necessary for such type of simulation. This, however, requires significant computational resources and time to obtain a solution. In the present work, in order to reduce the simulation time, an internal flow module was developed that solves the heat transfer problem associated with the hot-air impinging jets by means of Nusselt number correlations. Likewise, the use of 
CFD for simulating the thin passage flow can be time consuming, specially for parametric studies. Therefore, Nusselt number correlations were also developed for analyzing the thin passage flows.

The calibration of the heat transfer correlation for the piccolo tube jets was done using 3-d CFD data from a representative bleed air anti-icing system obtained from [15], whereas the heat transfer correlation for the thin passage flow was calibrated with 2-d CFD data obtained by performing viscous flow analysis with FLUENT for several passage inlet Reynolds numbers. Table 2.1 summarizes the type of correlation applied to each internal flow region and how the calibration data was obtained.

Table 2.1. Nusselt number correlations for internal flow module.

\begin{tabular}{|c|c|c|c|}
\hline Application Region & Correlation Type & $\begin{array}{c}\text { Heat Transfer } \\
\text { Calibration Data Type }\end{array}$ & $\begin{array}{c}\text { Source of Heat Transfer } \\
\text { Calibration Data }\end{array}$ \\
\hline \hline $\begin{array}{c}\text { Diffuser flow } \\
\text { (impinging jets) }\end{array}$ & $\begin{array}{c}\text { Same as LEWICE } \\
\text { correlation number 2 }\end{array}$ & 3-d CFD simulation & Zamora [15] \\
\hline Thin passages & Set of polynomials & 2-d CFD simulation & Present work \\
\hline
\end{tabular}

The hot-air anti-icing module was based on a steady state thermodynamic model. It deals with heat conduction within the LE airfoil skin and a phase-changing water film on the external skin. Required boundary conditions for the external airfoil upper and lower surfaces include the distributions of heat transfer coefficient, water catch, and surface pressure. For the internal flow, the boundary condition needed is the span-weighted average distribution of heat transfer coefficient based on a reference temperature. For the thin passage region, the reference temperature is the hot-air bulk temperature, while for the diffuser bay region, the reference temperature is the hot-air total temperature. The 2-d heat diffusion within the airfoil wall, which is a consequence of the internal and external skin thermal boundary conditions and the 
composition of the solid domain, was modeled via the conservation of energy principle and the Fourier heat conduction law, using a grid composed of finite control volumes. The water runback flow, resulting from the accumulation of the droplets impinging over the airfoil external skin, was treated as a 1-d wall bounded uniform film flow with a temperature equal to the LE wall external skin. The flow of information between the three computational modules is illustrated in

Fig. 2.2.

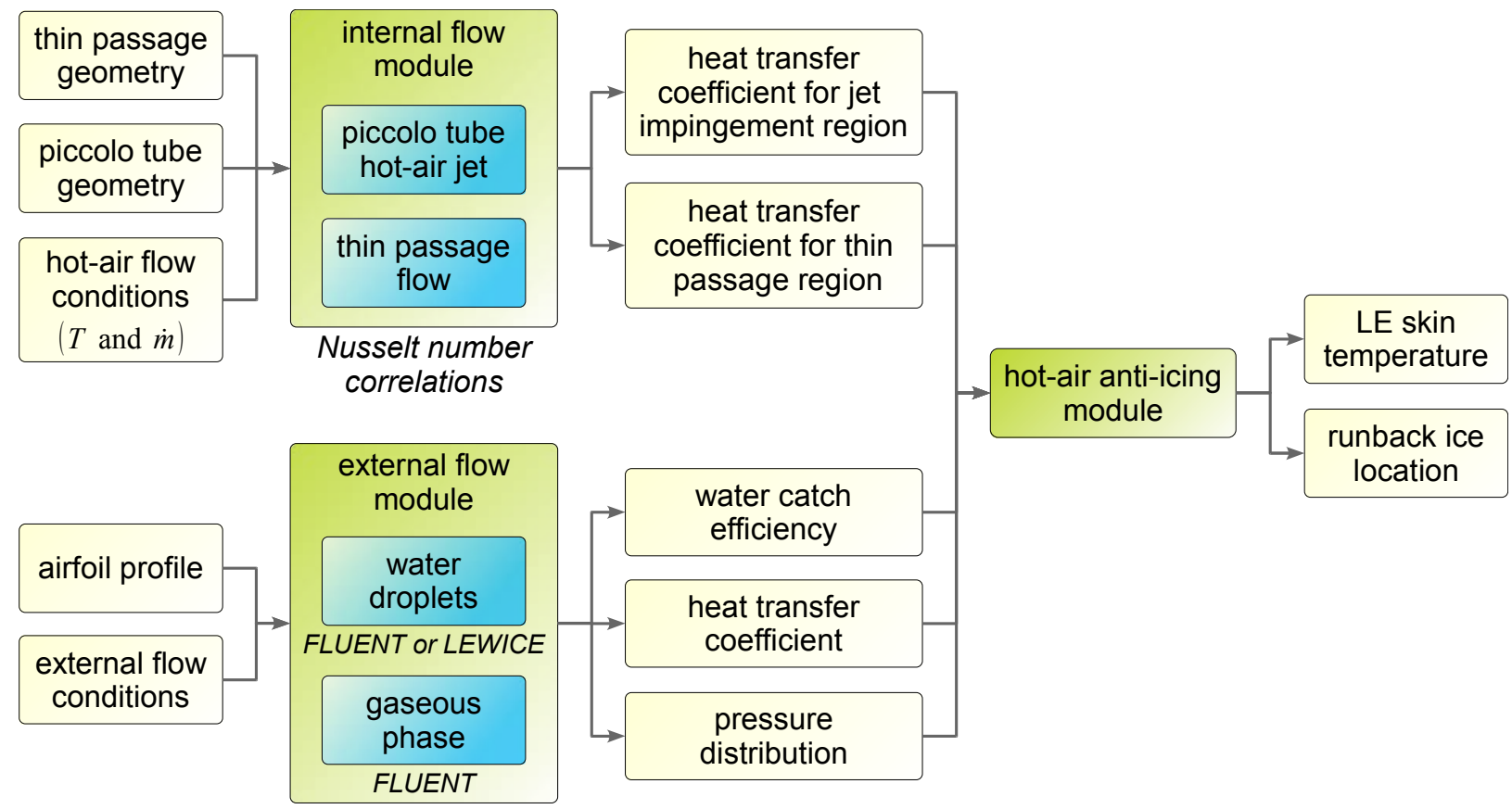

Figure 2.2. Bleed air anti-ice modular simulation process.

\subsection{Domain Discretization}

This section describes the computational grids used to solve the external flow about the airfoil, the energy balance within the airfoil wall, and the energy and mass balances on the airfoil external surface. Details of the grids used to generate heat transfer data for the flow in the thin passages formed by the inner liner skin and the airfoil interior surface (See Fig. 2.1) are also 
provided.

\subsubsection{External Flow Computational Grid}

In the present work, the 2-d external flow is computed with a C-grid topology composed of quadrilateral elements. The process of generating the mesh about a 2-d airfoil profile was automated with the commercial code ANSYS ICEM CFD. Figure 2.3 shows an example of the grid that was obtained when a section of the wing geometry used in $[15,24]$ was supplied to the grid generator module.

In the methodology developed, the airfoil mesh is always generated from a perfectly smooth surface, without any excrescence due to ice accretion, water film, rivulets, beads, or surface roughness. This is a fair assumption since the analysis is concentrated at the instant when ice starts forming.

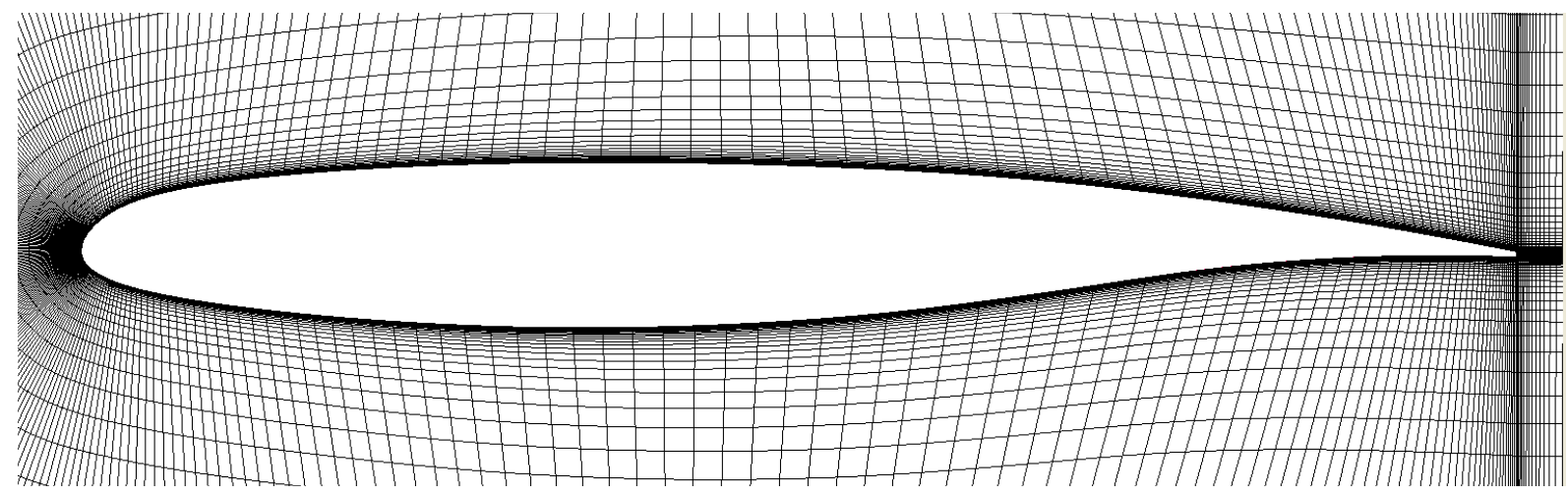

Figure 2.3. Close-up of computational grid for external airflow.

For dry air condition, the external flow is divided into laminar and turbulent zones (Fig. 2.4a), whereas for wet air condition the entire flow is treated as turbulent (Fig. 2.4b).

The orientation of the 2-d cutting plane used to obtain the wing section geometry must always be perpendicular to the LE of the wing, as illustrated in Fig. 2.5. This way, even in the 
case of swept wings, where the path of the runback water is three-dimensional and hence it cannot be contained within a two-dimensional plane, the misalignment between the 2-d profile and the water runback trajectory is minimized over the surface length of the thermally protected region.
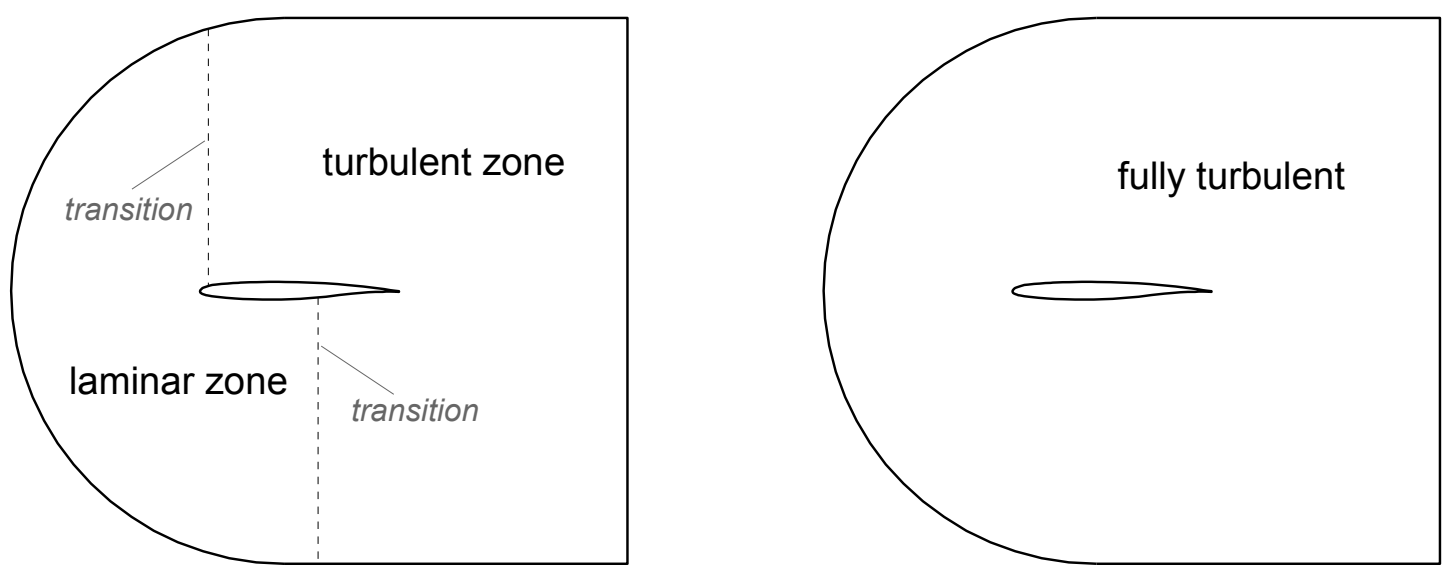

2.4a. Transitioning flow for dry air condition. 2.4b. Fully turbulent flow for wet air condition.

Figure 2.4. Domain division according to flow regime.

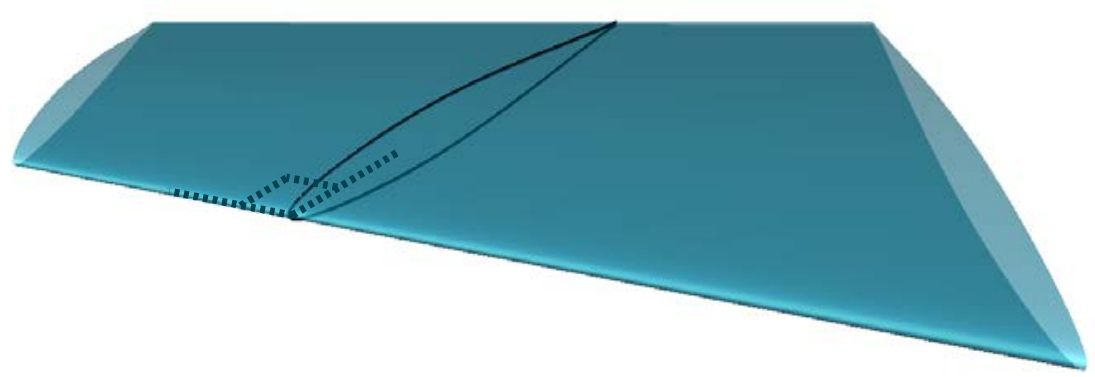

Figure 2.5. Orientation of 2-d cutting plane for obtaining the analysis section.

\subsubsection{Thin Passage Computational Grid}

The hot-air flow leaves the diffuser bay through narrow channels (passages) formed between the airfoil internal skin and the inner liner (Figs. 1.3 and 2.1). The flow constriction caused by these thin passages accelerates the flow and intensifies the heat transfer to the internal 
skin. This section describes the computational domain used in the 2-d CFD simulations, which were performed to compute heat transfer data for calibrating the Nusselt number correlation for the thin passage flow.

Figure 2.6 shows the computational grid used in the analysis of the flow in the thin passage, composed exclusively of quadrilateral elements, based on the airfoil geometry used in $[15,24]$, for the case of a passage $2.5 \mathrm{~mm}$ high. Passages with heights of $0.5,1.0,1.5$, and 2.5 $\mathrm{mm}$ were investigated to cover the range of passage heights typically found in hot-air anti-icing systems employing inner liner skins.

The length of the thin passages in anti-icing systems is determined by the chordwise extension of the thermally protected region. For the present study, the length of the thin passages was approximately 0.1 meter. The flow inlet is located at $5 \%$ of the chord length and the flow outlet was at $15 \%$ chord length. As illustrated in Fig. 2.6, the computational domain considers only the region of the thin passages, with the flow inlet imposed uniformly over curved boundary. 


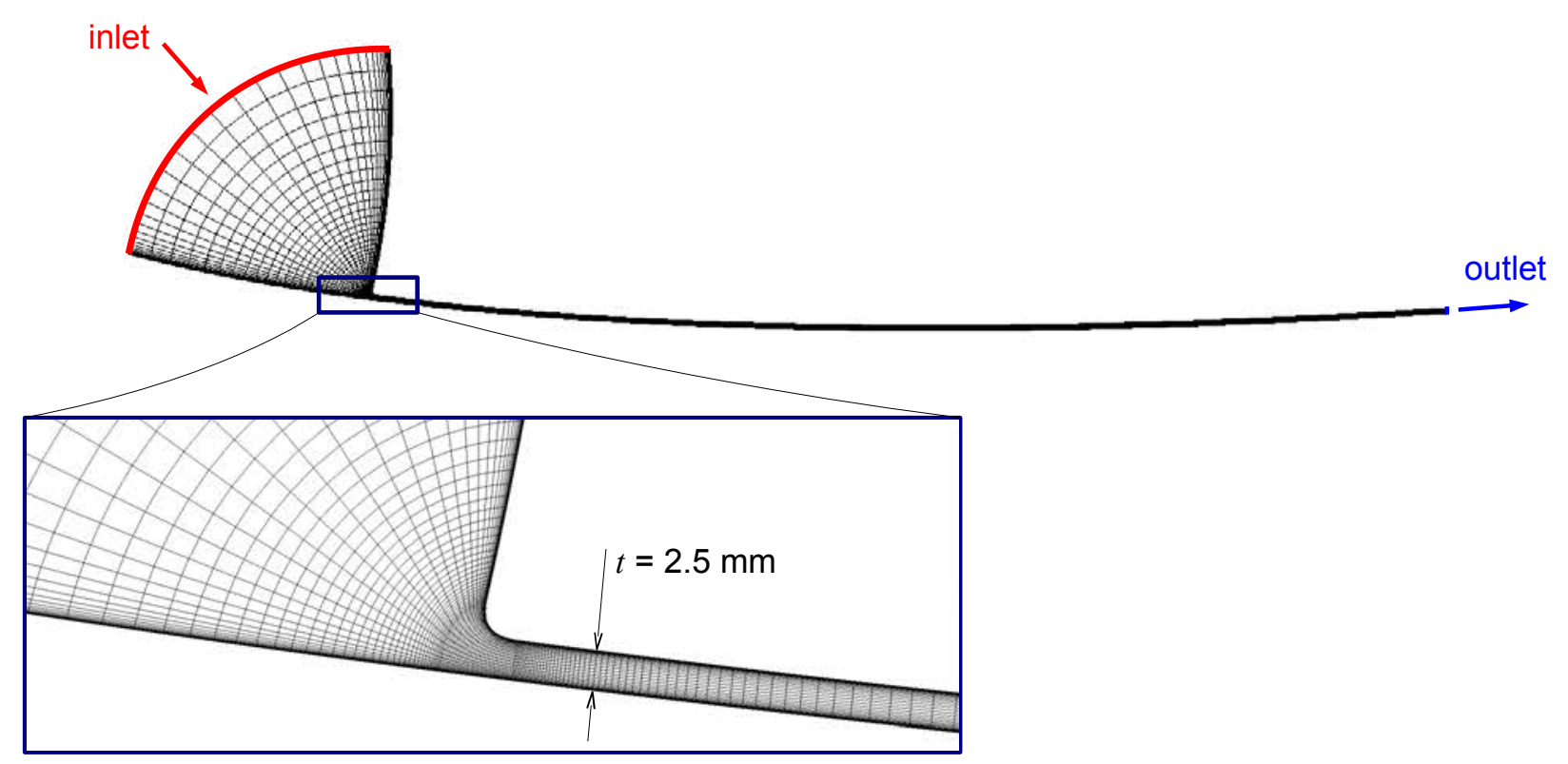

Figure 2.6. Thin passage flow computational grid (for a 2.5 [mm] high passage).

\subsubsection{Solid Wall Computational Grid}

The physical domain for the thermodynamic model is obtained from a 2-d cross section of the protected surface, shown in Fig. 2.7. The 2-d cut is perpendicular to the LE as illustrated in Fig. 2.5. The airfoil wall, given in $x$ and $y$ coordinates (Fig. 2.7), is opened into a rectangular computational domain with curvilinear and normal coordinates, $c$ and $n$, respectively, as shown in Fig. 2.8.

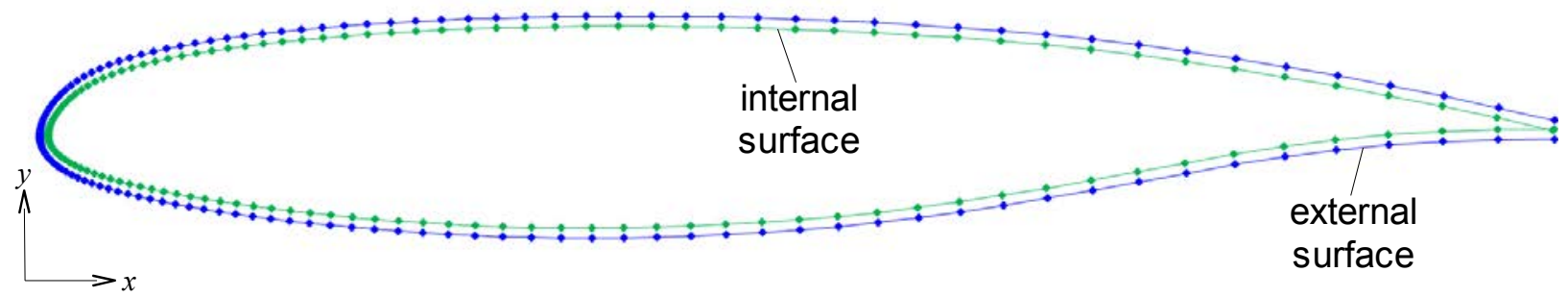

Figure 2.7. Solid wall physical domain. 


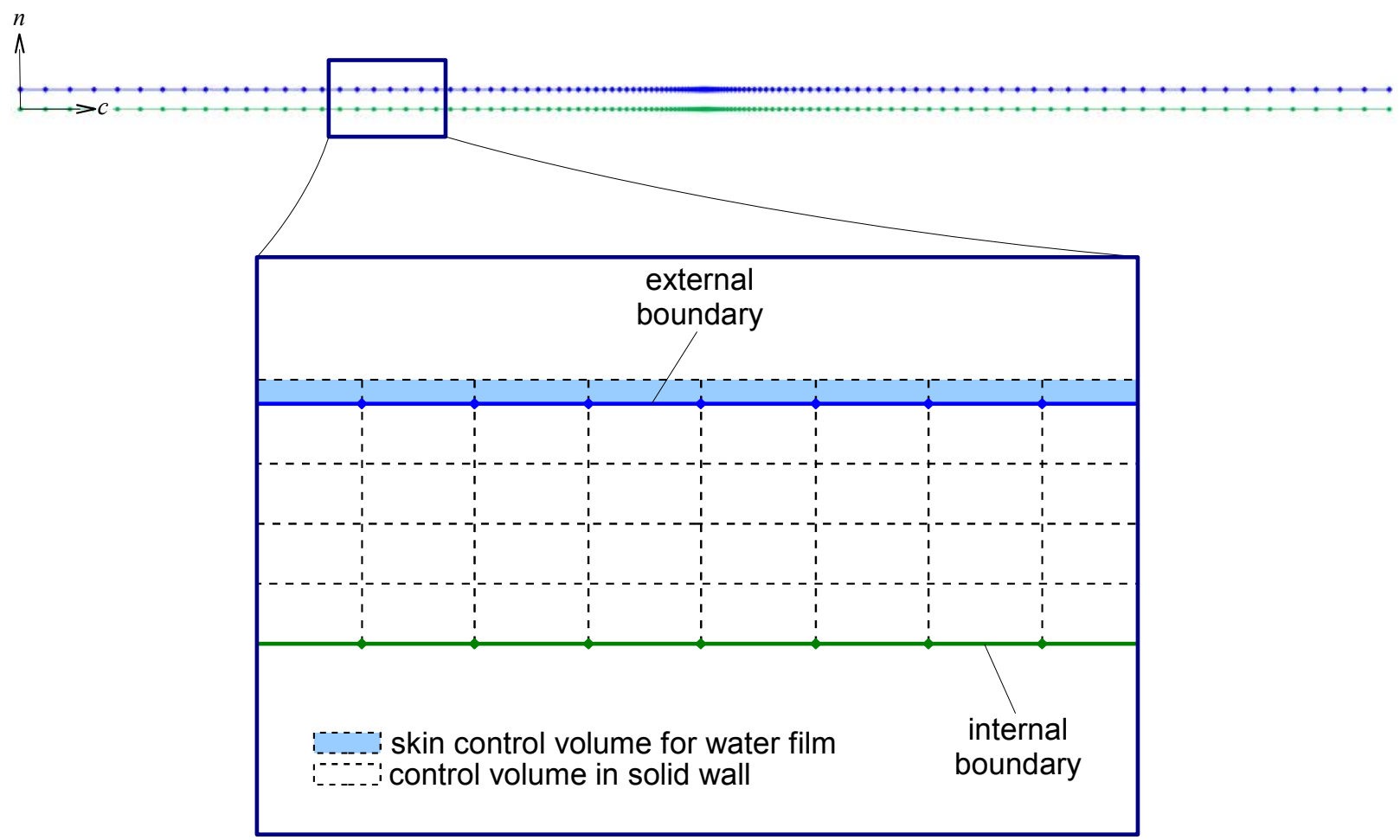

Figure 2.8. Solid wall computational domain.

The rectangular computational domain (Fig. 2.8) for thermodynamic analysis discretized with quadrilateral elements (2-d control volumes) embedded in the interior of the solid wall to capture the temperature gradients in both $c$ and $n$ directions. In addition, a single layer of thin (1-d) control volumes is used to model the external boundary (external surface) for the water film energy and mass balance computations.

\subsection{Governing Equations}

Since the computational procedure developed in [15] for simulating the external airflow is replicated for a 2-d computational domain, only a succinct description of the corresponding governing equations is presented. The same happens with the formulation for the thin passage flow and droplet impingement models, which have been widely used and validated in the 
industry. More attention is given to the equations representing the anti-icing thermodynamic model that is proposed and to the heat transfer correlations for the internal hot-air flow.

\subsubsection{External Flow Gas Phase}

The partial differential equations used to represent the compressible gas phase of the external flow, in the conservative form, are:

Continuity $\quad \frac{\partial \rho}{\partial t}+\frac{\partial}{\partial x_{i}}\left(\rho u_{i}\right)=S_{m}$
equation:

$\begin{aligned} & \text { Momentum } \\ & \text { equation: }\end{aligned} \frac{\partial}{\partial t}\left(\rho u_{i}\right)+\frac{\partial}{\partial x_{i}}\left(\rho u_{i} u_{j}\right)=-\frac{\partial P}{\partial x_{i}}+\frac{\partial \tau_{i j}}{\partial x_{j}}+\rho g_{i}+F_{i}$

$\begin{aligned} & \text { Energy } \\ & \text { equation: }\end{aligned} \quad \frac{\partial}{\partial t}(\rho E)+\frac{\partial}{\partial x_{i}}\left[u_{i}(\rho E+P)\right]=\frac{\partial}{\partial x_{i}}\left[k \frac{\partial T}{\partial x_{j}}-\sum_{j^{\prime}} h_{j^{\prime}} J_{j^{\prime}}+u_{j} \tau_{i j}\right]+S_{h}$

The momentum equation includes terms for static pressure $P$, gravitational body force $\rho g_{i}$, and external body forces $F_{i}$. The stress tensor is given by

$$
\tau_{i j}=\left[\mu\left(\frac{\partial u_{i}}{\partial x_{j}}+\frac{\partial u_{j}}{\partial x_{i}}\right)\right]-\frac{2}{3} \mu \frac{\partial u_{i}}{\partial x_{i}} \delta_{i j}
$$

where $\mu$ is the molecular viscosity and $\delta_{i j}$ is the unit tensor.

The energy term is defined by

$$
E=h-\frac{P}{\rho}+\frac{u_{i}^{2}}{2}
$$

where $h$ is enthalpy.

The system of equations is closed by introducing thermodynamic relations and auxiliary relations for the coefficient of viscosity and thermal conductivity. The relationships between the four thermodynamic variables ( $\rho, P, h$, and $T)$ are obtained based upon the assumption of thermodynamic equilibrium, which for a perfect gas is represented by 


$$
\begin{gathered}
\rho=f(P, T)=\frac{P}{R T} \\
h=g(P, T)=\frac{P}{\rho}-C_{v} T
\end{gathered}
$$

The two equations for viscosity and thermal conductivity are also dependent on the composition of the fluid, temperature, and pressure.

The conservation equations $[(2.1),(2.2)$, and (2.3)] have the same general form and can be expressed by a general conservation equation for transport that uses the variable $\phi$ to represent any scalar flow property and where $\Gamma$ is the diffusion coefficient.

$$
\frac{\partial(\rho \phi)}{\partial t}+\nabla\left(\rho \phi u_{i}\right)=\nabla(\Gamma \vec{\nabla} \phi)+S_{\phi}
$$

In the transport equation the terms from left to right are the rate of change term, the convective term, the diffusive term, and the source term, respectively, for the property $\phi$.

The governing transport equations are solved with FLUENT, which uses a finite volume approach to convert the differential equations to algebraic equations. In the finite volume approach, Equation (2.9) is integrated over a control volume using Gauss' Divergence theorem yielding a final equation which is then discretized for a control volume and solved aided by initial and boundary conditions. Details of the boundary conditions are provided in Section 2.5.1.

$$
\frac{\partial}{\partial t}\left(\int_{C V} \rho \phi d V\right)+\int_{A} \vec{n} \cdot(\rho \phi \vec{u}) d A=\int_{A} \vec{n} \cdot(\Gamma \vec{\nabla} \phi) d A+\int_{C V} S_{\phi} d V
$$

The form in which the governing equations were presented is applicable to the simulation of laminar flows. However, since turbulence is always present in an icing environment, the Navier-Stokes equations are actually solved in a time-averaged manner, adding a turbulent viscosity to the molecular viscosity. The result is a system of equations known as the ReynoldsAveraged Navier-Stokes (RANS). In dry air cases, the computation domain is divided into two 
regions, laminar and turbulent; and in wet air conditions the flow is treated as fully turbulent.

Turbulence models are statistical formulations designed to calculate the value of the turbulent viscosity term. The time-averaged products of the flow velocity fluctuation components about their mean values are called Reynolds stresses or turbulent shear stresses. These terms represent the time-averaged rate of transfer of momentum. Turbulence models are used to model the Reynolds Stresses and close the RANS system of equations. The choice of turbulence model for this study was the SST $k$ - $\omega$ model. This choice was based on the results presented in [15], where an extensive turbulence model study performed with a representative bleed air system showed that the use of the SST $k$ - $\omega$ model provided the best overall agreement with experimental data.

The Shear-Stress Transport (SST) $k-\omega$ model was developed by Menter $[59,60]$ to effectively blend the robust and accurate formulation of the standard $k$ - $\omega$ model proposed by Wilcox [61] in the near-wall region with the freestream independence of the $k-\varepsilon$ model in the far field. This hybrid model has, in essence, the same transport equation as the standard $k$ - $\omega$ formulation, but includes a cross-diffusion term $\left(D_{\omega}\right)$ in the $\omega$-equation $(2.10)$ that monitors the transport of shear stresses. The formulation also includes a limiter for the turbulent kinetic energy production term,

$$
\frac{\partial(\rho \omega)}{\partial t}+\frac{\partial\left(\rho \omega u_{i}\right)}{\partial x_{i}}=\frac{\partial}{\partial x_{j}}\left[\left(\mu+\frac{\mu_{t}}{\sigma_{\omega}}\right) \frac{\partial \omega}{\partial x_{j}}\right]+G_{\omega}-Y_{\omega}+D_{\omega}+S_{\omega}
$$

where $G_{\omega}$ is the generation of dissipation due to mean velocity gradients and $Y_{\omega}$ accounts for the dissipation of $\omega$.

The SST $k$ - $\omega$ model includes a modified definition of the turbulence viscosity to account for the transport of turbulent shear stress. FLUENT provides an option to operate the SST $k$ - $\omega$ 
model as a low Reynolds number turbulence model. Under this condition, the calculations receive enhanced wall treatment and the required mesh must be fine with a $y+$ within the viscous sub-layer (not exceeding 1).

The governing equations for the external flow presented in this section were written for a single fluid phase, i.e., the gas phase. The effect of the water phase on the convective heat exchange between the air and the airfoil external surface are neglected, based on the small thickness of the water film.

The CFD solution of the external flow is post-processed to obtain the curvilinear distribution of heat transfer coefficient $h_{e}$ (in $\left.\left[\mathrm{W} / \mathrm{m}^{2}-\mathrm{K}\right]\right)$ over the external airfoil upper and lower surfaces. This is calculated from Equation (2.11) using the surface heat flux $q_{e}$ (in [W]), the external surface temperature $T_{e}$ (in $[\mathrm{K}]$ ), and a reference temperature, which for this case is the local recovery temperature $T_{\text {rec }}$ (in $[\mathrm{K}]$ ).

$$
h_{e}=\frac{q_{e}}{T_{e}-T_{r e c}}
$$

The local recovery temperature is obtained from Equation (2.12),

$$
T_{r e c}=T_{e d g}\left(1+\operatorname{rec} \frac{1.4-1}{2} M_{e d g}^{2}\right)
$$

where the recovery factor $r e c$ is computed as a function of the Prandtl number Pr. The value of the recovery factor for turbulent flow is set to $\sqrt[3]{\operatorname{Pr}}$, and for laminar flow is set to $\sqrt{\operatorname{Pr}} ; M_{\text {edg }}$ is the local Mach number at the edge of the boundary layer; and $T_{\text {edg }}$ is the air static temperature at the edge of the boundary layer (in $[\mathrm{K}]$ ), defined as:

$$
T_{e d g}=T_{0}\left(\frac{P}{P_{0}}\right)^{\frac{1.4-1}{1.4}}
$$

In Equation (2.13), $T_{0}$ is the ambient total temperature (in $[\mathrm{K}]$ ) of the gas phase, $P$ is the 
air static pressure at the respective position (in $[\mathrm{Pa}]$ ), and $P_{0}$ is the ambient total pressure (in $[\mathrm{Pa}])$ of the gas phase.

\subsubsection{External Flow Liquid Phase (Water Catch Efficiency)}

The perturbation in the uniform flow field that is introduced by the airfoil is strong enough to deflect the relative trajectory lines of the suspended water droplets, leading to a nonuniform water impingement concentration over the airfoil leading edge region. The concept of water catch (or water collection) efficiency allows the determination of the local rate at which water is collected by a body. According to [5], the collection efficiency can be interpreted as:

$$
\begin{aligned}
& \text { Amount of water caught on infinitesimal area of surface } \\
& \beta=\frac{\text { in a given unit of time }}{\text { Amount of water that could be caught in that time on that }} \\
& \text { area if the trajectories were straight lines parallel to the } \\
& \text { free-stream velocity direction and if the area was oriented } \\
& \text { to be perpendicular to the trajectories }
\end{aligned}
$$

The impingement is more intense close to the stagnation point, and fades out at the extremities of the impingement area, where the trajectory of the droplets become tangent to the surface.

The computation of the collection efficiency distribution is based either on the droplet trajectory (Lagrangian approach) or on the concept of droplet volume fraction (Eulerian approach). The trajectory of a droplet is governed by the forces acting on it, due to pressure gradient in the gas phase, gravity, viscous drag (due to the relative velocity between air and droplet), and momentum (droplet inertia).

The computation of the collection efficiency distribution in the anti-icing simulation tool developed is performed either by using FLUENT or LEWICE. Brief descriptions of the governing equations solved by each code are presented herein. Details of the computational 
methodologies can be found in [13] and [28], respectively. The assumptions used in both FLUENT and LEWICE are: negligible effect of the liquid phase on the gas flow; no droplet break up, splash, bouncing or coalescence prior to the impact; no heat or mass transfer between the droplets and the surrounding air; and spherical droplets (in LEWICE, the user may provide lift, drag, and pitching moment coefficients for arbitrarily shaped particles).

\subsubsection{Lagrangian Approach (LEWICE)}

LEWICE adopts the Lagrangian approach for the solution of the local catch efficiency $\beta$ by integrating the droplets motion over time on a previously computed gaseous flowfield. The value of $\beta$ is obtained by applying its definition, as illustrated in Figures 2.9 and 2.10, for 2-d and 3-d conditions, respectively.

It can be shown that the governing equations for spherical particles for the $x$ and $y$ components of the 2-d motion solved by LEWICE [28] can be written in vector notation as

$$
\frac{d \vec{V}_{p}}{d t}=K_{1}\left(\vec{V}_{a}-\vec{V}_{p}\right)+\vec{F}_{B}
$$

where $\vec{V}_{p}$ is the droplet velocity vector, $\vec{V}_{a}$ is the gas phase velocity vector, $\vec{F}_{B}$ is the body force per unit mass due to gravity, and $K_{l}$ is the exchange coefficient, which can be interpreted as the viscous force-to-droplet inertia ratio, given by

$$
K_{1}=\frac{18 \mu_{a} f}{\rho_{p} d_{p}^{2}}
$$

In Equation 2.16, $\mu_{a}$ is the gas phase viscosity, $\rho_{p}$ is the droplet density, and $d_{p}$ is the droplet diameter. The factor $f$ is the drag function and it is defined as

$$
f=C_{D} \operatorname{Re} / 24
$$

The droplet Reynolds number, $R e$, based on the droplet diameter, is computed with the 
relative velocity of the droplet with respect to the air

$$
R e=\frac{\rho_{a}\left|\vec{V}_{a}-\vec{V}_{p}\right| d_{p}}{\mu_{a}}
$$

and the drag coefficient, $C_{D}$, which depends on the Reynolds regime, is calculated from

$$
C_{D}=\frac{24}{R e}+0.4+\frac{6}{1+\sqrt{R e}} \quad \text { for } \quad R e \leq 100
$$

and

$$
C_{D}=\frac{24}{R e}+0.3+\frac{6}{1+\sqrt{R e}} \quad \text { for } \quad \text { Re }>100
$$

For particles with diameters of less than $10 \mu \mathrm{m}$, the drag coefficient can be corrected with the Cunningham correction factor, as shown in [28].

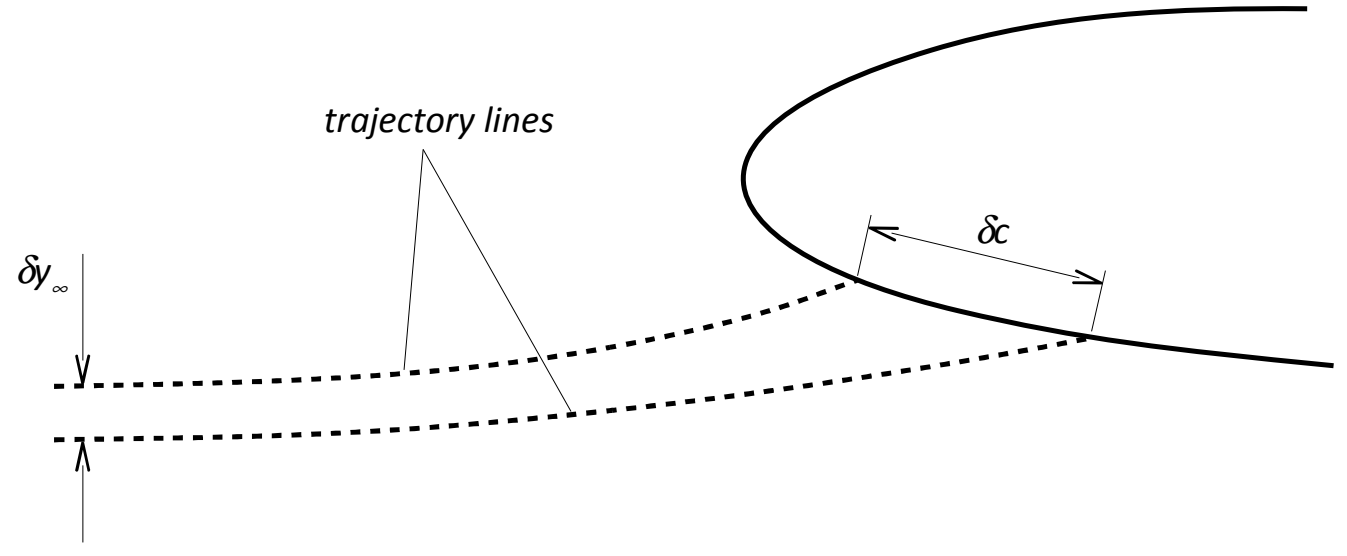

Figure 2.9. Definition of 2- $d$ water catch efficiency, $\beta=\delta y_{\infty} / \delta c$, for Lagrangian method. 


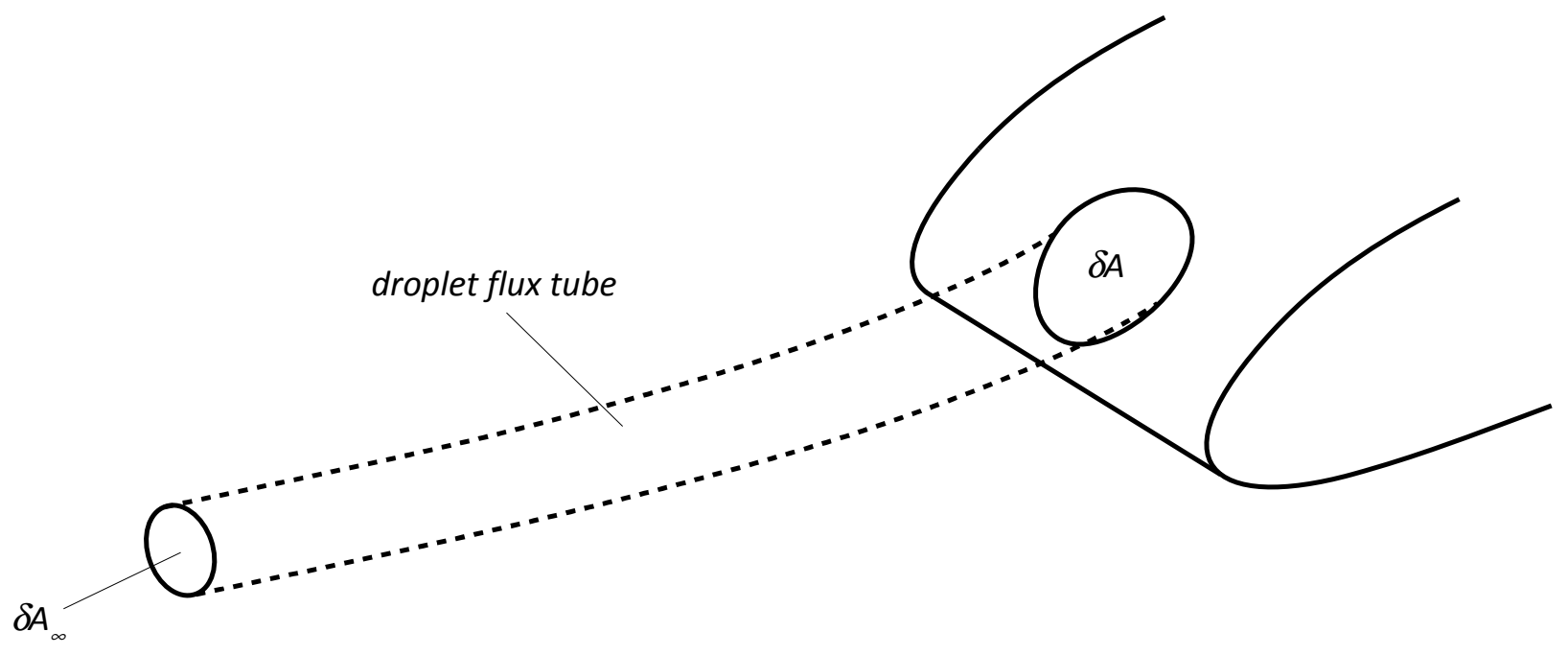

Figure 2.10. Definition of 3-d water catch efficiency, $\beta=\delta A_{\infty} / \delta A$, for Lagrangian method.

\subsubsection{Eulerian Approach (FLUENT)}

The Eulerian method available in FLUENT treats the droplets as a continuous phase and uses the concept of droplet volume fraction to represent the amount of water within a given control volume. Based on this concept, the momentum and continuity equations for the droplets can be derived and solved in the same manner as the gas phase equations [13]. The equations are:

$$
\frac{\partial \alpha \rho}{\partial t}+\nabla \cdot\left(\alpha \rho \vec{V}_{p}\right)=0
$$

and

$$
\frac{\partial \alpha \rho \vec{V}_{p}}{\partial t}+\nabla\left(\alpha \rho \vec{V}_{p} \otimes \vec{V}_{p}\right)=K_{1} \alpha \rho\left(\vec{V}_{a}-\vec{V}_{p}\right)+\alpha \rho \vec{F}
$$

where $\otimes$ is the dyadic product, $\alpha$ is the droplet volume fraction, $K_{l}$ is the exchange coefficient defined in Equation (2.16), $\vec{F}$ is the force per unit mass on the droplet due to external sources other than the drag. Such external forces can be the pressure gradients in the fluid or the force due to gravity.

In the Eulerian approach, $\beta$ can be written as 


$$
\beta=\frac{-\alpha_{n}\left(\vec{V}_{p} \cdot \vec{n}\right)}{V_{\infty}}
$$

where $\vec{n}$ is the unit surface normal vector, $\alpha_{n}$ is the normalized droplet volume fraction on the surface, and $V_{\infty}$ is the freestream speed.

The droplet drag coefficient is computed with the Morsi and Alexander method for spherical droplets, and is applicable to a wide range of Reynolds number [77].

On both Eulerian and Lagrangian methods, the computation of local collection efficiency in a cloud composed of $N$ different droplet diameters requires the computation of the individual $\beta_{i}$ distributions for each droplet size. The composite local collection efficiency is then determined by the local average, weighted by the water mass fraction $n_{i}$ associated with each droplet diameter, as shown in Equation (2.24).

$$
\beta(x, y)=\sum_{i=1}^{N} n_{i} \beta_{i}(x, y)
$$

\subsubsection{Hot-Air Internal Flow}

In this work, the calculation of the local heat transfer coefficient over the airfoil internal surface is based on Nusselt number correlations. This technique, if consistently applied, allows efficient computation of local heat transfer coefficient associated with the complex internal flows typically found in hot-air anti-icing systems. However, the correlations can be sensitive to system configuration, and thus may require extensive calibration with experimental or numerical data. The following sections present details of the heat transfer correlations used and developed for the hot-air impinging jets in the diffuser bay, and the thin passage flow between the wing internal skin and the inner liner. 


\subsubsection{Heat Transfer Correlation for Hot-Air Impinging Jet}

Many forms of heat transfer correlations for impinging jet can be found in the literature, including correlations for cooling or heating applications; with slot or round jets; and impinging on surfaces that are flat, concave, or convex. These correlations express the local Nusselt number as a function of the flow Prandtl and Reynolds numbers, and of the jet geometric configuration.

The Nusselt number correlation employed in the present methodology for the hot-air jet impingement surface region is the piccolo tube correlation referred to as number 2 in LEWICE [64], given in Equation (2.25), which provides the local Nusselt number $\left(N u_{d}\right)$ over the airfoil internal surface as a function of both the curvilinear distance $(c)$ and the spanwise distance $(s)$ (note that both $c$ and $s$ are embedded in the curvilinear variable $r$ [Fig. 2.11c]). This correlation, besides taking into account the jet Prandtl and Reynolds numbers, also considers several piccolo tube geometric parameters. The right side of Equation (2.25) can be interpreted as a "modular" expression in the form of a product of dimensionless parameters. If another system characteristic or flow property is deemed necessary, such as diffuser chamber volume, diffuser cross flow, hotair jet incidence angle, etc, it can easily be incorporated into the correlation.

$$
N u_{d}=(H C O N S T)(P r)^{1 / 3}\left(R e_{d}\right)^{R E P}(z / d)^{Z P}\left(c_{n} / d\right)^{R R P}(r / d)^{R P}(D / d)^{D P}
$$

In Equation (2.25), the terms are defined as:

$\rightarrow \operatorname{Pr}=$ Prandtl number

$\rightarrow d=$ diameter of hot-air jet orifice on piccolo tube (in [m])

$\rightarrow R e_{d}=$ Reynolds number at piccolo tube hole, based on hole diameter

$\rightarrow z=$ distance from the piccolo orifice exit plane to the impingement point at the leading edge wall (in $[\mathrm{m}]$ )

$\rightarrow c_{n}=$ hole pattern pitch (in [m]) 
$\rightarrow r=$ surface (curvilinear) distance from a given point on the internal skin to the stagnation point of the nearest hot-air jet (in [m]), as defined in Fig. 2.11c

$\rightarrow D=$ piccolo tube diameter (in $[\mathrm{m}]$ )

$\rightarrow H C O N S T, R E P, Z P, R R P, R P$, and $D P=$ calibration constants

Figure 2.11 illustrates the geometric parameterization of the piccolo tube and its location with respect to the leading edge.

The local convective heat transfer coefficient on the internal skin $h_{i}$ in the jet impingement region is calculated from the local Nusselt number $\left[N u_{d}=\left(h_{i} d\right) / k\right]$ as

$$
h_{i}=\frac{N u_{d} k}{d}
$$

with the thermal conductivity of the air $k$ (in $[\mathrm{W} / \mathrm{m}-\mathrm{K}]$ ) evaluated at the hot-air total temperature $T_{p}$ in the respective piccolo tube cross section.
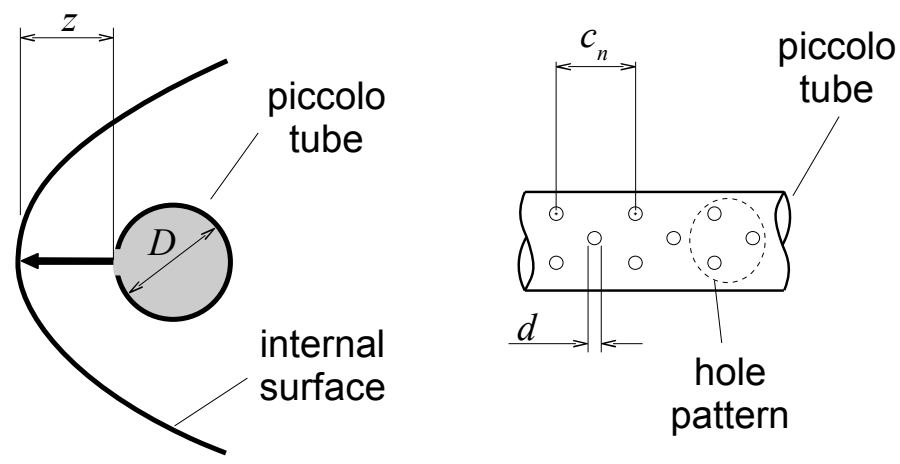

2.11a. D and z parameters.

2.11b. $c_{n}$ and d parameters.

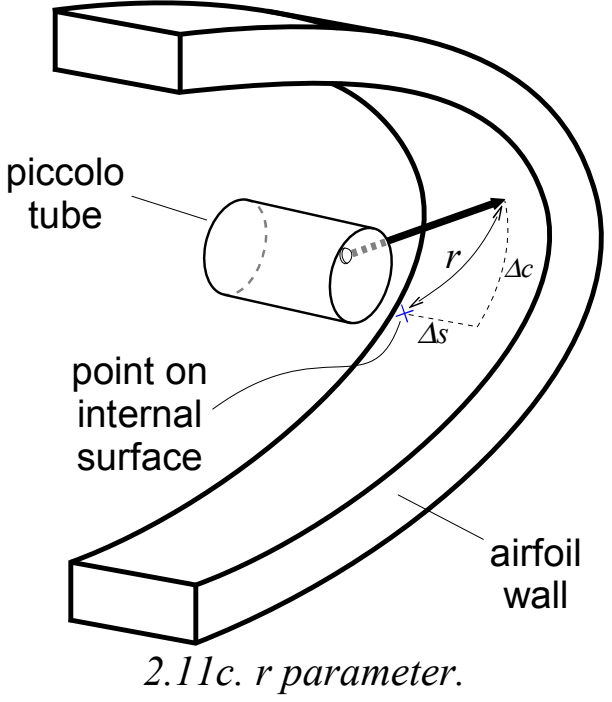

Figure 2.11. Geometric parametrization of piccolo tube.

The disadvantage associated with the use of Equation (2.25) is that the parameters HCONST, REP, ZP, RRP, RP, and DP need to be calibrated with representative preexisting heat 
transfer data for impinging jets. In this work, the calibration of these constants was based on heat transfer data obtained from viscous flow simulations performed in [15], where the internal and external flows were coupled by the heat exchange through the leading edge wall. The simulations were performed for a range of internal and external flow conditions, on a model representative of business jet wing air anti-icing system.

The correlation given in Equation (2.25) has a singularity at the stagnation point of the jet impingement. This is caused by the negative sign of the exponent $R P$ of the $r / d$ ratio. $R P$ must be negative to correctly account for the decay in the Nusselt number with the distance $r$ from the jet impingement point. As a result, $N u_{d}$ tends to infinity as $r$ tends to zero. This singularity is artificially overcome by applying a limiter to the output of the correlation. Details of the calibration of the stagnation Nusselt number limiter and the parameters HCONST, REP, ZP, $R R P, R P$, and $D P$ from Equation (2.25) are provided in Section 3.2.1.

A noteworthy aspect of the selected piccolo tube Nusselt number correlation is that it computes the Nusselt number at a given point by considering the effects of one single hot-air jet. However, for the case of a piccolo tube system, the protected surface involves heat transfer from an array of jets. Therefore, care must be taken at the regions in between the zone of influence of two or more adjacent jets. For simplification, the evaluation of the local heat transfer coefficient at any point in the region subjected to hot-air jet impingement considers only the nearest hot-air jet.

In order to qualitatively illustrate the spatial distribution of heat transfer coefficient that can be achieved with the current approach, Fig. 2.12 provides the results obtained for a piccolo tube with a diamond hole pattern in the generic business jet wing used in this study. 


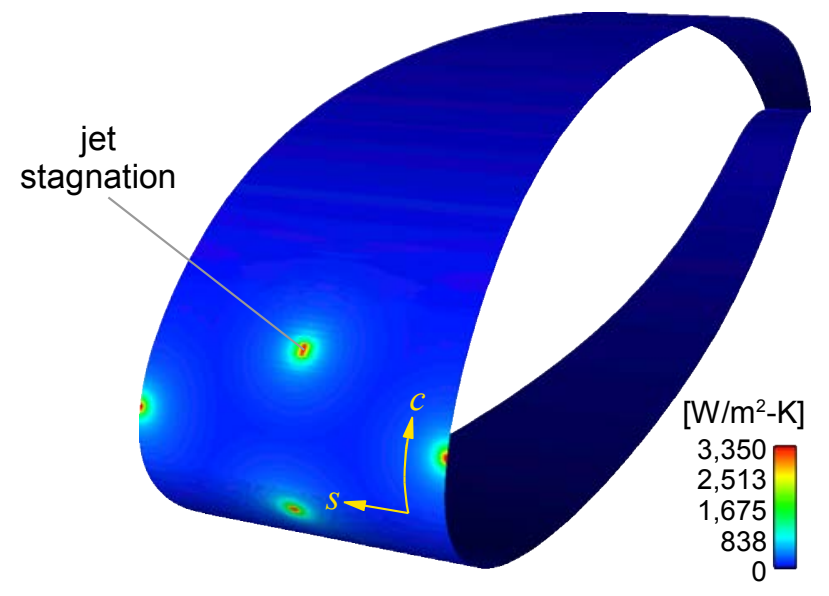

Figure 2.12. Contours of local of heat transfer coefficient on the internal skin $\left[h_{i}(c, s)\right]$ obtained with the hot-air jets Nusselt number correlation.

Figure 2.12 also indicates that the effect of such a heat transfer coefficient distribution generates a three-dimensional heat flux vector field across the leading edge wall. The directional components of this vector field $\left(q_{n}, q_{c}\right.$, and $\left.q_{s}\right)$ are illustrated in Fig. 2.13.

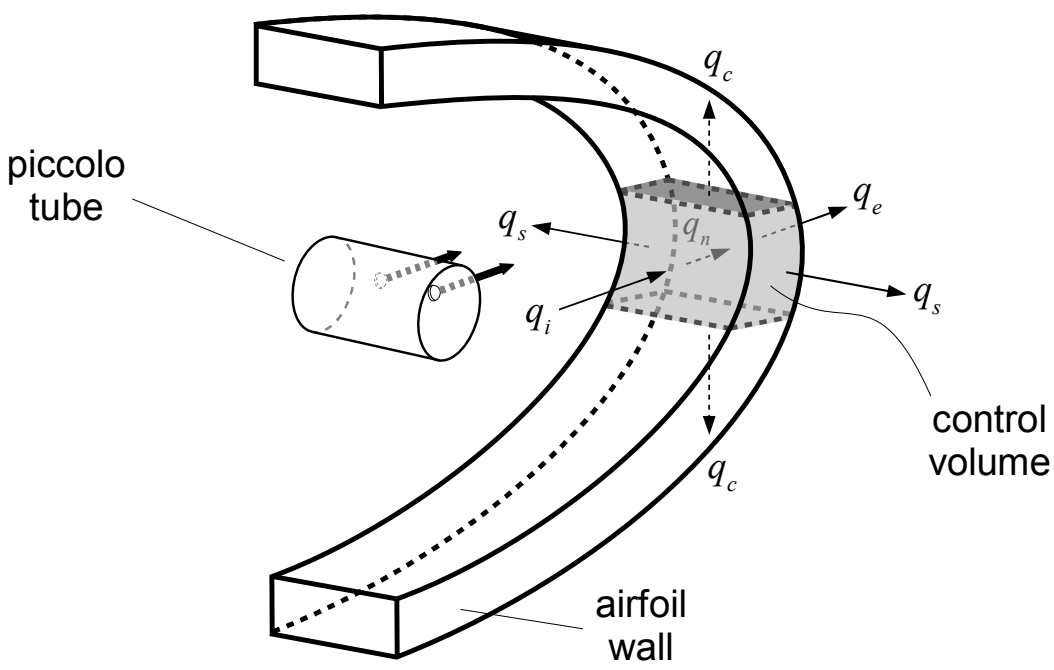

Figure 2.13. Directional components $q_{n}, q_{s}$, and $q_{c}$ of the heat flux field within an airfoil leading edge slice in the normal (n), spanwise (s) and curvilinear (c) coordinates, and convective heating $\left(q_{i}\right)$ and cooling $\left(q_{e}\right)$ on the airfoil internal and external skins, respectively.

Due to the 3-d nature of the heat flux in the solid wall, the corresponding 3-d temperature field cannot be captured with a 2-d heat conduction model. However, given that for an airfoil 
protected by a piccolo tube anti-icing system the skin temperature gradient is much higher in the direction of the curvilinear coordinate $c$, and the temperature distribution in the spanwise direction has a cyclic pattern, the performance of such a system can be represented with the span-weighted average properties of the internal flow. This eliminates the spanwise dimension $(s)$ of the physical domain while keeping the most important one, the curvilinear $(c)$. This task can be accomplished with the use of the classical concept of average heat transfer coefficient, which inherently conserves the total energy dissipation per unit span. The method consists on taking the average of the heat transfer coefficient along the spanwise direction only, in order to maintain an equivalent distribution along the curvilinear distance $c$, as shown in Equation (2.27),

$$
\bar{h}_{i}(c)=\frac{\int_{s_{1}}^{s_{2}} h_{i}(c, s) d s}{s_{2}-s_{1}}=\frac{\int_{s_{1}}^{s_{2}} h_{i}(c, s) d s}{0.5 c_{n}}
$$

where the integration is performed over one hole pattern (half pitch), represented by the integration limits $s_{1}$ and $s_{2}$. In order to illustrate the span-weighted averaging process, Fig. 2.14 presents the internal heat transfer coefficient distribution $\bar{h}_{i}(c)$ along the curvilinear coordinate $c$ that is obtained by applying Equation (2.27) to the heat transfer coefficient field $h_{i}(c, s)$ from Fig. 2.12. As it can be observed, the spatial variation of spanwise averaged $\bar{h}_{i}$ depends only on the curvilinear distance $c$, and now it can be used as a boundary condition in a 2-d heat conduction analysis. 


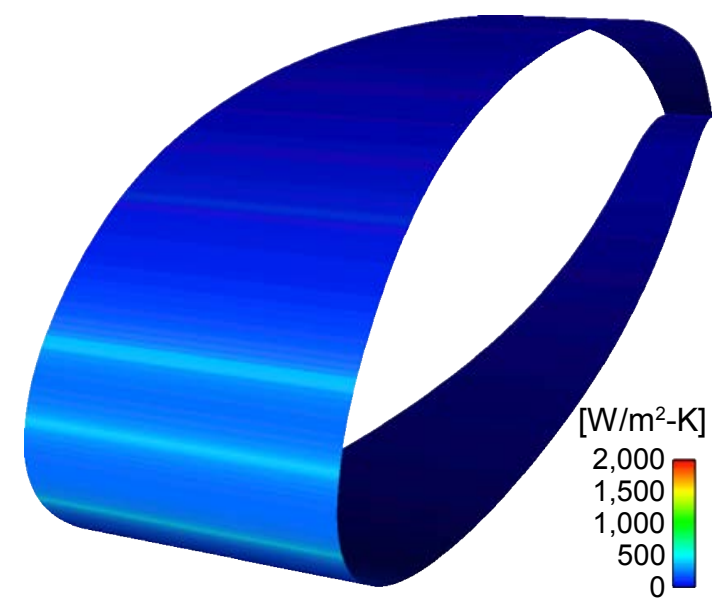

Figure 2.14. Contours of span-weighted average heat transfer coefficient $\left[\bar{h}_{i}(c)\right]$.

Comparisons of the skin temperature distributions predicted with and without the application of the averaging scheme are compared against each other and against experimental data in Section 3.2.1 - Fig. 3.10b.

\subsubsection{Heat Transfer Correlation for Thin Passages}

After impinging on the protected surface, the bleed air exits the diffuser chamber through thin passages formed between the inner liner and the wing internal skin, as shown in Figs. 1.3 and 2.1. Since the flow in these thin passages is nearly two-dimensional, the heat transfer coefficient is assumed to vary along the curvilinear distance $c$ only. This makes the coefficient a function of a single curvilinear variable $c$ and thus, it can be directly applied as a boundary condition in the $2-\mathrm{d}$ heat conduction analysis within the airfoil wall.

The thin passage local convective heat transfer coefficient $h_{i}$ can be approximated by means of correlations that are calibrated with available (experimental/numerical) heat transfer data. In the present work, the heat transfer data for calibration were generated with 2-d viscous flow analysis using FLUENT.

This section presents the governing equations used in extracting the heat transfer data 
from the 2-d CFD simulations, and for the process used for calibrating the thin passage Nusselt number correlation. Details of the 2-d viscous flow simulations used to generate the thin passage flow calibration data are presented in Section 2.3.3.3.

The first step in the calibration process consisted of obtaining the local heat transfer coefficient $h_{i}$ along the internal airfoil surface from the CFD simulations. The computation was performed with Equation (2.28)

$$
h_{i}=\frac{q_{i}{ }^{\prime \prime}}{T_{h}-T_{i}}
$$

where the terms on the right hand side are defined as:

$q_{i}^{\prime \prime}$ is the heat flux per unit at the internal surface (in $\left[\mathrm{W} / \mathrm{m}^{2}\right]$ )

$T_{h}$ is the bulk temperature of the hot-air at the inlet boundary of the computational domain (see Fig. 2.6) (in [K])

$T_{i}$ is the internal surface temperature (in $[\mathrm{K}]$ )

The internal heat transfer coefficient $h_{i}$ obtained from the 2-d CFD simulations was then converted to a non-dimensional heat transfer Nusselt number $N u_{t}$ using Equation (2.29),

$$
N u_{t}=\frac{h_{i} t}{k}
$$

based on the passage thickness $t$ (in [m]), and the thermal conductivity of air $k$ (in [W/m-K]), which was evaluated at the previously defined $T_{h}$.

The final step is to calibrate the thin passage Nusselt number correlation to match the data obtained from the CFD simulations. The correlation is composed of a series of $6^{\text {th }}$ degree polynomials, with each polynomial expressing the internal skin Nusselt number as a function of the curvilinear location $(c)$, as shown in Equation (2.30),

$$
N u_{t}=a_{0}+a_{1} c+a_{2} c^{2}+\ldots+a_{6} c^{6}
$$


where $c$ is measured from the passage inlet (in [m]), and $a_{0}, a_{1}, a_{2} \ldots a_{6}$ are the coefficients of the polynomial. For each configuration simulated with CFD (involving a different inlet passage Reynolds number, $\left.R e_{t}\right)$ a set of coefficients $\left(a_{0}, a_{1}, a_{2} \ldots a_{6}\right)$ was obtained through calibration. The correlation developed is used by the anti-icing simulation tool to predict the local Nusselt number at the thin passage as a function of $c, \operatorname{Re}_{t}$, and $t$.

The inlet Reynolds number $R e_{t}$ is defined as:

$$
R e_{t}=\frac{\dot{m}^{\prime}}{\mu}
$$

where $\dot{m}^{\prime}$ is the bleed air mass flow rate per unit span entering the passage (in $[\mathrm{kg} /(\mathrm{s}-\mathrm{m})]$ ), and $\mu$ is the absolute viscosity of the air (in [Pa-s]), evaluated at $T_{h}$.

For intermediary values of $R e_{t}$ and $t$ (values between those used in the calibration process), linear interpolation is applied to compute the thin passage local Nusselt number.

\subsubsection{Thin Passage Laminar Flow Simulation}

The governing equations applied to the solution of the thin passage flow were the NavierStokes equations for the laminar flow condition, discussed in Section 2.3.1.

The objective of simulating the compressible viscous flow inside the inner liner passages was to generate heat transfer data for the calibration of the Nusselt number correlation for the thin passage flow. The analyses were performed with FLUENT using 2-d computational grids like the one shown in Section 2.2.2 - Fig. 2.6. In the 2-d CFD simulations, the flow was treated as laminar due to the following: (1) since the passage is very thin (typically of the order of $1 \mathrm{~mm}$ ), it is reasonable to assume that any upstream large turbulence scale will not be able advance through the passage inlet; and (2) based on previous experience with bleed air anti-icing systems, typical Reynolds numbers at the passage inlet usually do not exceed 1,900 suggesting laminar flow conditions. Furthermore, although some engineering applications use corrugated 
surfaces to enhance the heat exchange in thin passages [63] and the same principle could be applied for hot-air anti-icing systems, the thin passages in most bleed air systems are smooth. These assumptions simplify the analysis and are conservative because they result in a lower internal heat transfer coefficient (less heat to the airfoil skin).

\subsubsection{Hot-Air Anti-icing Thermodynamic Model}

The physical phenomena governing the anti-icing problem are difficult to model because of the complex behavior of the water after impinging on the wing leading edge. The droplets tend to coalesce and then stream over the surface, driven by the shear forces while exchanging heat by conduction, radiation, and convection. In addition, the streaming droplets over the wing surface are subjected to evaporation, freezing, shedding, and sublimation. The prediction of the water flow over the wing surface (runback flow) is one of the most challenging aspects in icing simulations, because it can occur in the form of beads, rivulets, or non uniform films perturbed by the impinging droplets and external flow turbulence.

High fidelity simulation of anti-icing systems including computation of the water runback flow is very time consuming and computationally expensive. Thus high fidelity parametric design studies of bleed air ice protection systems for a wide range of icing and flight conditions to determine off-and-on design system performance can be prohibitively expensive. The simulation methodology presented in this thesis aims at reducing, by at least two orders of magnitude, the effort related to the anti-icing simulation problem. This is accomplished with the use of a cost efficient methodology based on a simplified, yet sufficiently accurate for engineering applications, thermodynamic model capable of determining wing LE temperature distributions and estimates of the runback freezing locations.

The anti-icing thermodynamic model essentially deals with the heat conduction in the 
airfoil wall and the water film over the external surface, as illustrated in Fig. 2.15. The airfoil wall is divided into layers with different thermal properties, taking into account the local variation of wall thermal conductivity with temperature.

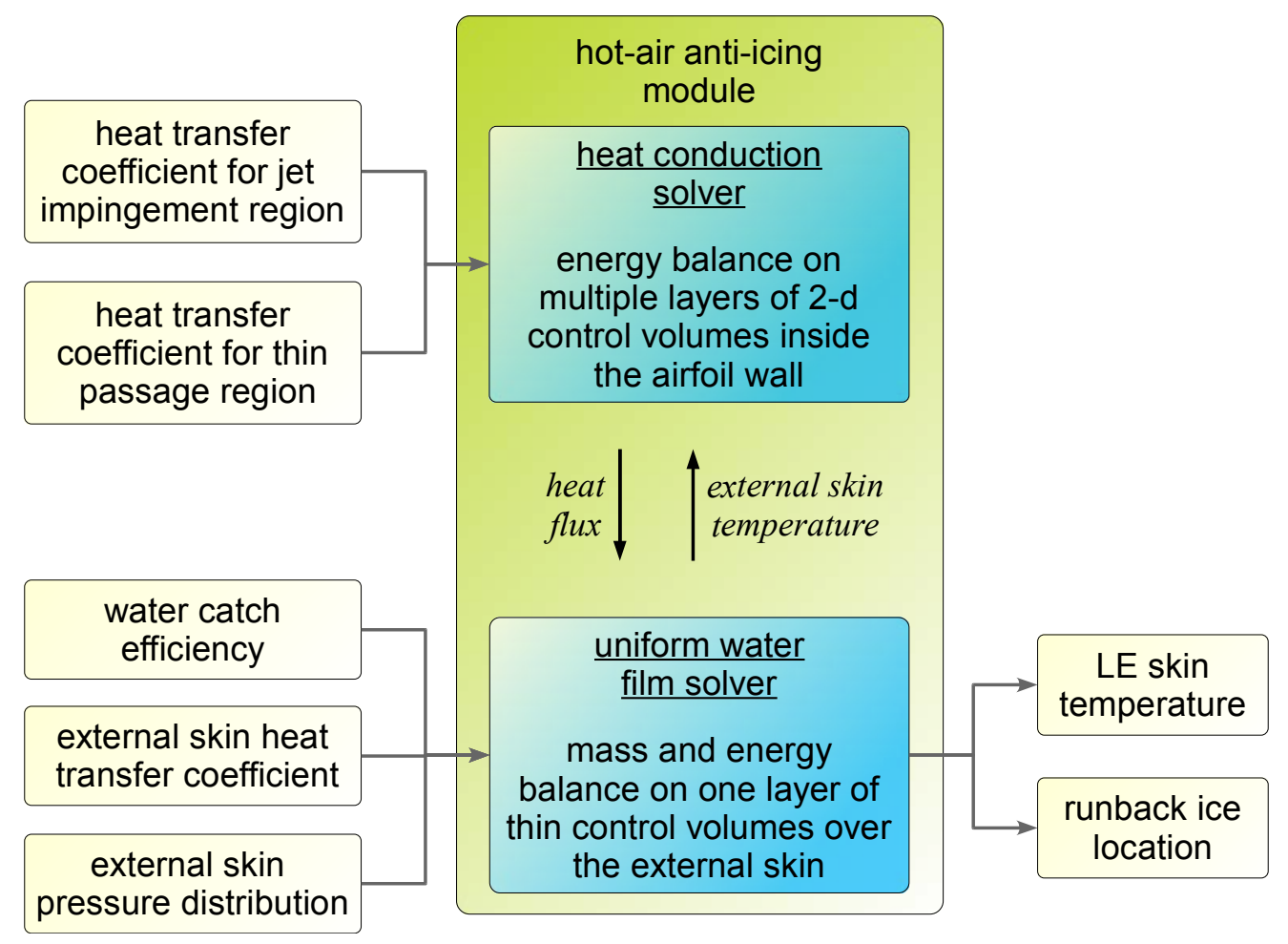

Figure 2.15. Information flow in the anti-icing thermodynamic model.

The steady state temperature field is obtained by discretizing the solid domain into smaller rectangular control volumes where the energy balance is solved. A convective heat transfer boundary condition is applied at the interior surface of the airfoil and the external surface is covered with a layer of thin control volumes (or surface control volumes) for mass and energy balance analysis, as shown in Fig. 2.16. 


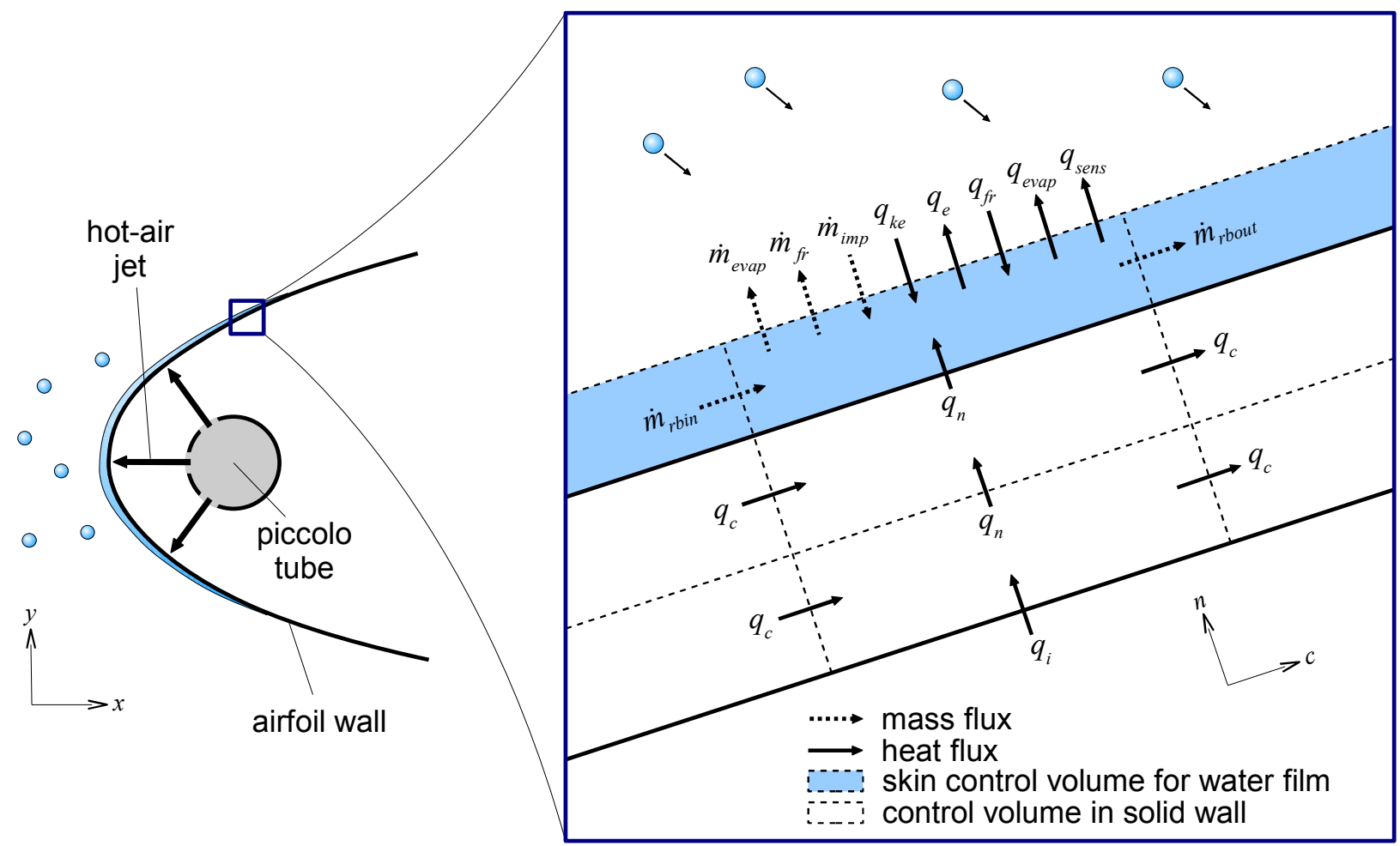

Figure 2.16. Heat and mass fluxes considered in the anti-icing thermodynamic model.

The mass and heat fluxes terms considered in the anti-icing module displayed in Fig. 2.16 are:

$\dot{m}_{\text {evap }}=$ rate of evaporation

$\dot{m}_{f r}=$ rate of freezing

$\dot{m}_{i m p}=$ rate of impingement

$\dot{m}_{r b i n}=$ rate of incoming runback flow

$\dot{m}_{r b o u t}=$ rate of outgoing runback flow

$q_{\text {evap }}=$ latent heat flux due to evaporation

$q_{f r}=$ latent heat flux due to solidification

$q_{e}=$ net convective heat flux due to the external flow

$q_{\text {sens }}=$ rate of sensible heat exchange with the impinging droplets, incoming runback flow, 
and rime ice (if any)

$$
\begin{aligned}
& q_{k e}=\text { kinetic energy released by the droplets at impact } \\
& q_{n}=\text { heat flux due to conduction in the normal direction } n \\
& q_{c}=\text { heat flux due to conduction in the direction of the curvilinear coordinate } c \\
& q_{i}=\text { convective heat flux from the hot-air flow }
\end{aligned}
$$

In the thin control volumes over the wing external surface, the incoming water that does not evaporate or freeze is allowed to flow to the next downstream element. When the airfoil wall external surface temperature reaches the freezing point, the incoming water freezes. The freezing rate depends on the latent heat of solidification gain and the evaporative, convective, and sensible heat loss. The solution of the water film energy balance and mass balance starts at the two elements placed immediately downstream of the stagnation point of the external flow and advances towards the subsequent downstream elements on the upper and lower airfoil surfaces. Sections 2.3.4.1 to 2.3.4.8 provide the details of the steady state formulation used in the hot-air anti-icing thermodynamic model.

\subsubsection{Water Film Flow (Runback)}

According to the study performed by Hedde and Guffond [39], the runback water flow closely follows the near wall streamlines in three-dimensional configurations. For the two-dimensional analysis model used in this work, the runback flow follows the external boundary line of the airfoil (Fig. 2.8). Additional simplifications imposed in the modeling of the water film flow are as follows:

$\rightarrow$ 1-d film, with properties varying with the curvilinear coordinate $c$

$\rightarrow$ Small film thickness so the water remains at the temperature of the external skin (the incoming water to a surface control volume, due to impingement and 
runback, instantly reaches the skin temperature, releasing or absorbing sensible heat accordingly)

$\rightarrow$ At the impingement region $(\beta>0)$ the water film is homogeneously spread over the external surface, whereas outside the impingement region $(\beta=0)$ the water film instantly occupies $25 \%$ of the external surface area (based on experimental observations [79])

$\rightarrow$ No water shedding from the film to the external flow

$\rightarrow$ Water that is not evaporated, sublimated, or frozen is completely transferred to the next downstream control volume, with no accumulation

$\rightarrow$ At the stagnation point of the external flow, the only income of water is due to impingement (no incoming water runback flow), and half of the accumulated water streams to the airfoil upper surface and half streams to the airfoil lower surface

\subsubsection{Evaporation}

The computation of the evaporative heat loss rate $q_{\text {evap }}$ within a surface control volume is similar to the method used in [30], and is given in Equation (2.32). In this work, however, the area exposed to evaporation is obtained by the product of the wetness factor and the control volume external surface area (area exposed to external flow only), due to the assumption of uniform water film coverage.

$$
q_{\text {evap }}=\frac{N_{w} A L_{v} h_{m}(M W)_{w}}{\hat{R}}\left(\frac{e_{e}}{T_{e}}-\frac{e_{e d g}}{T_{\text {edg }}}\right)
$$

The definition of the terms in the governing equation for evaporative heat loss is:

$\rightarrow N_{w}=$ wetness factor, representing the wet-to-dry area ratio at the external face of 
the film control volume, assumed to be 1 at regions with $\beta>0$ and 0.25 for $\beta=0$

$\rightarrow A=$ control volume external surface area (in $\left[\mathrm{m}^{2}\right]$ ) defined as $A=(\Delta c) * 1$, where $\Delta c$ is the surface length of the control volume along the curvilinear coordinate $c$ (in [m]) and 1 represents a unit span (in [m])

$\rightarrow L_{v}=$ latent heat of evaporation of water (in $[\mathrm{J} / \mathrm{kg}]$ )

$\rightarrow h_{m}=$ mass transfer coefficient (in $[\mathrm{m} / \mathrm{s}]$ )

$\rightarrow(M W)_{w}=$ molecular weight of water, $18.01056[\mathrm{~kg} / \mathrm{kg}-\mathrm{mol}]$

$\rightarrow \hat{R}=$ molar ideal gas constant, $8314.472[\mathrm{~J} / \mathrm{kg}-\mathrm{mol}-\mathrm{K}]$

$\rightarrow T_{e}=$ external surface temperature (in $[\mathrm{K}]$ )

$\rightarrow T_{\text {edg }}=$ air static temperature at the edge of the boundary layer (in [K]), defined in Equation (2.13)

$\rightarrow e_{e}$ and $e_{e d g}$ are the saturated evaporative pressures of water (in [Pa]) evaluated at $T_{e}$ and $T_{\text {edg }}$, respectively, defined in [30] as:

$$
\begin{aligned}
& e=6894.7 \exp \left(20.15247167-\frac{11097.16963}{1.8 T}\right), \quad \text { for } \quad T<T_{f r}=273.15[\mathrm{~K}] \\
& \text { and } \\
& e=6894.7 \exp \left(14.56594634-\frac{7129.219482}{1.8 T-72}\right), \quad \text { for } \quad T \geq T_{f r}=273.15[\mathrm{~K}]
\end{aligned}
$$

The term $T_{f r}$ in Equation 2.33 is the water freezing point.

In Equation (2.32), the mass transfer coefficient $h_{m}$ is correlated to the external skin convective heat transfer coefficient $h_{e}$ by

$$
h_{m}=\frac{h_{e}}{\left(\rho C_{p}\right)_{a i r} L^{2 / 3}}
$$

where $\rho_{\text {air }}$ is the density of air (in $\left.\left[\mathrm{kg} / \mathrm{m}^{3}\right]\right) ;\left(C_{p}\right)_{a i r}$ is the specific heat of air at constant pressure (in $[\mathrm{J} / \mathrm{kg}-\mathrm{K}]$ ); and $L$ is the dimensionless Lewis number defined as the ratio of the thermal 
diffusivity-to-mass diffusivity. The Lewis number is used to characterize fluid flows where there is simultaneous heat and mass transfer by convection, and is expressed as:

$$
L=\frac{\alpha_{a i r}}{D_{a w}}=\frac{k_{a i r}}{\left(\rho C_{p}\right)_{a i r} D_{a w}}
$$

In Equation (2.35), $k_{a i r}$ is the thermal conductivity of air (in $[\mathrm{W} / \mathrm{m}-\mathrm{K}]$ ), and $D_{a w}$ is the binary mass diffusion coefficient for air-water vapor mixtures (in $\left[\mathrm{m}^{2} / \mathrm{s}\right]$ ). Both are evaluated at the average temperature between $T_{e}$ and $T_{\text {edg. }}$.

The water evaporation rate $\dot{m}_{\text {evap }}$ at the surface of a given control volume is computed from the evaporative heat loss, according to Equation (2.36).

$$
\dot{m}_{\text {evap }}=\frac{q_{\text {evap }}}{L_{v}}
$$

\subsubsection{Convective Heat Transfer}

The net convective heat exchange $q_{e}$ at a given location on the external skin, resulting from the convective cooling and aerodynamic heating of the external flow, is based on the concept of convective heat transfer coefficient, as in [52], given by

$$
q_{e}=h_{e} A\left(T_{e}-T_{r e c}\right)
$$

where $h_{e}$ is the convective heat transfer coefficient at the external surface of the airfoil (in $\left.\left[\mathrm{W} / \mathrm{m}^{2}-\mathrm{K}\right]\right)$ and $T_{\text {rec }}$ is the recovery temperature, defined in Equation (2.12).

Inside the leading edge, the convective heat transfer $q_{i}$ from the hot-air to the interior skin, at a given surface location, is given by

$$
q_{i}=h_{i} A\left(T_{p}-T_{i}\right)
$$

for the diffuser bay region, and by

$$
q_{i}=h_{i} A\left(T_{h}-T_{i}\right)
$$


for the thin inner liner passages. The terms $T_{p}$ and $T_{h}$ are reference temperatures (in [K]) for the diffuser and thin passage flows, respectively.

\subsubsection{Solidification}

Following the methodology applied in $[30,52,54]$, the solidification of the water over the airfoil surface is assumed to happen over a small artificial temperature range [from $T_{f r}$ to $\left(T_{f r}+\Delta T_{f r}\right)$ ] above the freezing point of water. The portion of the incoming water that freezes on a skin control volume is defined as the freezing fraction $N_{f r}$, and it is computed as a linear function of the film temperature, according to Equation (2.40),

$$
N_{f r}=1-\frac{T_{e}-T_{f r}}{\Delta T_{f r}}
$$

where $T_{e}$ is effectively the water film temperature. When the combination of the thermal loads provides sufficient cooling for a complete freezing of the incoming water, i.e., when the skin temperature is below $T_{f r}$, the freezing fraction is 1 . For skin temperatures beyond $T_{f r}+\Delta T_{f r}$, the freezing fraction is set to 0 .

The freezing fraction is used to compute the freezing rate at a given curvilinear location (c) according to Equation (2.41).

$$
\dot{m}_{f r}=N_{f r}\left(\dot{m}_{i m p}+\dot{m}_{r b i n}-\dot{m}_{\text {evap }}\right)
$$

The latent heat flux, $q_{f r}$, dissipated due to the solidification of the water is computed with Equation (2.42),

$$
q_{f r}=L_{f r} \dot{m}_{f r}
$$

where $L_{f r}$ is the latent heat of solidification of water (in $[\mathrm{J} / \mathrm{kg}]$ ).

\subsubsection{Heat Diffusion in the Solid Wall}

Typically, the 2-d steady state temperature field in a solid medium with defined boundary 
conditions is solved with the heat equation, which is a second order partial differential equation whose derivation can be obtained from the application of the first law of thermodynamics to a control volume. The solution of the heat equation can be obtained either analytically, in the form of infinite series; or numerically, by converting the differential equation to an approximate algebraic equation.

In this work, the solution of the heat conduction problem follows the same approach used by Al-Khalil [43], which applies the first law of thermodynamics to the finite control volumes of the solid domain and, thus, satisfies the energy conservation principle. The formulation is presented with the superscripts $i$ and $j$ to denote the position of the control volumes in the computational domain along the curvilinear coordinate $c$ and normal coordinate $n$, respectively. For steady state analysis, the energy balance for a control volume in a solid medium without heat generation can be written as:

$$
q_{n 1}^{i, j}+q_{c l}^{i, j}+q_{n 2}^{i, j}+q_{c 2}^{i, j}=0
$$

where $q_{n 1}^{i, j}$ and $q_{n 2}^{i, j}$ are the heat fluxes (in [W]) leaving control volume $i, j$ in the wall normal direction ( $n$ ) towards the internal and external surfaces of the airfoil, respectively; and $q_{c l}^{i, j}$ and $q_{c 2}^{i, j}$ are the heat fluxes (in [W]) leaving control volume $i, j$ in the curvilinear coordinate (c) to the left and to the right, towards the lower and upper trailing edge walls, respectively, as illustrated in Fig. 2.17.

The heat flux conducted in each direction is computed with Fourier's law, by approximating the directional derivative of the temperature with a first order discretization scheme as shown in Equation (2.44), 


$$
\begin{aligned}
& q_{n 1}^{i, j}=\frac{T^{i, j}-T^{i, j-1}}{R_{n 1}^{i, j}} \\
& q_{n 2}^{i, j}=\frac{T^{i, j}-T^{i, j+1}}{R_{n 2}^{i, j}} \\
& q_{c 1}^{i, j}=\frac{T^{i, j}-T^{i-1, j}}{R_{c 1}^{i, j}} \\
& q_{c 2}^{i, j}=\frac{T^{i, j}-T^{i+1, j}}{R_{c 2}^{i, j}}
\end{aligned}
$$

where $T$ represents the control volume temperature (in $[\mathrm{K}]$ ) and $R$ the medium resistance to heat conduction (in $[\mathrm{K} / \mathrm{W}]$ ), computed with Equation (2.45), from the center of element $i, j$ to the center of each adjacent element (see Fig. 2.18a), taking into account the spatial variation of the thermal conductivity.

$$
\begin{aligned}
& R_{n 1}^{i, j}=\frac{1}{2(\Delta c)^{i}}\left[\frac{(\Delta n)^{j}}{k^{i, j}}+\frac{(\Delta n)^{j-1}}{k^{i, j-1}}\right] \\
& R_{n 2}^{i, j}=\frac{1}{2(\Delta c)^{i}}\left[\frac{(\Delta n)^{j}}{k^{i, j}}+\frac{(\Delta n)^{j+1}}{k^{i, j+1}}\right] \\
& R_{c 1}^{i, j}=\frac{1}{2(\Delta n)^{j}}\left[\frac{(\Delta c)^{i}}{k^{i, j}}+\frac{(\Delta c)^{i-1}}{k^{i-1, j}}\right] \\
& R_{c 2}^{i, j}=\frac{1}{2(\Delta n)^{j}}\left[\frac{(\Delta c)^{i}}{k^{i, j}}+\frac{(\Delta c)^{i+1}}{k^{i+1, j}}\right]
\end{aligned}
$$

For the particular case of a control volume located at the outer most layer of the solid domain, i.e., adjacent to the external surface of the airfoil wall (see Fig. 2.18b), the thermal resistances $R_{n 2}^{i, j \max }$ is computed with Equation (2.46).

$$
R_{n 2}^{i, j \max }=\frac{(\Delta n)^{j \max }}{2 k^{i, j \max }(\Delta c)^{i}}
$$

Similarly, at the inner most layer (see Fig. 2.18c) the thermal resistance from the cell 
center to the internal surface of the airfoil wall $R_{n 1}^{i, 1}$ is defined as:

$$
R_{n l}^{i, 1}=\frac{(\Delta n)_{1}}{2 k_{i, 1}(\Delta c)_{i}}
$$

For the control volumes at the left and right extremities of the computational domain (lower and upper trailing edge in the physical domain, respectively, illustrated in Figures $2.18 \mathrm{~d}$ and 2.18e), the knowledge of the cell center-to-boundary thermal resistance is not necessary because the adiabatic condition is applied to the trailing edge walls.

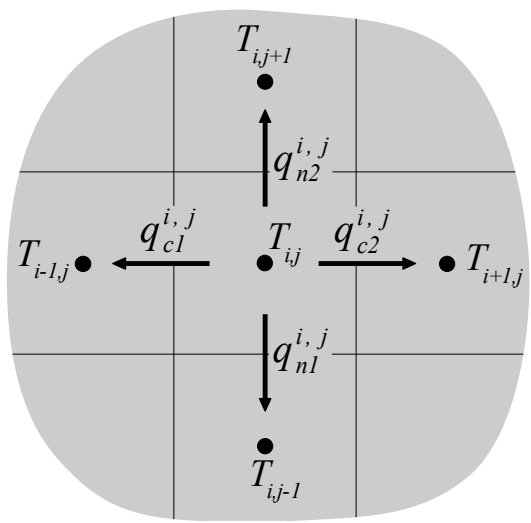

Figure 2.17. Energy balance on control volume i,j in the solid domain.

The steady state temperature of a control volume can be obtained explicitly by combining Equations (2.43) and (2.44). For the control volumes adjacent to the left and right boundaries of the computational domain, the temperatures $T^{1, j}$ and $T^{i m a x, j}$ are given by Equation (2.48).

$$
T^{1, j}=\frac{\frac{T^{1, j-1}}{R_{n 1}^{1, j}}+\frac{T^{1, j+1}}{R_{n 2}^{1, j}}+\frac{T^{2, j}}{R_{c 2}^{1, j}}}{\frac{1}{R_{n 1}^{1, j}}+\frac{1}{R_{n 2}^{1, j}}+\frac{1}{R_{c 2}^{1, j}}} \text { and } T^{i \max , j}=\frac{\frac{T^{i \max , j-1}}{R_{n 1}^{\text {imax }, j}}+\frac{T^{i \max , j+1}}{R_{n 2}^{\text {imax }, j}}+\frac{T^{i \max -1, j}}{R_{c 1}^{\text {imax }, j}}}{\frac{1}{R_{n 1}^{\text {imax }, j}}+\frac{1}{R_{n 2}^{\text {imax }, j}}+\frac{1}{R_{c 1}^{\text {imax }, j}}}
$$




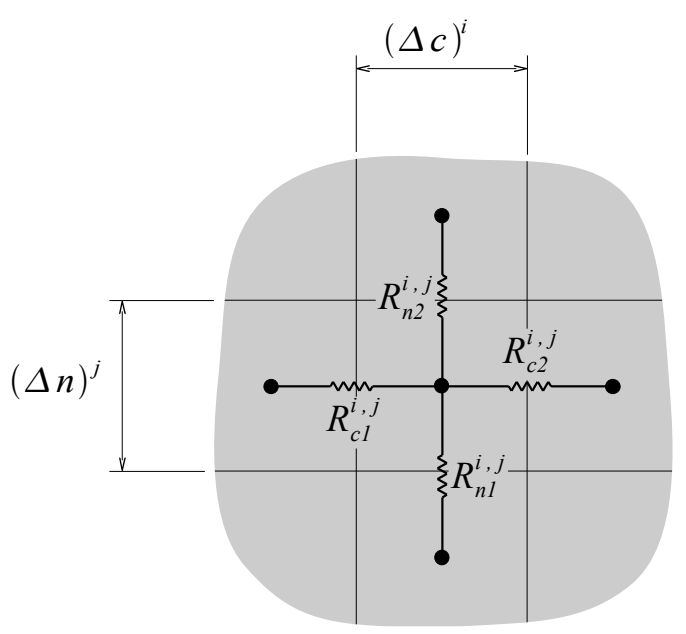

2.18a. CV not on a boundary.

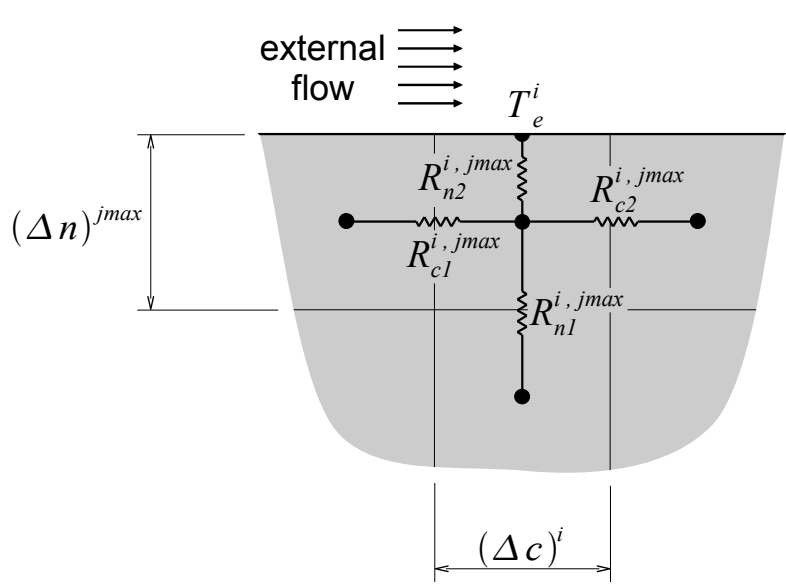

2.18b. $C V$ on the external surface.

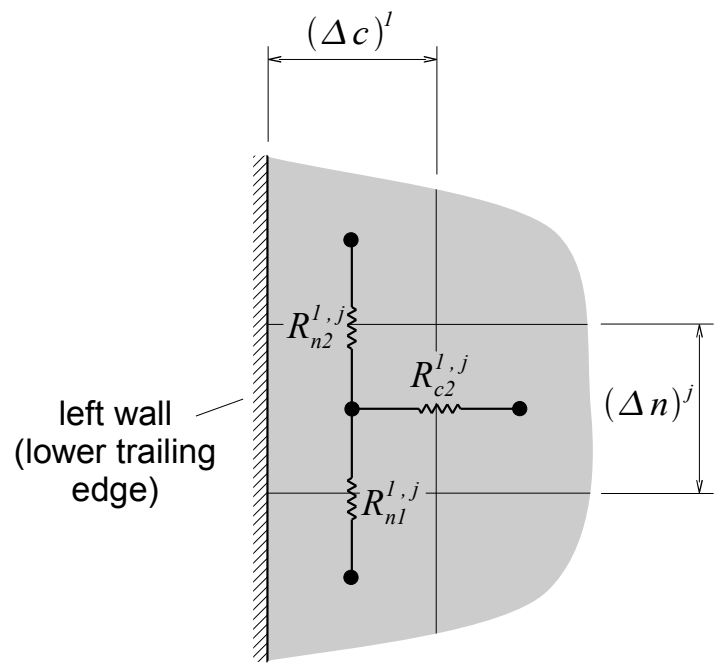

2.18d. CV on the lower trailing edge.

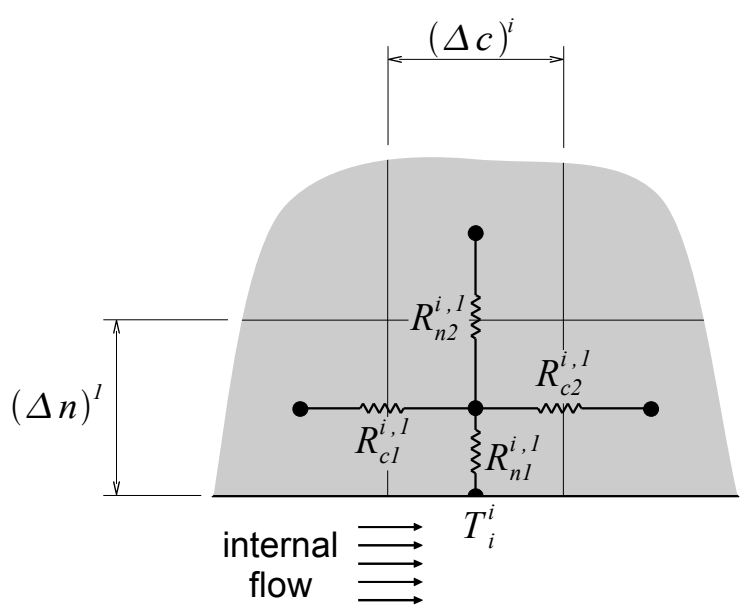

2.18c. CV on the internal surface.

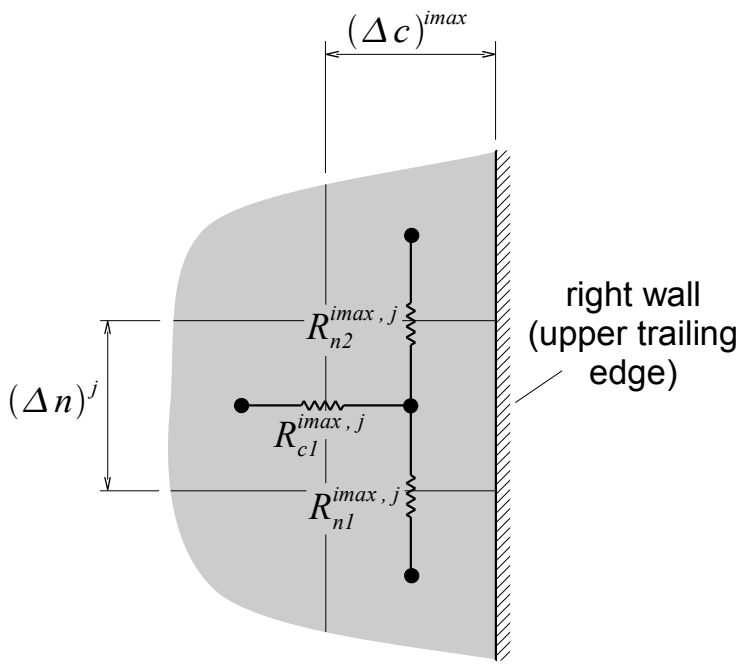

2.18e. $C V$ on the upper trailing edge.

Figure 2.18. Thermal resistance between control volumes in the solid domain. 
Similarly, the temperature of the elements adjacent to the internal skin $T^{i l}$ is given by Equation (2.49), with $T_{i}^{i}$ representing the internal skin temperature at the $i^{\text {th }}$ location over the airfoil internal surface.

$$
T^{i, 1}=\frac{\frac{T_{i}^{i}}{R_{n 1}^{i, 1}}+\frac{T^{i, j+1}}{R_{n 2}^{i, 1}}+\frac{T^{i-1, j}}{R_{c 1}^{i, l}}+\frac{T^{i+1, j}}{R_{c 2}^{i, l}}}{\frac{1}{R_{n 1}^{i, l}}+\frac{1}{R_{n 2}^{i, l}}+\frac{1}{R_{c l}^{i, l}}+\frac{1}{R_{c 2}^{i, l}}}
$$

For the control volumes adjacent to the external surface, the temperature $T^{i, j m a x}$ is given by Equation (2.50), with $T_{e}^{i}$ representing the external skin temperature at the $i^{\text {th }}$ location over the airfoil external surface.

$$
T^{i, j \max }=\frac{\frac{T^{i, j-1}}{R_{n 1}^{i, j \max }}+\frac{T_{e}^{i}}{R_{n 2}^{i, j \max }}+\frac{T^{i-1, j}}{R_{c 1}^{i, j \max }}+\frac{T^{i+1, j}}{R_{c 2}^{i, j \max }}}{\frac{1}{R_{n 1}^{i, j \max }}+\frac{1}{R_{n 2}^{i, j \max }}+\frac{1}{R_{c 1}^{i, j \max }}+\frac{1}{R_{c 2}^{i, j \max }}}
$$

For the remaining control volumes in the solid domain, the temperature is computed with Equation (2.51).

$$
T^{i, j}=\frac{\frac{T^{i, j-1}}{R_{n 1}^{i, j}}+\frac{T^{i, j+1}}{R_{n 2}^{i, j}}+\frac{T^{i-l, j}}{R_{c 1}^{i, j}}+\frac{T^{i+1, j}}{R_{c 2}^{i, j}}}{\frac{1}{R_{n 1}^{i, j}}+\frac{1}{R_{n 2}^{i, j}}+\frac{1}{R_{c 1}^{i, j}}+\frac{1}{R_{c 2}^{i, j}}}
$$

\subsubsection{Sensible Heat Exchange}

On the external surface control volumes, the water inflow due to runback and impingement instantly reaches the external skin temperature. The sensible energy exchange 
$\left(q_{\text {sens }}\right)$ involved in the process is defined by Equations (2.52) and (2.53), for $T_{e} \leq T_{f r}$ and $T_{e}>T_{f r}$, respectively. In these equations the superscript $i$ denotes the position along the external skin. The sensible heat exchange method used in this thesis is similar to the one applied in [30].

$$
\begin{gathered}
q_{\text {sens }}^{i}=C_{w}\left[\dot{m}_{i m p}^{i}\left(T_{f r}-T_{\infty}\right)+\dot{m}_{r b i n}^{i}\left(T_{f r}-T_{e}^{i-1}\right)\right]+C_{i c e} \dot{m}_{f r}^{i}\left(T_{e}^{i}-T_{f r}\right) \\
q_{\text {sens }}^{i}=C_{w}\left[\dot{m}_{i m p}^{i}\left(T_{e}^{i}-T_{\infty}\right)+\dot{m}_{r b i n}^{i}\left(T_{e}^{i}-T_{e}^{i-1}\right)\right]
\end{gathered}
$$

The terms in Equations (2.52) and (2.53) are defined as:

$\rightarrow C_{w}$ is the specific heat of water (in $[\mathrm{J} / \mathrm{kg}-\mathrm{K}]$ )

$\rightarrow C_{i c e}$ is the specific heat of ice (in $\left.[\mathrm{J} / \mathrm{kg}-\mathrm{K}]\right)$

$\rightarrow T_{\infty}$ is the freestream static temperature (in $[\mathrm{K}]$ )

$\rightarrow$ The temperature of the runback flow is represented by the external skin temperature $T_{e}$ (in $\left.[\mathrm{K}]\right)$

\subsubsection{Kinetic Heating from Impinging Droplets}

Droplet collisions on the solid surface are assumed to be perfectly inelastic, with the droplet kinetic energy totally converted into heat. The equation for the rate of kinetic heating $q_{k e}$ received by a given surface control volume follows the approach used by Silveira [52]

$$
q_{k e}=\dot{m}_{i m p} \frac{V_{\infty}^{2}}{2}
$$

where:

$\rightarrow V_{\infty}$ is the freestream speed (in $\left.[\mathrm{m} / \mathrm{s}]\right)$

$\rightarrow \dot{m}_{\text {imp }}$ is the surface control volume water catch rate (in $[\mathrm{kg} / \mathrm{s}]$ ), defined as $A \beta(L W C) V_{\infty}$, where:

$\diamond \mathrm{A}$ is the control volume external surface area (in [m2]) 
$\diamond \beta$ is the non-dimensional local water catch efficiency

$\diamond L W C$ is the freestream liquid water content (in $\left[\mathrm{kg} / \mathrm{m}^{3}\right]$ )

\subsubsection{Energy and Mass balances}

The energy balance in the control volumes of the solid domain used for solving the heat conduction problem was discussed in Section 2.3.4.5. This section presents the mass and energy balances performed on the outer control volumes to determine the external skin equilibrium temperature and rates of evaporation and freezing. According to the first law of thermodynamics for control volumes in steady state, the energy balance can be written as:

$$
f\left(T_{e}\right)=q_{n}+q_{k e}+q_{f r}-q_{\text {sens }}-q_{e}-q_{\text {evap }}=0
$$

Analogously, the steady state mass balance for a water film control volume, based on the principle of mass continuity, can be formulated as:

$$
\dot{m}_{r b i n}+\dot{m}_{\text {imp }}-\dot{m}_{\text {evap }}-\dot{m}_{f r}-\dot{m}_{r b o u t}=0
$$

Equation (2.55) is a transcendental function of the external skin temperature whose root is found by applying the Newton-Raphson method. In the root finding process, the mass flux terms in Equation (2.56) that depend on $T_{e}$ are updated simultaneously. For the control volumes with non-zero incoming water flow, the computation of the external skin temperature is initialized with a freezing fraction of 0 . As the value of $T_{e}$ changes during the iterative process, the freezing fraction is updated whenever $T_{e}$ reaches the freezing range, according to Equation (2.40).

The external skin temperature is solved for all external control volumes in a marching process that starts at the stagnation point of the external flow, proceeding along the upper and lower surfaces towards the upper and lower trailing edges. After computing $T_{e}$ for all surface control volumes, the temperature field in the solid domain is iterated a few times in a marching 
process with alternating direction, using an over-relaxation factor of 1.95 to accelerate convergence. The entire cycle is repeated until global convergence is achieved.

\subsection{CFD Numerical Schemes}

FLUENT provides two numerical schemes to solve the nonlinear system of equations $[(2.1),(2.2)$, and (2.3)] and the integral equations for the turbulent scalars, a pressure-based solver $[72,73]$ and a density based solver [74]. Both methods use a control-volume technique. The computational domain is divided into discrete control volumes and integration of the conservation equations on individual control volumes yields a set of equations for the discrete flow variables. These equations are linearized (implicitly or explicitly) and solved. The pressurebased formulation linearizes each governing equation implicitly with respect to that equation's dependent variable. The result is a scalar system of linear equations with one equation per cell in the domain. These equations are solved sequentially (i.e. segregated), one field variable after another considering all the cells at the same time.

The segregated solver employs a point implicit linear equation solver (Gauss-Seidel or Incomplete Lower Upper Decomposition) in conjunction with an algebraic multigrid (AMG) method $[72,75]$ to solve all implicitly linearized system of equations. Multigrid schemes accelerate solver convergence by computing corrections on a series of coarser grid levels. The immediate benefit is a considerable reduction in the number of iterations and the CPU time required to obtain a converged solution. FLUENT uses the AMG method to accelerate the removal of low frequency (global) errors and thus enhance convergence for implicit solvers. The concept behind the AMG methodology is that long wavelength (low frequency) errors on a fine

level appear as short wavelength (high frequency) errors on a coarser level where they can be 
more effectively damped out by the relaxation scheme. Without a multigrid scheme, the removal of low frequency errors is completed at a rate inversely related to the grid size. For a fine grid with a large number of nodes, the solver may stall with a prohibitively low error reduction rate [76]. Coarse level equations are generated algebraically and no additional independent mesh is required.

The CFD studies presented in this thesis related to the external gaseous flow and the thin passage flow were completed using a pressure-based implicit solver with AMG, following the procedure developed in [15].

\subsection{Boundary Conditions}

Boundary conditions specify the flow and thermal variables on the boundaries of the computational domain including walls, inflow, and outflow planes.

In the anti-icing module, the external skin (airfoil outer surface) boundary conditions are obtained from the solution of the external flow. The internal skin (airfoil inner surface) boundary conditions over the protected area are obtained from Nusselt number correlations (see Sections 2.3.3.1 and 2.3.3.2). The unprotected regions of the airfoil interior skin and the trailing edge walls are treated as adiabatic surfaces.

The boundary conditions necessary for the internal flow Nusselt number correlations are the hot-air inflow Reynolds number and the reference temperature. For the thin passage region, the reference temperature is the hot-air bulk temperature, while for the diffuser bay region, the reference temperature is the hot-air total temperature. The boundary conditions for the other models of the simulation tool developed are presented in Sections 2.5.1 and 2.5.2, for the external flow gaseous and liquid phases, respectively. In addition to the boundary conditions 
required by the simulation tool developed, Section 2.5 .3 presents the boundary conditions applied to the 2-d viscous flow analyses used to generate heat transfer data for calibration of the inner liner passage flow correlation.

\subsubsection{External Flow Gas Phase}

The computation of the convective cooling over the external skin is based on the convective heat transfer coefficient that is obtained from the 2-d CFD solution of the external airflow. With the objective of reducing the computational cost, it is assumed that the airfoil skin temperature gradient along the curvilinear coordinate $c$ has no effect on the heat transfer coefficient. Based on this assumption, the external flow is decoupled from the rest of the computational domain and the flowfield solution is obtained by applying an isothermal condition to the airfoil external skin. The quantitative effect of such a simplification on the heat transfer coefficient is analyzed in Section 3.1. Moreover, the overall effect of this simplification can be evaluated by comparing the experimental and predicted airfoil skin temperature distributions and locations of runback ice for a representative wing anti-icing system, presented in Section 3.3.2.

At the far field boundary of the external flow a pressure far field boundary condition is used in FLUENT. This condition requires the specification of the freestream Mach number and static thermodynamic properties.

The angle of attack $(\alpha)$ used for the 2-d external flow analysis was the same as in the validation cases discussed in Section 3.1. Note that for 2-d analysis of a swept surface, the $\alpha$ must be adjusted so that the pressure distribution of the 2-d airfoil is as close as possible to the 3-d wing at the desired spanwise station. 


\subsubsection{External Flow Liquid Phase (Water Collection Efficiency)}

Solution of the liquid phase with the Lagrangian or the Eulerian method requires the specification of droplet size, density, and freestream speed at the inflow boundaries. The mass and thermal diffusivity of the liquid phase are set to zero. In the Eulerian method, the gradients of water phase velocity and water volume fraction are set to zero at the outflow elements.

In the validation cases for wet air condition presented in Section 3.1, the computation of local water catch efficiency for a given MVD was performed with the Langmuir D droplet distribution given in Table 2.2.

Table 2.2. Langmuir D distribution

\begin{tabular}{|c|c|}
\hline $\begin{array}{c}\text { Water mass } \\
\text { fraction }\left(n_{i}\right)\end{array}$ & $\begin{array}{c}\text { Ratio of droplet } \\
\text { diameter to MVD }\end{array}$ \\
\hline \hline 0.05 & 0.31 \\
\hline 0.10 & 0.52 \\
\hline 0.20 & 0.71 \\
\hline 0.30 & 1.00 \\
\hline 0.20 & 1.37 \\
\hline 0.10 & 1.74 \\
\hline 0.05 & 2.22 \\
\hline
\end{tabular}

\subsubsection{Thin Passage Laminar Flow Simulation}

Analysis of the flow in the upper and lower bleed air system thin passages formed by the inner liner and the airfoil interior surface was performed with FLUENT for a range of inlet Reynolds numbers that was obtained by varying the inlet hot-air mass flow rate and passage thickness. Flow boundary conditions for this analysis included:

$\rightarrow$ Inlet boundary - uniformly distributed mass flow inlet; for total mass flow rates of 
0.005, 0.025 and $0.05[\mathrm{~kg} / \mathrm{s}-\mathrm{m}]$, representing low, medium, and high hot-air mass flow rates respectively for the business jet anti-icing system examined in this study. The associated inlet air total temperature was maintained at $550[\mathrm{~K}]$ in all cases.

$\rightarrow$ Outlet boundary - pressure outlet, with a static pressure of 57,000 [Pa], representing a typical holding altitude of approximately 15,000 [ft].

$\rightarrow$ Airfoil wall internal surface boundary - isothermal wall, with a temperature of $273.15[\mathrm{~K}]$. 


\section{CHAPTER 3}

\section{RESULTS AND DISCUSSION}

The presentation of the simulation results is divided into four parts. The first (Section 3.1) deals with the external flow analysis, starting with a grid resolution study and concluding with an evaluation of the effects of the external skin thermal boundary condition on the external heat transfer coefficient. The second part (Section 3.2) presents the results of the calibration of the Nusselt number correlation for impinging jet, and the heat transfer data obtained with the 2-d CFD analysis for the laminar flow in the thin passage. The third part (Section 3.3) assesses the performance of the simulation methodology developed, by comparing analysis data with experimental data published in [24] for a representative hot-air anti-icing system operating under warm and cold hold in-flight icing conditions. Section 3.4 demonstrates with a practical example how the numerical methodology presented in this thesis can be used to support hot-air anti-icing developments.

The results presented refer to the hot-air anti-icing wing model tested in IRT described in [24], whose cross section and piccolo tube hole patterns are shown in Fig. 3.1.

For the comparisons of skin temperature and heat transfer coefficient, both the 2-d analysis results and the data from $[15,24]$ were obtained from the same 2 -d section of the wing model tested in IRT. This 2-d section corresponds to wing spanwise Station B, located $0.766 \mathrm{~m}$ from the piccolo tube inlet, as illustrated in Fig. 3.2. The flight, atmospheric, and hot-air conditions and the piccolo tube configurations used in the validation studies are summarized in Table 3.1. 


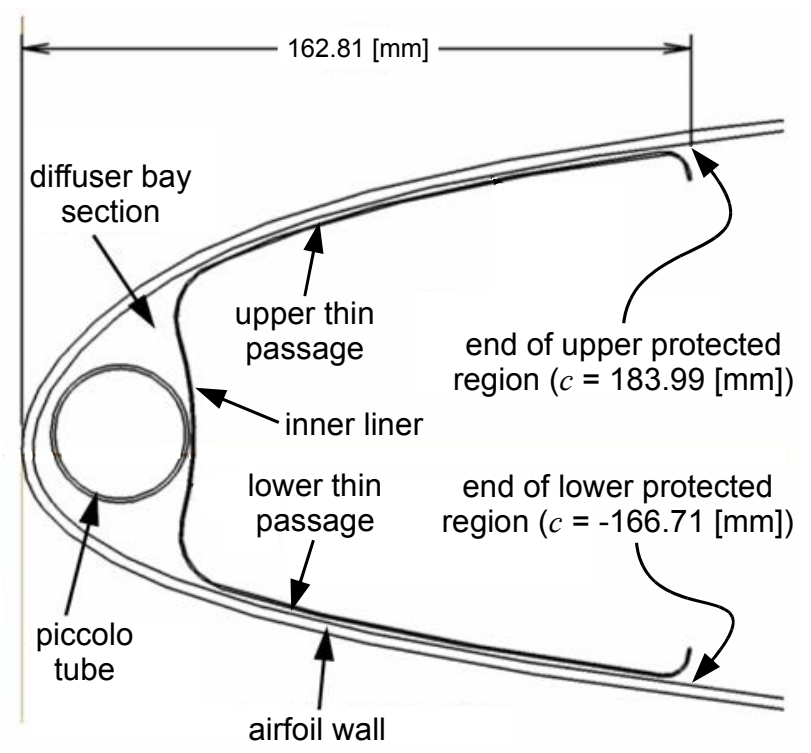

3.1a. Leading edge cross section.

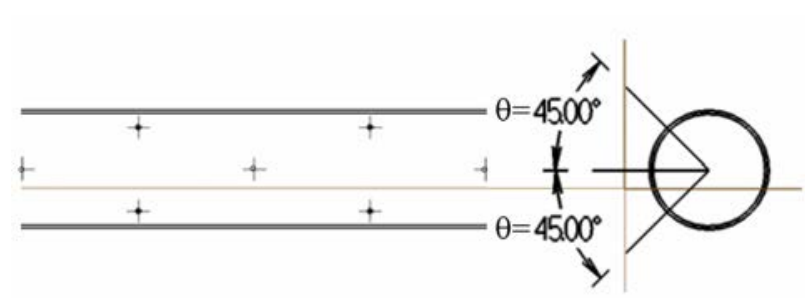

3.1b. Details of P45-0-M45 piccolo tube.

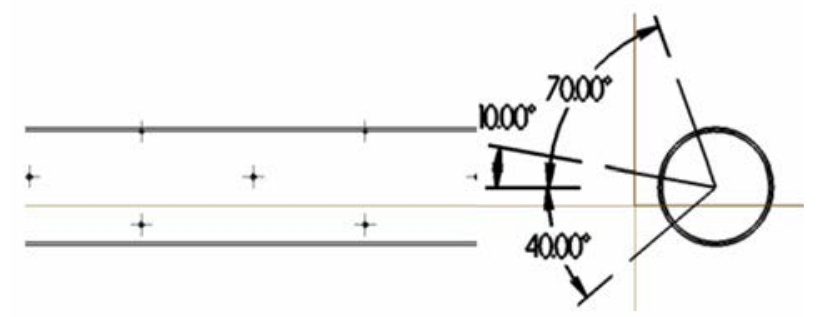

3.1c. Details of P70-P10-M40 piccolo tube.

Figure 3.1. Hot-air anti-icing wing model tested in IRT [24].

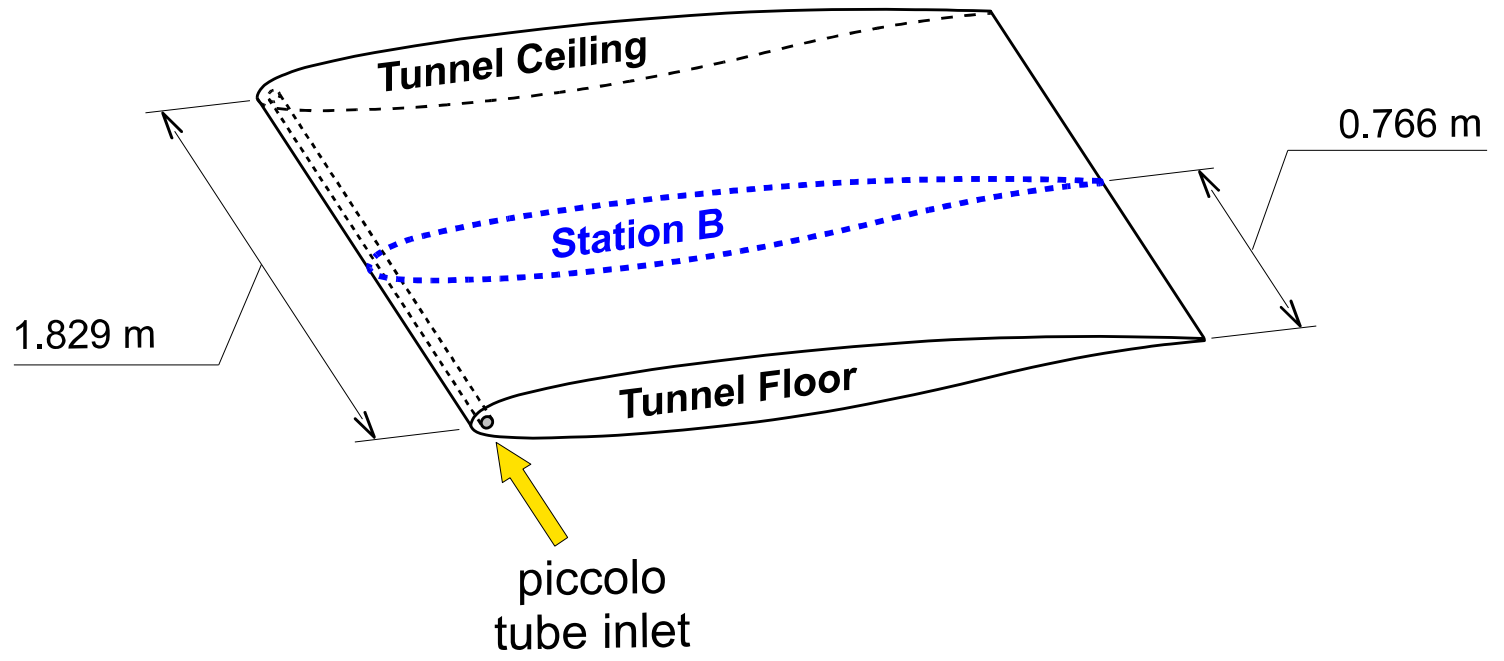

Figure 3.2. Spanwise location of the 2-d section (Station B) of the simulated and experimental results. 
Table 3.1. Conditions for hold cases from $[15,24]-M V D=29[\mu m], \alpha=3\left[^{\circ}\right]$.

\begin{tabular}{|c|c|c|c|c|c|c|c|c|c|c|}
\hline $\begin{array}{c}\text { Run } \\
\#\end{array}$ & $\begin{array}{c}V_{\infty} \\
{[\mathrm{m} / \mathrm{s}]}\end{array}$ & $\begin{array}{c}\text { Dry/ } \\
\text { Wet }\end{array}$ & $\begin{array}{c}L W C \\
{\left[\mathrm{~g} / \mathrm{m}^{3}\right]}\end{array}$ & $\begin{array}{c}\text { Spray Time } \\
{[\mathrm{min}]}\end{array}$ & $\begin{array}{c}\dot{\bar{m}}^{\prime}{ }^{*} \\
{[\mathrm{~kg} / \mathrm{s}-\mathrm{m}]}\end{array}$ & $\begin{array}{c}\dot{m}^{\prime} \\
{[\mathrm{kg} / \mathrm{s}-\mathrm{m}]}\end{array}$ & $\begin{array}{c}\bar{T}_{p} \\
{[\mathrm{~K}]}\end{array}$ & $\begin{array}{c}T_{p} \\
{[\mathrm{~K}]}\end{array}$ & $\begin{array}{c}T_{\infty} \\
{[\mathrm{K}]}\end{array}$ & $\begin{array}{c}\text { Piccolo } \\
\text { Configuration }\end{array}$ \\
\hline \hline 26 & 59.2 & Dry & - & - & 0.0193 & 0.0205 & 449.72 & 449.49 & 266.48 & P45-0-M45 \\
\hline 39 & 59.2 & Wet & 0.87 & 22.5 & 0.0191 & - & 437.75 & & 266.48 & P45-0-M45 \\
\hline 43 & 59.2 & Wet & 0.87 & 22.5 & 0.0243 & - & 452.65 & & 266.48 & P45-0-M45 \\
\hline 48 & 59.2 & Wet & 0.87 & 22.5 & 0.0080 & - & 391.05 & & 266.48 & P45-0-M45 \\
\hline 59 & 56.6 & Wet & 0.69 & 8.6 & 0.0195 & - & 435.46 & & 243.15 & P45-0-M45 \\
\hline 66 & 59.2 & Dry & - & - & 0.0083 & 0.0095 & 432.39 & 425.64 & 266.48 & P45-0-M45 \\
\hline 67 & 59.2 & Wet & 0.87 & 22.5 & 0.0081 & - & 432.35 & & 266.48 & P45-0-M45 \\
\hline 73 & 59.2 & Wet & 0.87 & 22.5 & 0.0171 & - & 388.25 & & 266.48 & P45-0-M45 \\
\hline 76 & 59.2 & Dry & - & - & 0.0484 & 0.0479 & 394.35 & 396.41 & 266.48 & P45-0-M45 \\
\hline 76 & 59.2 & Wet & 0.87 & 7.0 & 0.0485 & - & 391.12 & & 266.48 & P45-0-M45 \\
\hline 106 & 59.2 & Wet & 0.87 & 22.5 & 0.0243 & - & 449.35 & & 266.48 & P70-P10-M40 \\
\hline
\end{tabular}

* Total mass flow normalized with the effective length of the piccolo tube, 1.6764 [m]

\subsection{External Flow Gas Phase}

The use of CFD for computing pressure and water catch distributions over 2-d airfoils is well established and further validation was not deemed necessary. Instead, the study performed was focused on the effects of grid resolution and wall boundary conditions on the computed convective heat transfer coefficient over the airfoil outer surface. Details of this study are presented in Sections 3.1.1 and 3.1.2.

\subsubsection{Grid Resolution Study}

The mesh refinement level for the external flow analysis was determined using an iterative process where grids with progressively higher resolutions were tested for the same external flow condition (Run 26, Table 3.1). The $y+$ was gradually reduced by refining the near wall elements in the direction normal to the wall, and keeping the number of nodes and the 
spacing along the curvilinear coordinate constant. A separate study was performed to determine the effect of mesh refinement in the direction of the curvilinear coordinate, by increasing the number of points along the airfoil wall, as specified in Table 3.2.

Table 3.2. Grid refinement study for 2-d external airflow

\begin{tabular}{|c|c|c|c|}
\hline \multirow[b]{2}{*}{ Grid \# } & \multirow{2}{*}{$\begin{array}{l}\text { Number of points } \\
\text { along airfoil wall }\end{array}$} & \multicolumn{2}{|c|}{ Maximum $y+$ on the protected region } \\
\hline & & $\begin{array}{l}\text { Transitioning Flow } \\
\text { (for dry air) }\end{array}$ & $\begin{array}{l}\text { Fully Turbulent Flow } \\
\text { (for wet air) }\end{array}$ \\
\hline 1 & 320 & 2.75 & 4.10 \\
\hline 2 & 320 & 1.41 & 1.95 \\
\hline 3 & 320 & 0.72 & 0.98 \\
\hline 4 & 320 & 0.37 & 0.52 \\
\hline 5 & 640 & 0.36 & 0.50 \\
\hline
\end{tabular}

For the dry air cases, the transition from laminar to turbulent flow on the upper surface (approximately at $0.12 \mathrm{~m}$ from the leading edge, in surface distance, or at $x / c=3.94 \%$ ) was obtained from the study of Zamora [15], who predicted the transition location with the CFD software CFX that has a local correlation-based transition model that is coupled with the SST $k$ - $\omega$ turbulence model. The results for dry air condition are presented in Fig. 3.3, where negative surface distance corresponds to the wing lower surface (LS) and positive surface distance corresponds to the wing upper surface (US). The increase in the heat transfer coefficient over the turbulent part of the flow can be seen in Fig. 3.3. Moreover, the results of the 2-d simulation overpredicted the turbulent heat transfer coefficient as contrasted to the 3-d results of [15]. This overprediction is a consequence of the external wall isothermal boundary condition, as discussed in Section 3.1.2. 


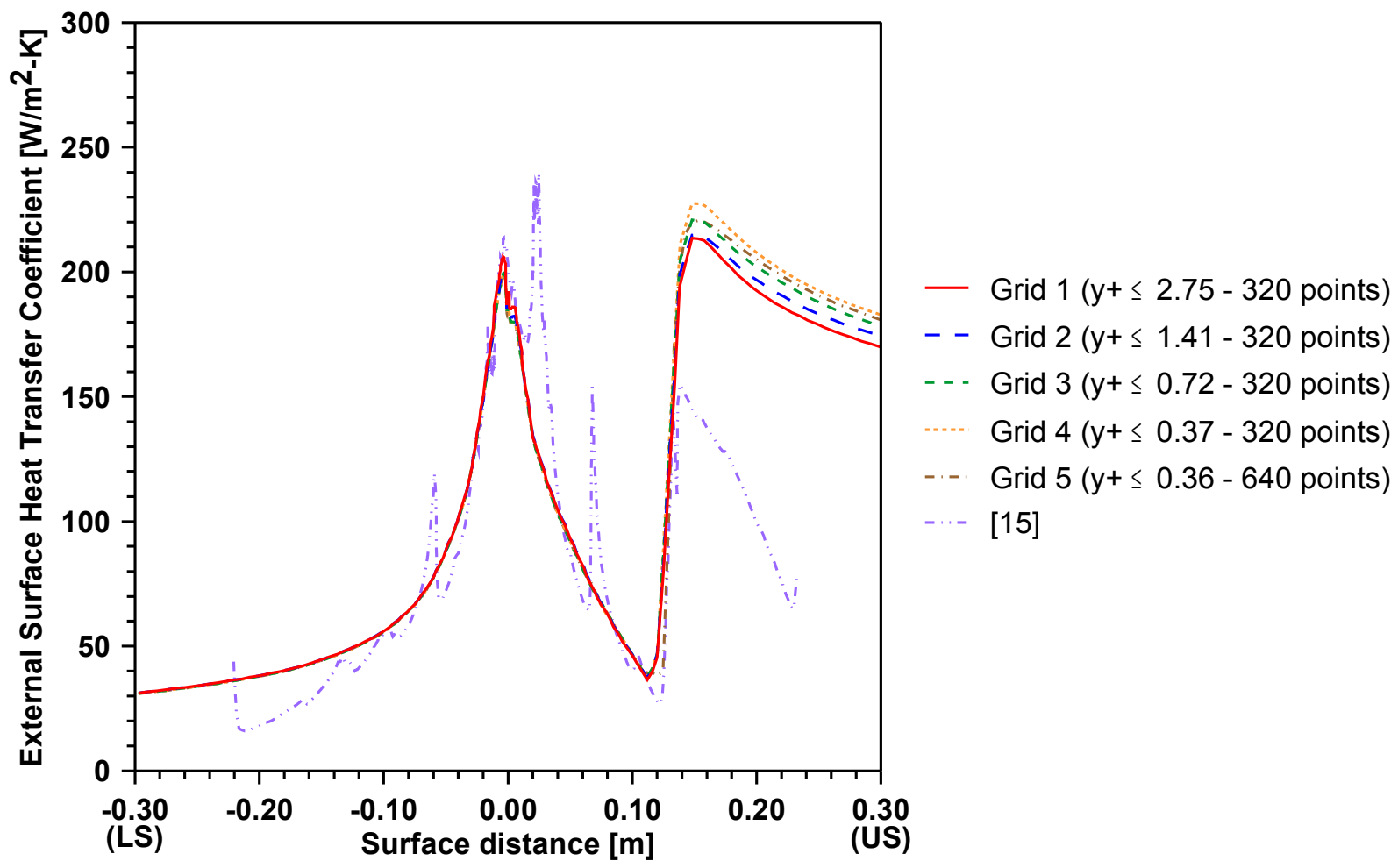

Figure 3.3. Grid resolution study for external heat transfer coefficient. Specifying location of transition from laminar to turbulent flow, (Run 26).

As Fig. 3.3 shows, the difference in the dry air results for Grids 1 to 5 was fairly low. The gradual percentage change in the integral of the external heat transfer coefficient over the thermally protected region is presented in Table 3.3.

Table 3.3. Percentage variation in integral of external heat transfer coefficient over the thermally protected area as a function of gird refinement (dry air condition).

\begin{tabular}{|c|c|c|c|}
\hline From Grid 1 to 2 & From Grid 2 to 3 & From Grid 3 to 4 & From Grid 4 to 5 \\
\hline \hline 1.85 & 1.95 & -0.10 & -2.32 \\
\hline
\end{tabular}

Note that from grids 1 to 4 , the density of points in the direction of the curvilinear coordinate was kept constant while the $y+$ was gradually decreased. At the last iteration (Grid 3 to 4$)$, a very small change $(-0.10 \%)$ was observed in the results. From grid 4 to 5 , the number 
points along the curvilinear coordinate was doubled (from 320 to 620 points) while the grid resolution in the wall normal direction was maintained constant. The variation on the integral of external heat transfer coefficient in this case (Grid 4 to 5 ) was of $-2.32 \%$. These results suggested that sufficient grid resolution was attained for dry air condition.

For wet air simulations, the external flow was considered fully turbulent. The external heat transfer coefficient results for Grids 1 to 5 are shown in Fig. 3.4. The results confirm that adequate mesh refinement was also achieved for fully turbulent flow for all grids, as indicated by the gradual percentage variation in the integral of the external heat transfer coefficient presented in Table 3.4. The grid selected for the external flow analysis was Grid 4, which had the smallest $y+$ among the grids with 320 points along the curvilinear coordinate .

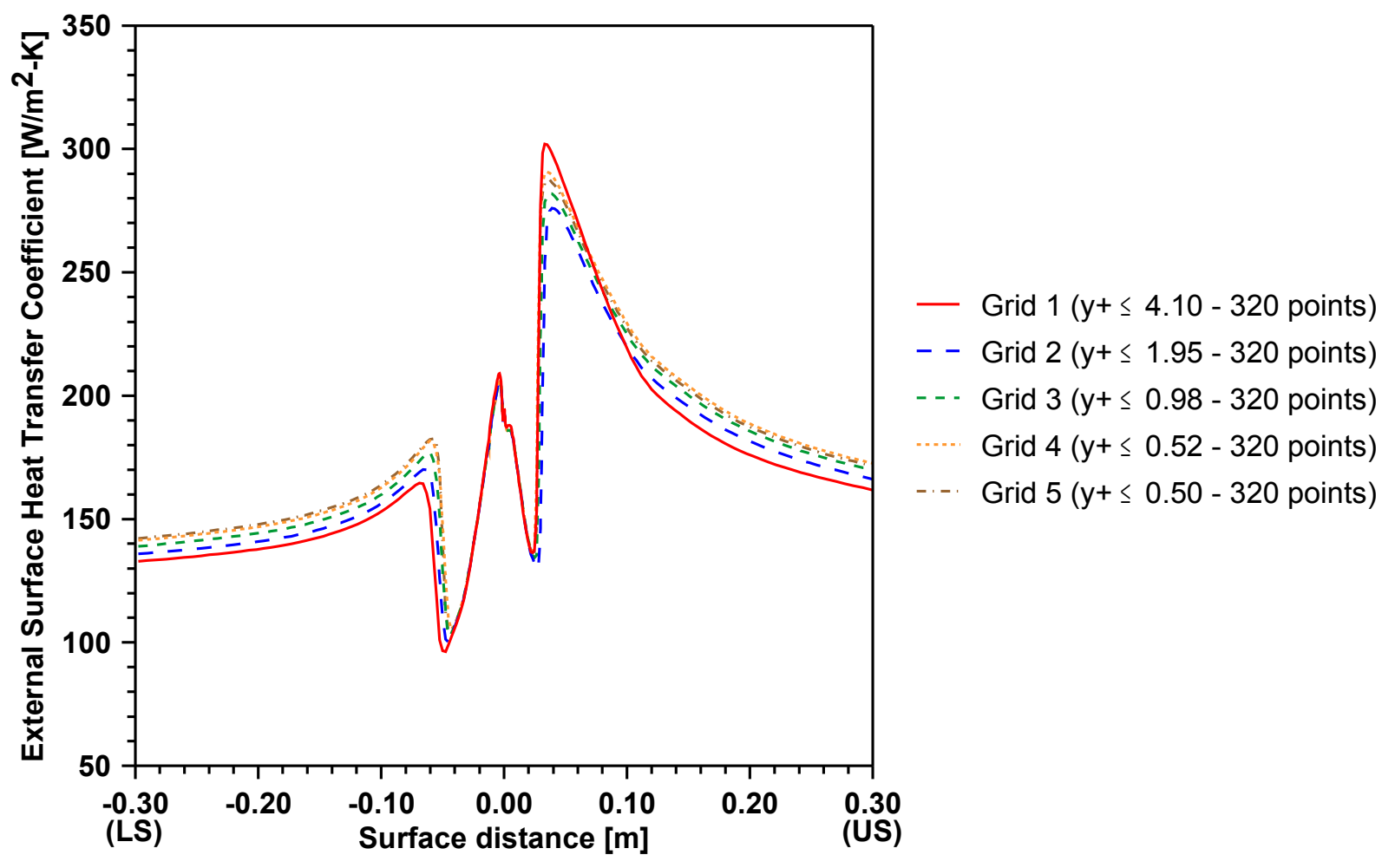

Figure 3.4. Grid resolution study for external heat transfer coefficient. Fully turbulent flow solution (Run 26). 
Table 3.4. Percentage variation in integral of external heat transfer coefficient over the thermally protected area as a function of gird refinement (wet air condition).

\begin{tabular}{|c|c|c|c|}
\hline From Grid 1 to 2 & From Grid 2 to 3 & From Grid 3 to 4 & From Grid 4 to 5 \\
\hline \hline 1.64 & 2.18 & 1.64 & -0.16 \\
\hline
\end{tabular}

\subsubsection{Assessment of the Isothermal Boundary Condition}

The application of an isothermal boundary condition to the external skin was based on the assumption that the heat transfer coefficient is weakly dependent on the distribution of surface temperature for hot-air anti-icing applications. The validity of this assumption was tested by comparing computed heat transfer coefficients obtained with and without the isothermal boundary condition for an external flow with the conditions of Run 26 (Table 3.1).

First a 2-d cut normal to the wing LE at model Station B was used to extract the skin temperature distribution from the 3-d FLUENT simulations presented in [15]. The 3-d temperature profile was then applied as a boundary condition in a 2-d CFD external flow analysis (Fig. 3.5a). Next, the 2-d external flow simulation was repeated by imposing an isothermal condition (Fig. 3.5a) on the airfoil external skin. The resultant heat transfer coefficients from the analyses performed are compared in Fig. 3.5b. Note that although the computed 2-d heat transfer coefficient over the turbulent zone was overpredicted (with respect to the 3-d results corresponding to wing Station B) when the isothermal wall condition was applied, the effect on the skin temperature distribution for dry air condition was small, as evident from the dry air simulation results presented in Section 3.3.1. Thus the use of an isothermal boundary condition in the solution of the external airflow provides an acceptable approximation for hot-air 
system parametric analysis, since it is capable of predicting correctly the trends in system performance as a function of icing conditions and system configuration.
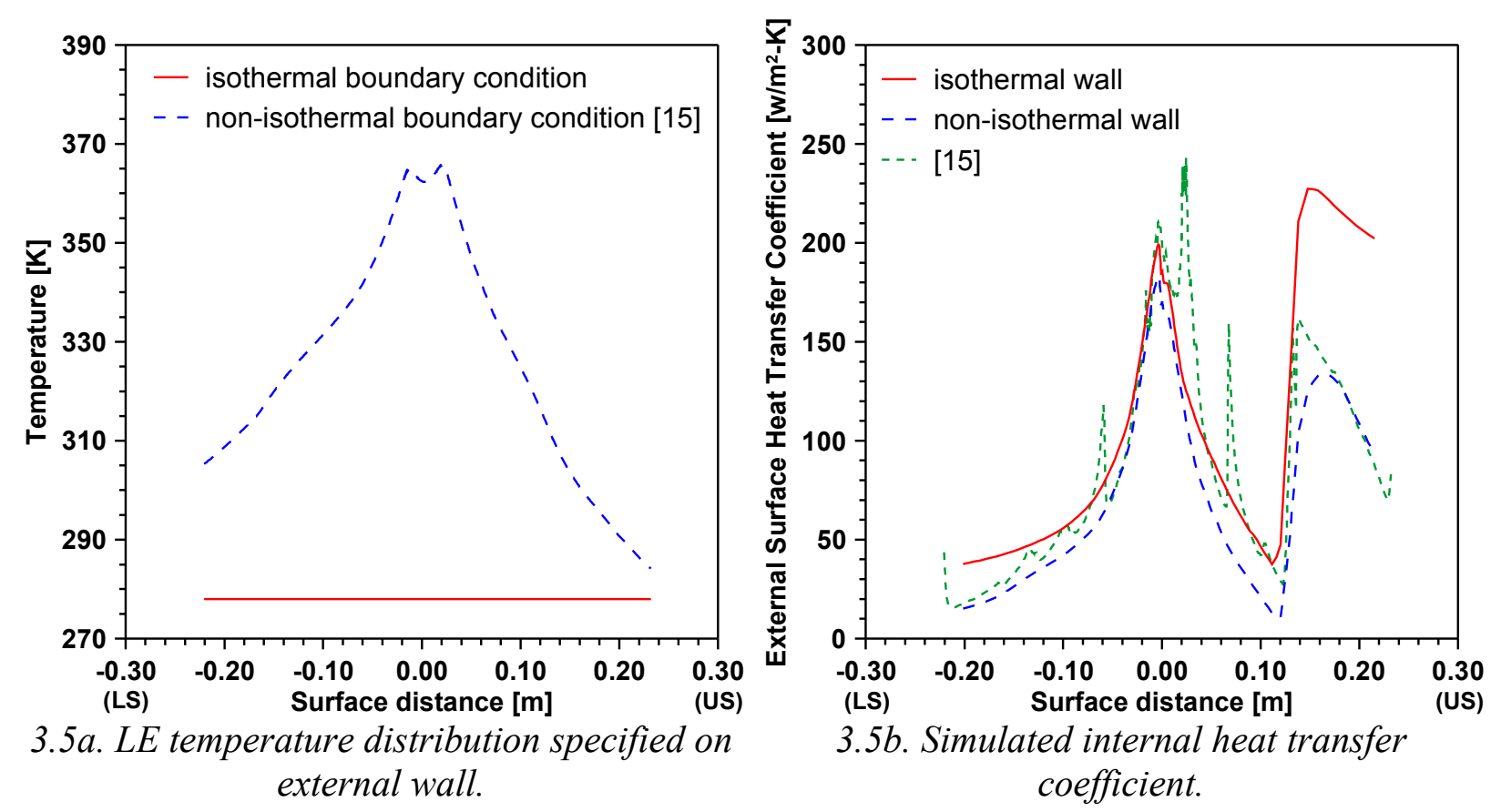

Figure 3.5. Influence of curvilinear distribution of skin temperature on the convective heat transfer coefficient, dry air (Run 26).

\subsection{Hot-Air Internal flow}

This section presents the calibration process of the two heat transfer correlations for application to the airfoil interior skin. One of the calibrations was developed for the piccolo tube hot-air jets, and the other for the flow inside the upper and lower inner liner flows. The thin passage heat transfer calibration data obtained from the 2-d CFD laminar flow analysis are also presented in this section.

\subsubsection{Calibration of Heat Transfer Correlation for Hot-Air Impinging Jet}

The calibration process of the six parameters (HCONST, REP, ZP, RRP, RP, and DP) 
used in the impinging jet heat transfer correlation [Equation (3.1)] is illustrated in this thesis for a limited set of 3-d CFD heat transfer data obtained from [15]. The objective was to prove the concept of representing the heat transfer coefficient distribution on the airfoil internal skin at the region of the impinging jets by means of a Nusselt number correlation.

$$
N u_{d}=(H C O N S T)(P r)^{1 / 3}\left(R e_{d}\right)^{R E P}(z / d)^{Z P}\left(c_{n} / d\right)^{R R P}(r / d)^{R P}(D / d)^{D P}
$$

The calibration process herein illustrated consisted on adjusting the correlation parameters values until the local Nusselt number results matched the 3-d CFD data from [15], for different hot-air mass flows and total temperatures. Local heat transfer coefficient $h_{i}$ computed from Equation (3.1) by converting $N u_{d}$ to $h_{i}$ with the use of Equation (2.26) are compared with $h_{i}$ data from [15] computed from Equation (3.2) in Figures 3.6, 3.7, and 3.8.

$$
h_{i}=\frac{q_{i} "}{T_{p}-T_{i}}
$$

where

$\rightarrow q_{i}{ }^{\prime \prime}$ is the local heat flux per unit surface area at the internal skin (in $\left[\mathrm{W} / \mathrm{m}^{2}\right]$ )

$\rightarrow T_{i}$ is the internal surface temperature (in $[\mathrm{K}]$ )

$\rightarrow T_{p}$ is the cross-sectional bulk temperature of the piccolo tube main flow, at the spanwise location of the analysis (in $[\mathrm{K}]$ )

Note that the three parameters in the right side of Equation (3.2) were taken from the 3-d FLUENT analysis data presented in [15].

Three experimental cases were used in the $N u_{d}$ calibration process, corresponding to a low, medium, and high hot-air mass flow rates (Runs 66, 26, and 76, respectively - see Table 3.1). The 3-d and 2-d internal heat transfer coefficient distributions (Figures 3.6, 3.7, and 3.8) are along 2-d cuts perpendicular to the wing LE near Station B. These cuts were made to 
coincide with the piccolo one- and two-jet spanwise stations, and with a spanwise location halfway between the single and dual jet stations. As it can be observed in Figures 3.6, 3.7, and 3.8, the impinging jet local heat transfer coefficient over the airfoil interior skin was in good agreement with the 3-d data at all three spanwise locations (single jet station, dual jet station, and half-way in between).

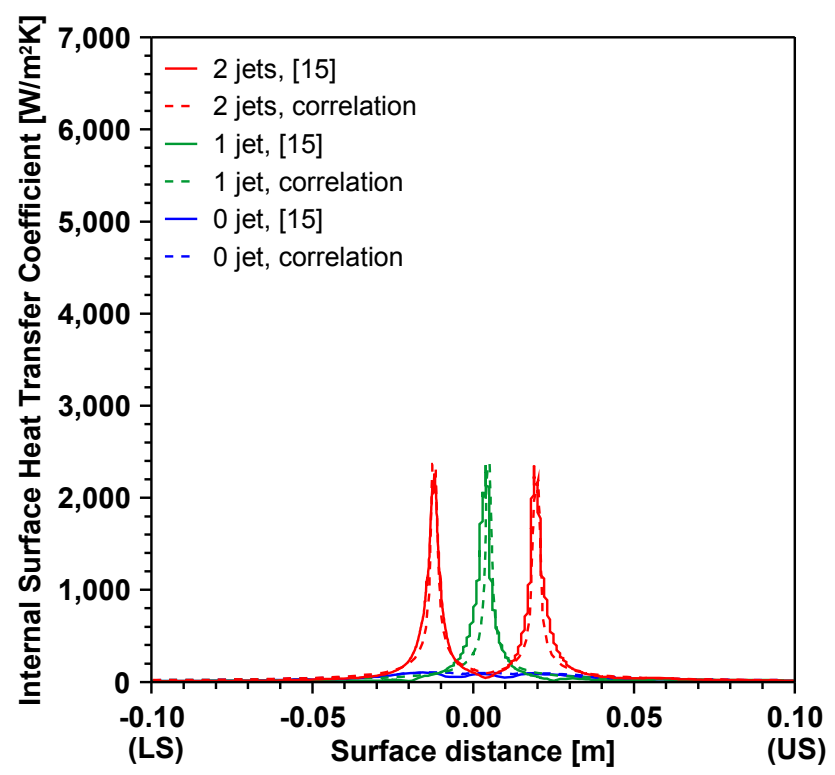

Figure 3.6. Impinging jets local heat transfer coefficient. Piccolo tube correlation vs 3-d CFD simulation from [15], low hot-air mass flow rate; $\dot{m}^{\prime}=0.0095[\mathrm{~kg} / \mathrm{s}-\mathrm{m}], T_{p}=425.64[\mathrm{~K}]$, piccolo configuration: P45-0-M45 (Run 66). 


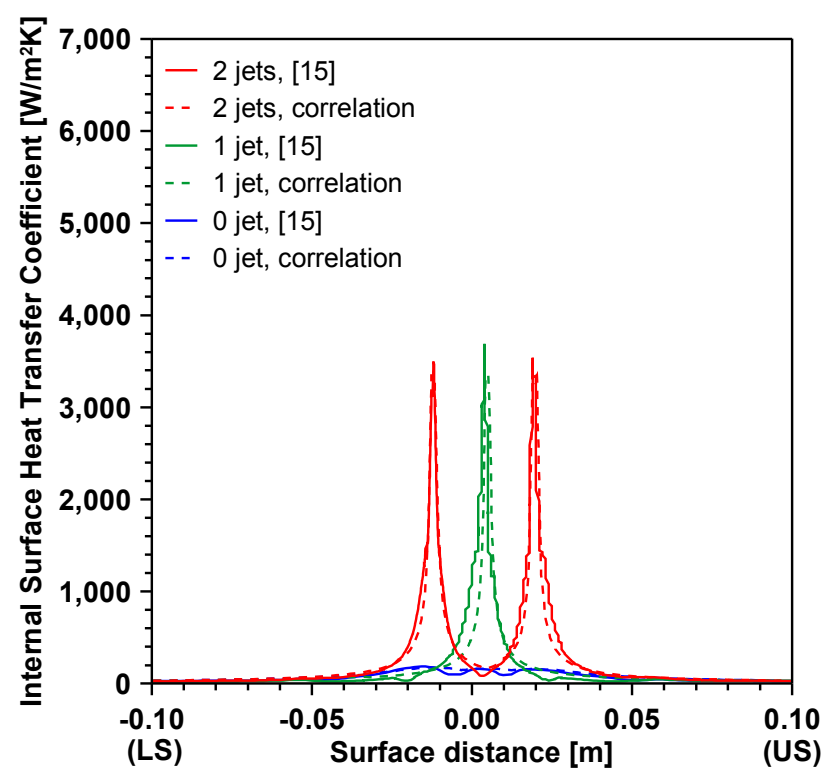

Figure 3.7. Impinging jets local heat transfer coefficient. Piccolo tube correlation vs 3-d CFD simulation from [15], medium hot-air mass flow rate; $\dot{m}^{\prime}=0.0205[\mathrm{~kg} / \mathrm{s}-\mathrm{m}], T_{p}=449.49[\mathrm{~K}]$, piccolo configuration: P45-0-M45 (Run 26).

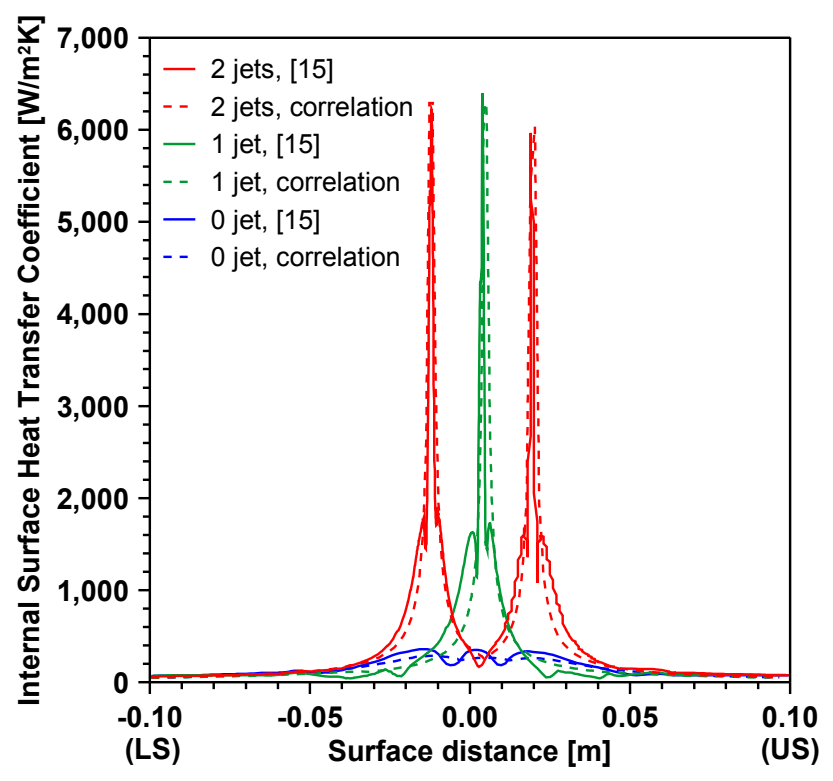

Figure 3.8. Impinging jets local heat transfer coefficient. Piccolo tube correlation vs 3-d CFD simulation from [15], high hot-air mass flow rate; $\dot{m}^{\prime}=0.0479[\mathrm{~kg} / \mathrm{s}-\mathrm{m}], T_{p}=396.41[\mathrm{~K}]$, piccolo configuration: P45-0-M45 (Run 76).

The results shown in Figures 3.6, 3.7, and 3.8 were obtained after applying the heat transfer coefficient limiter implemented to avoid the heat transfer coefficient overshoot near the 
jet stagnation region (see Section 2.3.3.1). The limiter is a linear function of the jet Reynolds number $R e_{d}$, defined by:

$$
h_{i-\max }=0.115063 R e_{d}+1454.35
$$

The calibration constants on the right-hand side of Equation [3.3] were determined via linear regression against 3-d CFD heat transfer data obtained from [15] for Runs 66, 26, and 76, corresponding to a low, medium, and high $R e_{d}$, respectively. The maximum value of heat transfer coefficient at a jet stagnation region, per run, was extracted from the 3-d CFD analysis data considering the stagnation region of the jets contained by the one- and two-hole stations closest to wing Station B. The maximum values of heat transfer coefficient extracted from the 3-d CFD analysis data from [15], and the values computed with the limiter function (Equation [3.3]) are illustrated in Fig. 3.9.

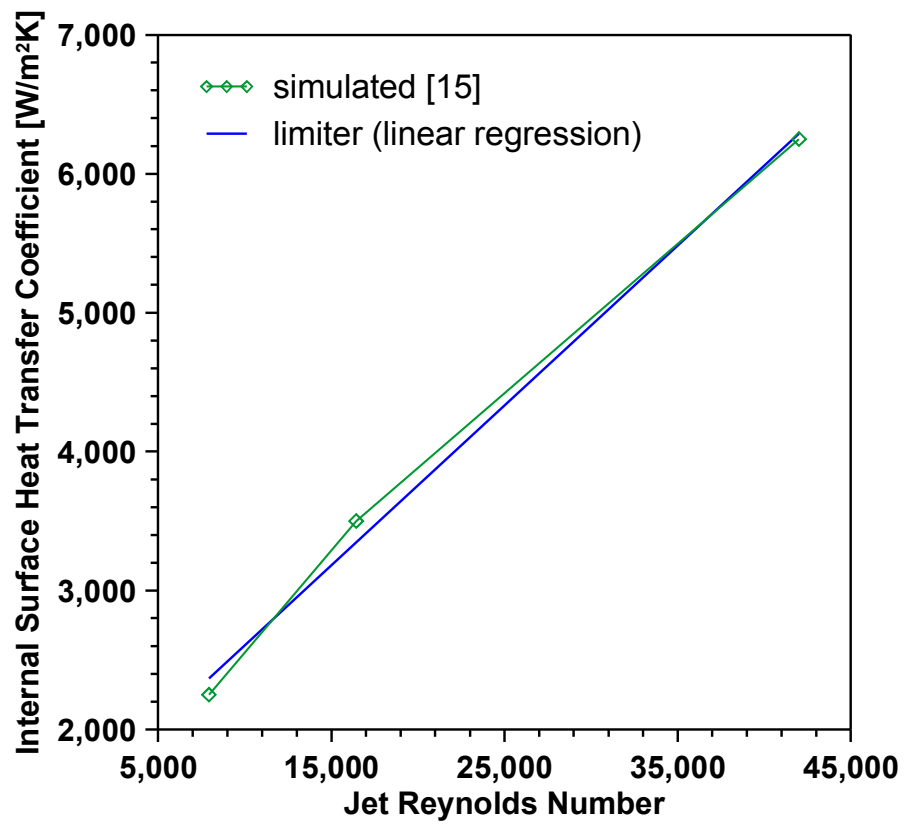

Figure 3.9. Internal skin heat transfer coefficient at the stagnation point of the hot-air jets [15], and limiter function adjusted via linear regression (Runs 66, 26 and 76).

Note that the values of the calibration constants of the limiter function (Equation [3.3]) 
are valid for the piccolo tube configuration used in Runs 66, 26, and 76 (P45-0-M45). For other piccolo tube geometric configuration, a different calibration is required.

The impinging jet Nusselt number correlation parameters [Equation (3.1)] used in the validation cases presented in Sections 3.3.1 and 3.3.2 were calibrated via an iterative process. The initial parameter values in this iterative process were obtained from the average of the parameter values available in [14] from several sources. The final values are listed in Table 3.5. The positive value of the $Z P$ parameter implies that the Nusselt number must increase with piccolo tube distance from the jet impingement location. Care must be taken with the interpretation of this result. Although the positive value of the $Z P$ exponent may be correct for the present piccolo tube configuration, it can become negative for piccolo tubes placed farther away from the wall. This was experimentally observed by Gau and Chung [57] for a rectangular (or slot) cooling jet impinging on a concave surface, as shown in Table 3.5.

Table 3.5: Calibration constants for impinging jet(s) correlation

\begin{tabular}{|c|c|c|c|c|c|c|c|c|c|}
\hline Source & $H C O N S T$ & $R E P$ & $Z P$ & $R R P$ & $R P$ & $D P$ & $\begin{array}{c}z / d \\
\text { range }\end{array}$ & $\begin{array}{c}R D I S T \\
\text { range }\end{array}$ & $R e_{d}$ limit \\
\hline \hline $\begin{array}{c}\text { Present } \\
\text { work }\end{array}$ & 0.430 & 0.640 & 0.120 & -0.980 & -0.310 & 0.000 & $2.3-4.9$ & 47 & 42,000 \\
\hline $\begin{array}{c}\text { Gau \& } \\
\text { Chung [57] }\end{array}$ & 0.251 & 0.68 & 0.15 & NA & NA & NA & $2-8^{*}$ & NA & $35,000^{*}$ \\
\hline $\begin{array}{c}\text { Gau \& } \\
\text { Chung [57] }\end{array}$ & 0.394 & 0.68 & -0.32 & NA & NA & NA & $8-16^{*}$ & NA & $35,000^{*}$ \\
\hline
\end{tabular}

${ }^{*}$ In [57] $d$ is the slot width

Note that the $D P$ parameter in the impinging jet Nusselt number correlation indicates the influence of the piccolo tube diameter $D$ on the internal flow heat transfer. In this work, since the impinging jet heat transfer data used in the calibration process was obtained from an anti-icing 
system with a fixed piccolo tube diameter, the value of the $D P$ parameter was not evaluated in the calibration process, i.e., it was set to 0 .

It must be emphasized that the present calibration was performed using heat transfer data from a single anti-icing system configuration, namely, the one tested at the NASA Glenn icing tunnel with the P45-0-M45 piccolo tube. Therefore, the current calibration should not be used for piccolo tubes with significantly different configurations, such as the distance from piccolo tube to the leading edge wall, piccolo tube diameter, etc. In such cases, an appropriate calibration must be used.

As discussed in Section 2.3.3.1, the local heat transfer coefficient obtained from the impinging jet correlation must be first converted to a span-weighted average form $\overline{h_{i}}(c)$ before it can be used in the anti-icing thermodynamic model developed. The raw and span-weighted average results are illustrated in Fig. 3.10a, for the hot-air flow conditions corresponding to icing tunnel Run 76. Figure $3.10 \mathrm{~b}$ provides the corresponding external surface temperature distributions obtained by running the complete simulation process (external flow + internal flow + anti-icing modules) using the local and span-weighted average internal heat transfer coefficient distributions.

In addition to the computational results, Fig. $3.10 \mathrm{~b}$ also provides the experimental skin temperature distribution obtained from [24]. The comparison between the experimental data and the simulated results obtained with the weighted average methodology clearly demonstrates the validity of the methodology proposed. 


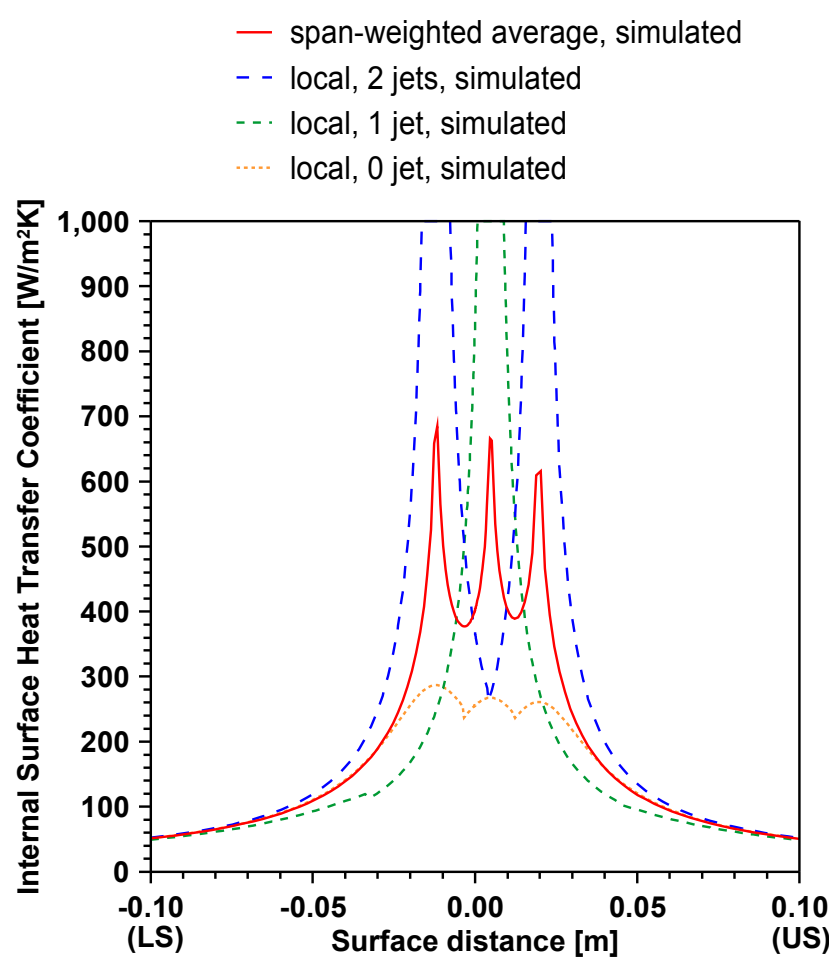

3.10a. Impinging jet correlation: averaged vs local results for 2-, 1-, and 0-jet stations.

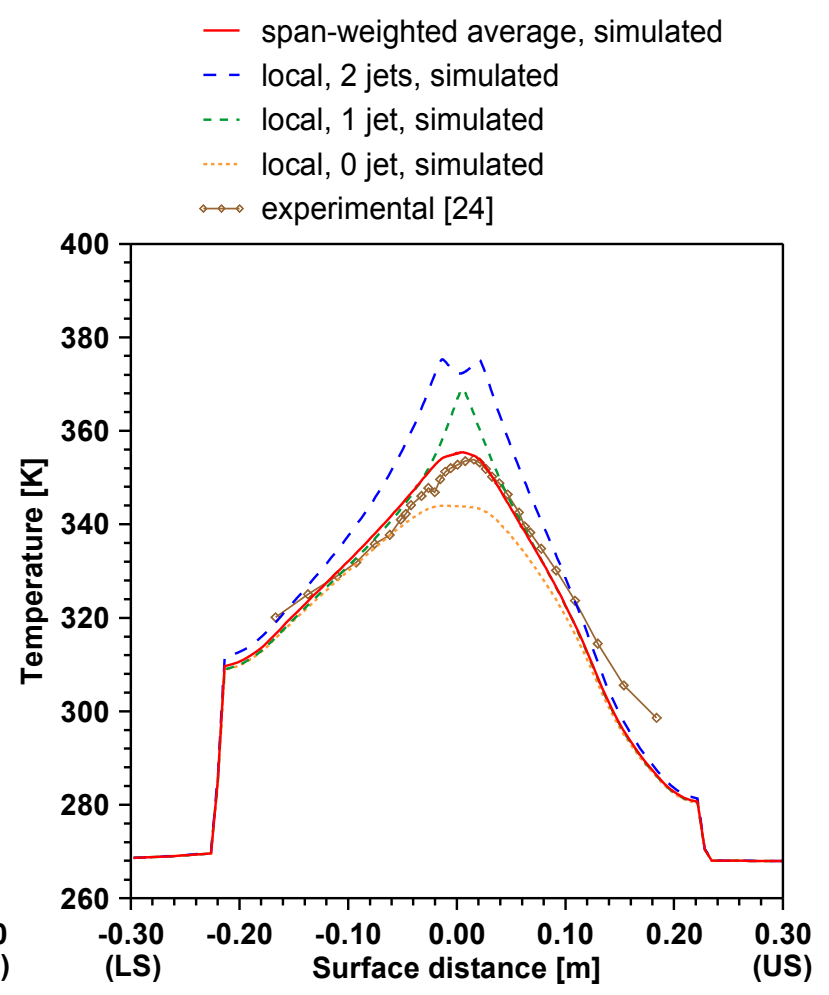

3.10b. External surface temperature in function of internal heat transfer coefficient.

Figure 3.10. Effect of internal heat transfer coefficient averaging scheme on the airfoil wall temperature distribution, warm hold, dry air condition; $V_{\infty}=59.2[\mathrm{~m} / \mathrm{s}], \alpha=3\left[^{\circ}\right]$, $T_{\infty}=266.48[\mathrm{~K}], \overline{\dot{m}^{\prime}}=0.0484[\mathrm{~kg} / \mathrm{s}-\mathrm{m}], \dot{m}^{\prime}=0.0479[\mathrm{~kg} / \mathrm{s}-\mathrm{m}], \overline{T_{p}}=394.35[\mathrm{~K}]$, $T_{p}=396.41[K]$, piccolo configuration: P45-0-M45 (Run 76 - Station B).

\subsubsection{Calibration of Heat Transfer Correlation for the Thin Passage Flow}

The correlation used for predicting the local Nusselt number for the flow in the upper and lower thin passages is composed of a set of $6^{\text {th }}$ degree polynomials whose coefficients were calibrated to reproduce heat transfer data obtained from 2-d CFD simulations. The calibration was performed over a range of passage mass flows and thicknesses (see Table 3.6), covering typical design values for business jets hot-air anti-icing systems.

Figure 3.11 provides the thin passage Nusselt number distribution obtained from 2-d 
CFD analysis and corresponding results obtained with the thin passage correlation using the $6^{\text {th }}$ degree polynomial curve fit.

For the cases with higher bleed flow rates and wider passage thicknesses $\left(\dot{m}^{\prime}=0.025\right.$ and $0.050[\mathrm{~kg} / \mathrm{s}-\mathrm{m}]$, and $t=1.5$ and $2.5[\mathrm{~mm}])$ a recirculation zone attached to the inner liner wall was observed immediately downstream of the passage inlet. The separation bubble can be seen in the velocity vector field presented in Fig. 3.12 for the case with $\dot{m}^{\prime}=0.050[\mathrm{~kg} / \mathrm{s}-\mathrm{m}]$ and $t=0.0025[\mathrm{~m}]$. The flow recirculation resulted in a local reduction of Nusselt number as evident from the results presented in Fig. 3.11d.

Table 3.6. Conditions for thin passage 2-d viscous flow simulations. (Airfoil internal skin temperature $=273.15[\mathrm{~K}]$, inlet total temperature $=550[\mathrm{~K}]$ )

\begin{tabular}{|c|c|c|}
\hline $\begin{array}{c}\text { Passage Thickness } t \\
{[\mathrm{~mm}]}\end{array}$ & Inlet Reynolds number $R e_{t}$ & $\begin{array}{c}\text { Mass flow rate } \dot{m}^{\prime} \\
{[\mathrm{kg} / \mathrm{s}-\mathrm{m}]}\end{array}$ \\
\hline 0.5 & 196 & 0.005 \\
\hline 1.0 & 193 & 0.005 \\
\hline 1.5 & 193 & 0.005 \\
\hline 2.5 & 191 & 0.005 \\
\hline 0.5 & 923 & 0.025 \\
\hline 1.0 & 913 & 0.025 \\
\hline 1.5 & 924 & 0.025 \\
\hline 2.5 & 917 & 0.025 \\
\hline 0.5 & 1,843 & 0.050 \\
\hline 1.0 & 1,823 & 0.050 \\
\hline 1.5 & 1,840 & 0.050 \\
\hline 2.5 & 1,823 & 0.050 \\
\hline & & \\
\hline
\end{tabular}



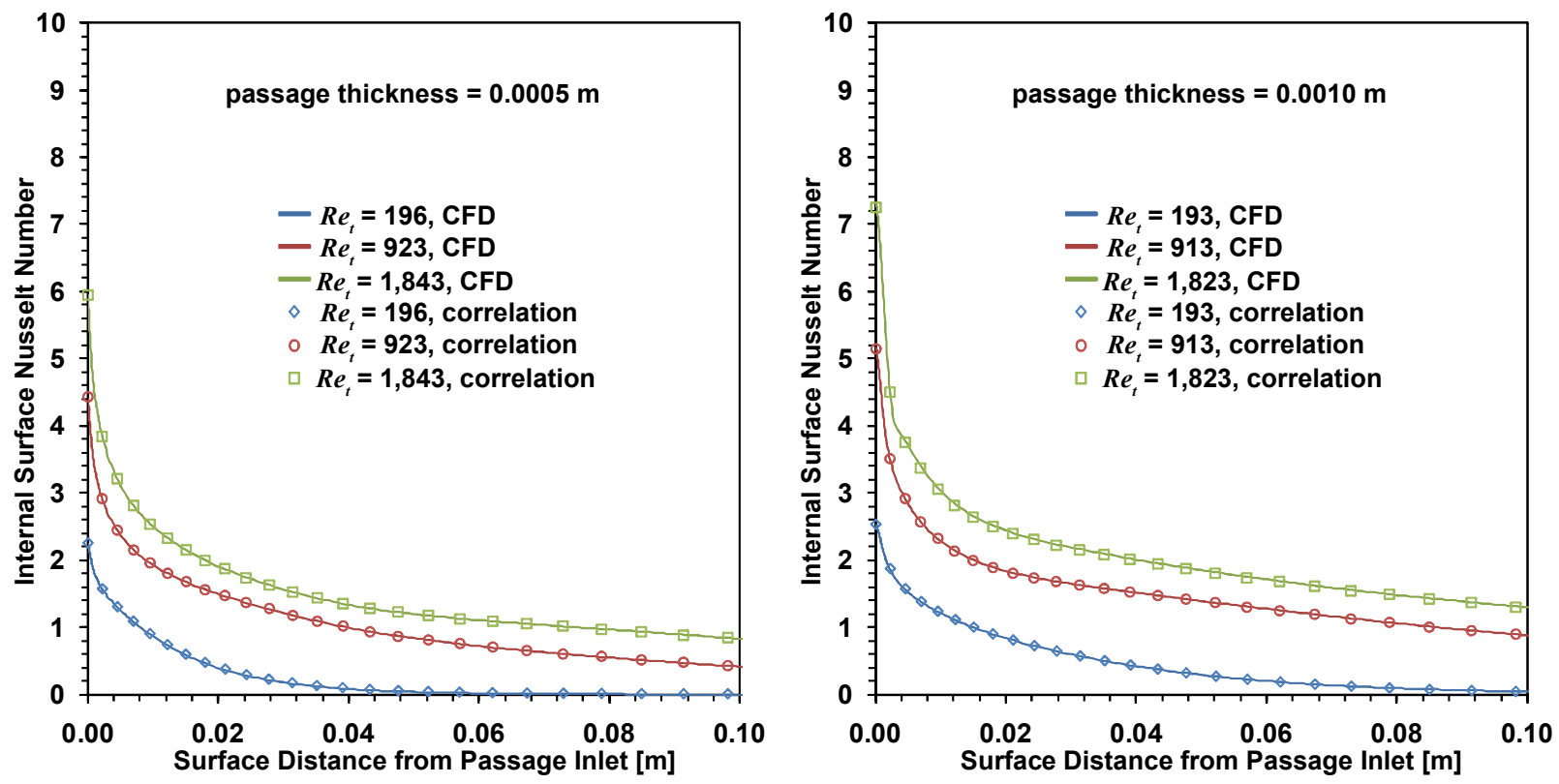

3.11a. Passage thickness $=0.0005 \mathrm{~m}$.
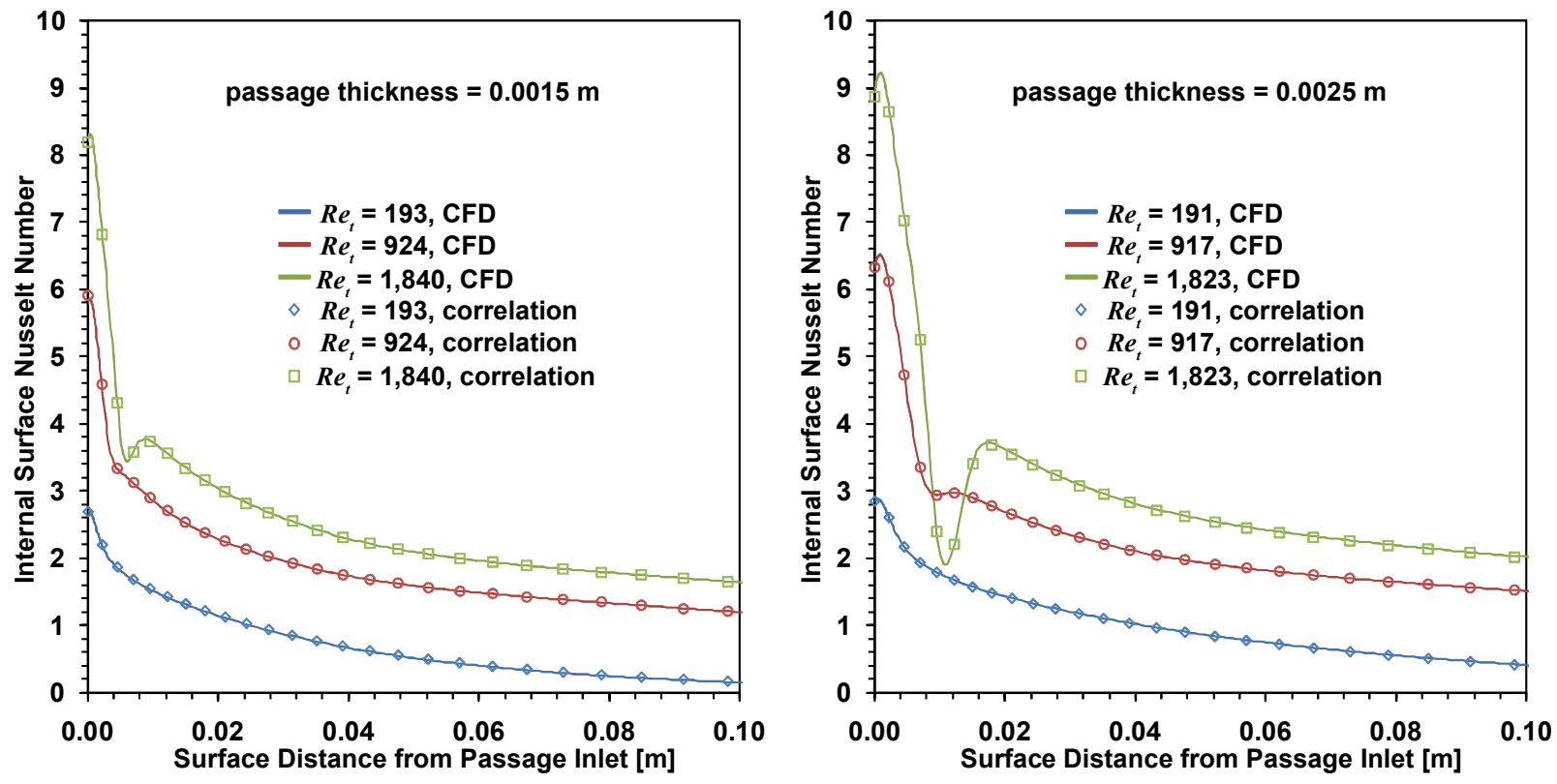

3.11c. Passage thickness $=0.0015 \mathrm{~m}$.

Figure 3.11. Thin passage local Nusselt number: CFD simulation versus correlation. 


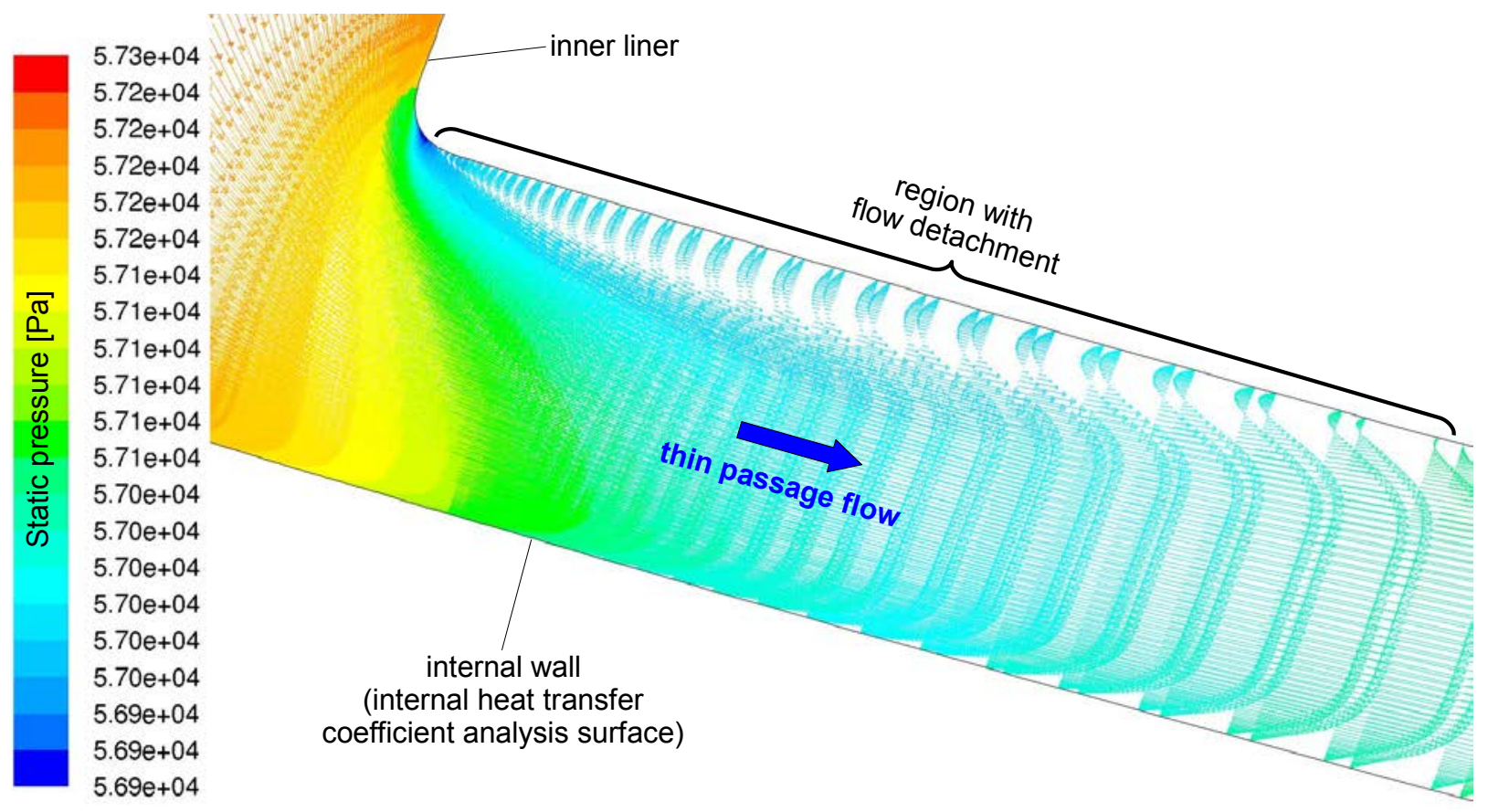

Figure 3.12. Flow detachment past thin passage inlet illustrated by velocity vectors, colored by static pressure. $\dot{m}^{\prime}=0.050[\mathrm{~kg} / \mathrm{s}-\mathrm{m}], t=0.025[\mathrm{~m}]$.

\subsection{Thermodynamic Model for Hot-air Anti-icing Systems}

Sections 3.1 and 3.2 focused on evaluating the performance of the main computational modules that constitute the simulation tool developed. The objective of the present section is to evaluate the hot-air anti-icing module combined with the internal and external flow modules, especially for wet air conditions associated with the formation of ice. Comparisons of computed skin temperature distributions and runback ice location with experimental data obtained from the icing tunnel tests published in [24] are presented to assess the overall performance of the computational methodology. The comparisons start with warm hold cases in dry air conditions followed by warm and cold hold cases in wet air condition. The methodology evaluation is completed with a comparison of numerical and experimental results for two piccolo tube configurations, where the Nusselt number correlation for impinging jet is used beyond its 
calibration range.

\subsubsection{Dry Air Results}

Computed and experimental LE temperature distributions for dry air conditions are presented in Figs. 3.13-3.15. Since the experimental data and the 2-d analysis plane corresponded to wing span Station B, the local spanwise hot-air conditions (total temperature and mass flow per unit span) provided to the impinging jet Nusselt number analysis were taken from wing span Station B. Additional simulations were performed using piccolo tube average spanwise hot-air properties (instead of local). For these additional analyses, the average mass flow per unit span was obtained by normalizing the piccolo tube total flow by its total effective length, and the average total temperature was computed as the spanwise average of the piccolo center line values. The objective of performing the additional analysis with average spanwise hot-air properties was to determine the influence of the inflow properties in the computed results, since for the wet air condition results (presented in Section 3.3.2) only the average spanwise values were available.

Fair agreement with the experiments was achieved for the three test cases (icing tunnel Runs 66, 26, and 76). The sudden decrease in the computed skin temperature distributions at the upper and lower ends of the thermally protected region was caused by the lower thermal conductivity of the Teflon ${ }^{\circledR}$ inserts I1 and I2, shown in Fig. 3.16. These inserts were used in the experimental investigation to reduce heat loss due to conduction.

Note that in all cases presented in Figs. 3.13-3.15, the computed results based on average and local piccolo tube hot-air properties are in good agreement, therefore indicating that the 2-d numerical analysis for wing Station B can be performed using hot-air average spanwise values without any visible loss of accuracy. This finding was applied to the wet air test cases (presented 
in Section 3.3.2) for wing span Station B, where the simulations were performed only with the piccolo tube hot-air average spanwise properties.

Table 3.7 provides the percentage difference between the computed and experimental peak skin temperatures $\Delta\left(T_{e-\max }\right)$. The percentage difference was computed using Equation (3.4) below.

$$
\Delta\left(T_{e-\max }\right)[\%]=\frac{\left(T_{e-\max }\right)_{\text {simulated }}-\left(T_{e-\max }\right)_{\text {experimental }}}{\left(T_{e-\max }\right)_{\text {experimental }}} \times 100
$$

The percentage difference ranged from a minimum of -0.09 to a maximum of $2.24 \%$ indicating good agreement between analysis and experiment.

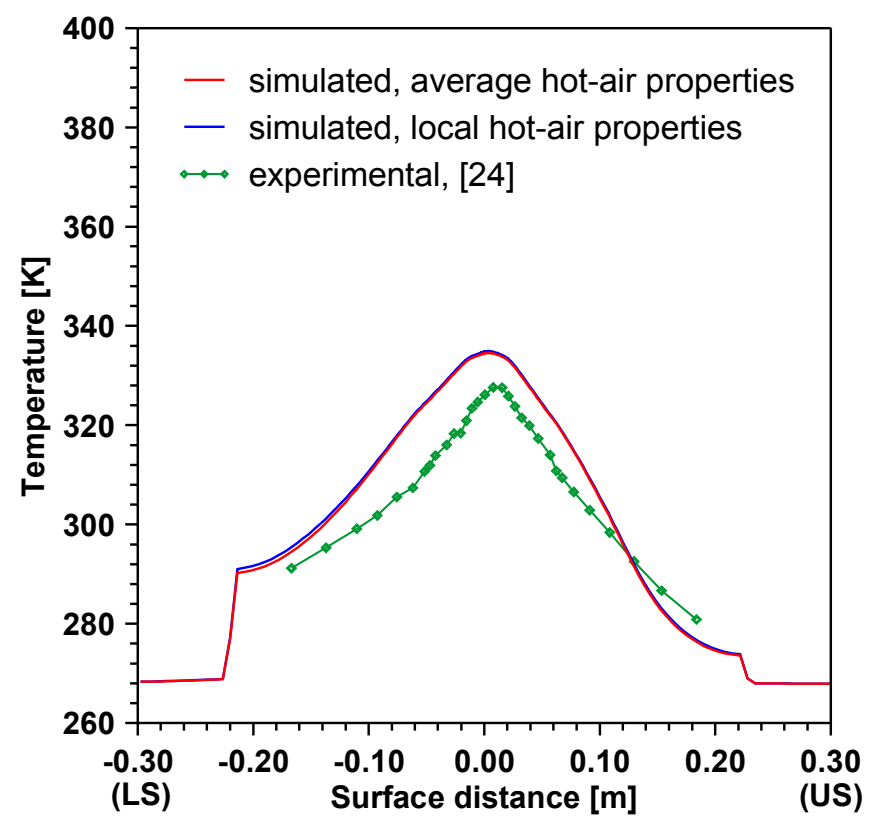

Figure 3.13. LE skin temperature, warm hold, dry air condition, low hot-air mass flow rate; $V_{\infty}=59.2[\mathrm{~m} / \mathrm{s}], \alpha=3\left[^{\circ}\right], T_{\infty}=266.48[\mathrm{~K}], \dot{\dot{m}^{\prime}}=0.0083[\mathrm{~kg} / \mathrm{s}-\mathrm{m}], \dot{m}^{\prime}=0.0095[\mathrm{~kg} / \mathrm{s}-\mathrm{m}]$, $\overline{T_{p}}=432.39[\mathrm{~K}], T_{p}=425.64[\mathrm{~K}]$, piccolo configuration: P45-0-M45 (Run 66 - Station B). 


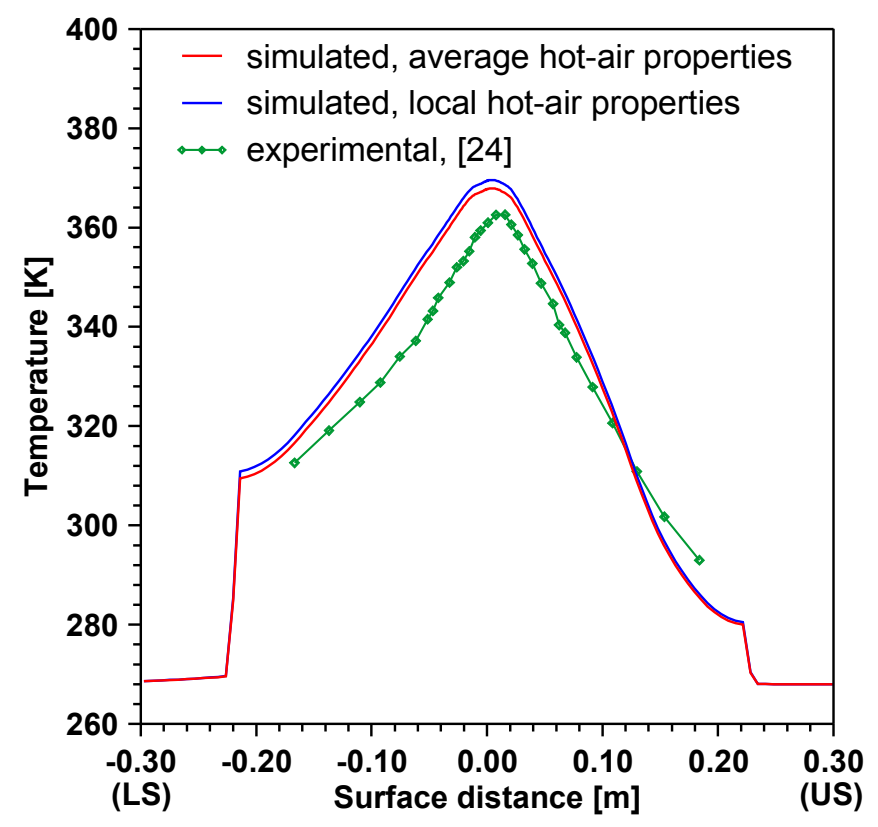

Figure 3.14. LE skin temperature, warm hold, dry air condition, medium hot-air mass flow rate; $V_{\infty}=59.2[\mathrm{~m} / \mathrm{s}], \alpha=3\left[^{\circ}\right], T_{\infty}=266.48[\mathrm{~K}], \dot{\dot{m}^{\prime}}=0.0193[\mathrm{~kg} / \mathrm{s}-\mathrm{m}], \dot{m}^{\prime}=0.0205[\mathrm{~kg} / \mathrm{s}-\mathrm{m}]$, $\overline{T_{p}}=449.72[\mathrm{~K}], T_{p}=449.49[\mathrm{~K}]$, piccolo configuration: P45-0-M45 (Run 26 - Station B).

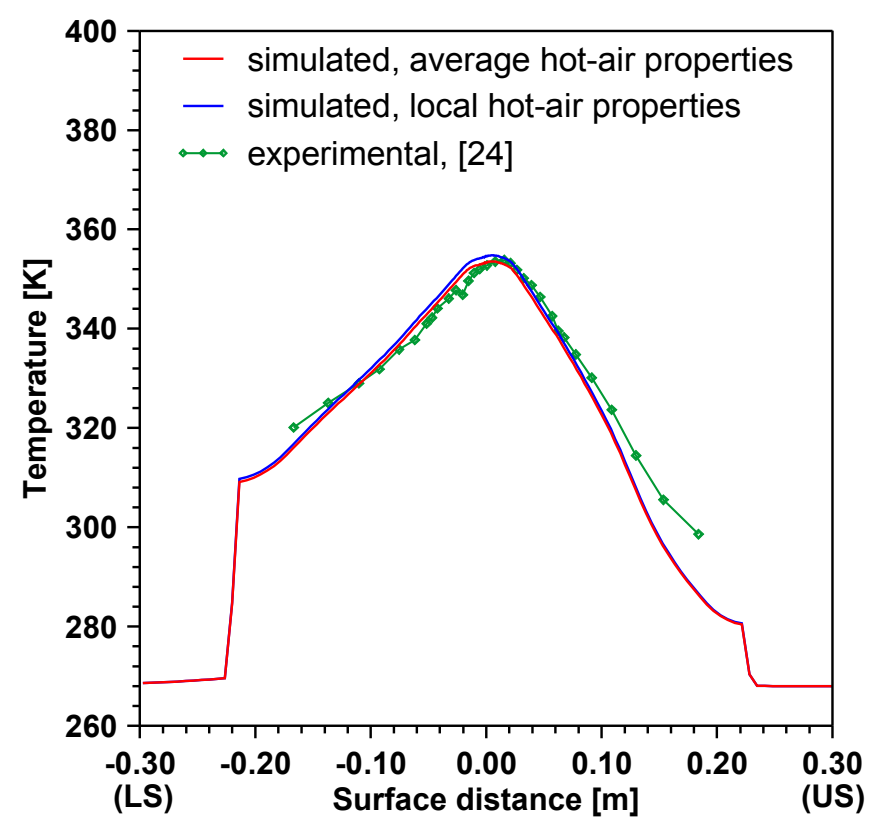

Figure 3.15. LE skin temperature, warm hold, dry air condition, high hot-air mass flow rate; $V_{\infty}=59.2[\mathrm{~m} / \mathrm{s}], \alpha=3\left[^{\circ}\right], T_{\infty}=266.48[\mathrm{~K}], \overline{\dot{m}^{\prime}}=0.0484[\mathrm{~kg} / \mathrm{s}-\mathrm{m}], \dot{m}^{\prime}=0.0479[\mathrm{~kg} / \mathrm{s}-\mathrm{m}]$, $\overline{T_{p}}=394.35[K], T_{p}=396.41[K]$, piccolo configuration: P45-0-M45 (Run 76 - Station B). 


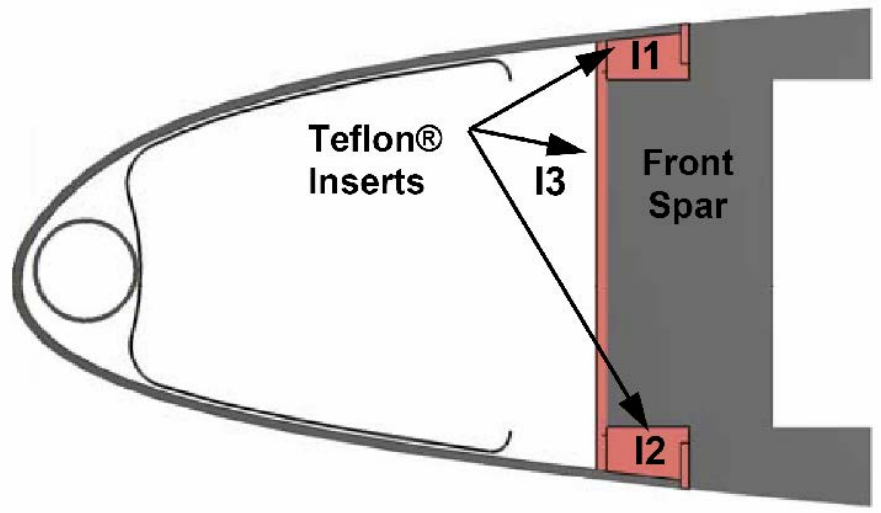

Figure 3.16. Teflon inserts on the anti-icing system [24].

Table 3.7: Percentage difference between simulated and experimental [24] skin peak temperature, dry air condition.

\begin{tabular}{|c|c|}
\hline Run \# & $\Delta\left(T_{e-\max }\right)[\%]$ \\
\hline \hline 66 & 2.24 \\
\hline 26 & 1.94 \\
\hline 76 & 0.26 \\
\hline $66^{*}$ & 2.12 \\
\hline $26^{*}$ & 1.48 \\
\hline $76^{*}$ & -0.09 \\
\hline
\end{tabular}

* Simulation performed using average hot-air properties along piccolo tube

\subsubsection{Wet Air Results}

For the wet air analyses presented in this section, the computation of the airfoil water droplet impingement efficiency was performed with FLUENT using the Eulerian method and the 7 bin Langmuir D droplet distribution given in Table 2.2. 
The computed and experimental LE temperatures for Run 76 are compared for dry and wet air conditions in Fig. 3.17. The cooling effect of the water film on the airfoil skin temperature is accurately captured by the thermodynamic model developed.

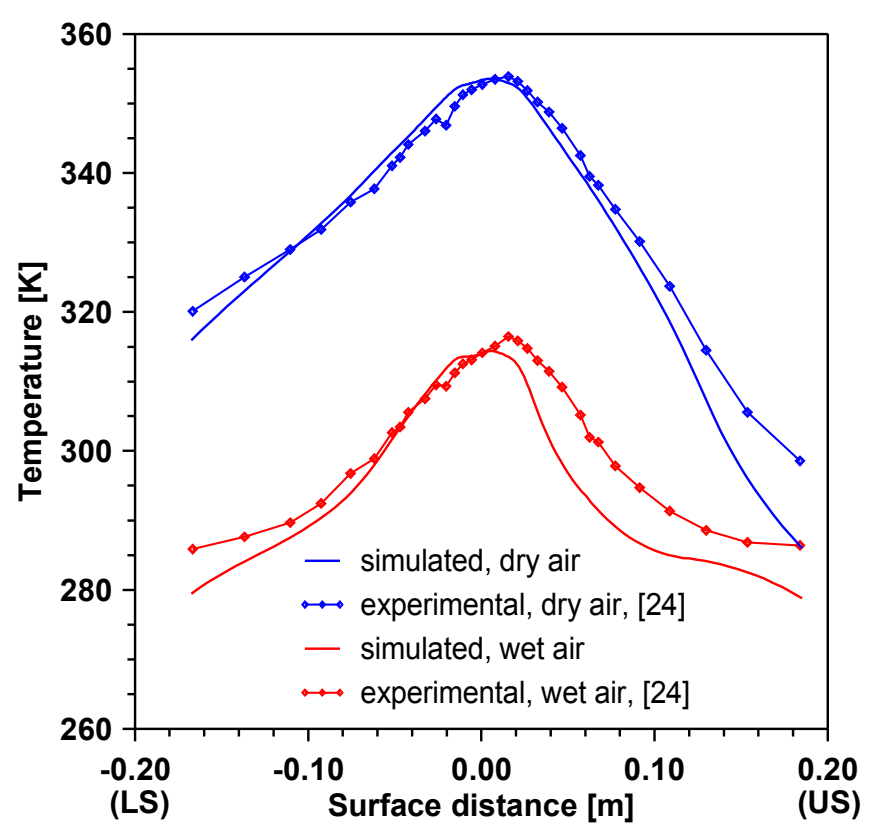

Figure 3.17. Cooling effect of evaporation on LE skin temperature, warm hold, dry and wet air conditions; $V_{\infty}=59.2[\mathrm{~m} / \mathrm{s}], \alpha=3\left[^{\circ}\right], L W C=0.87\left[\mathrm{~g} / \mathrm{m}^{3}\right], M V D=29[\mu \mathrm{m}], T_{\infty}=266.48[\mathrm{~K}]$, piccolo configuration: P45-0-M45 (Run 76 - Station B).

Figures 3.18 to 3.22 compare computed and experimental skin temperature distributions and freezing region for warm hold condition (Runs 48, 67, 73, 39, and 43). Figure 3.23 presents results for a cold hold condition (Run 59). 


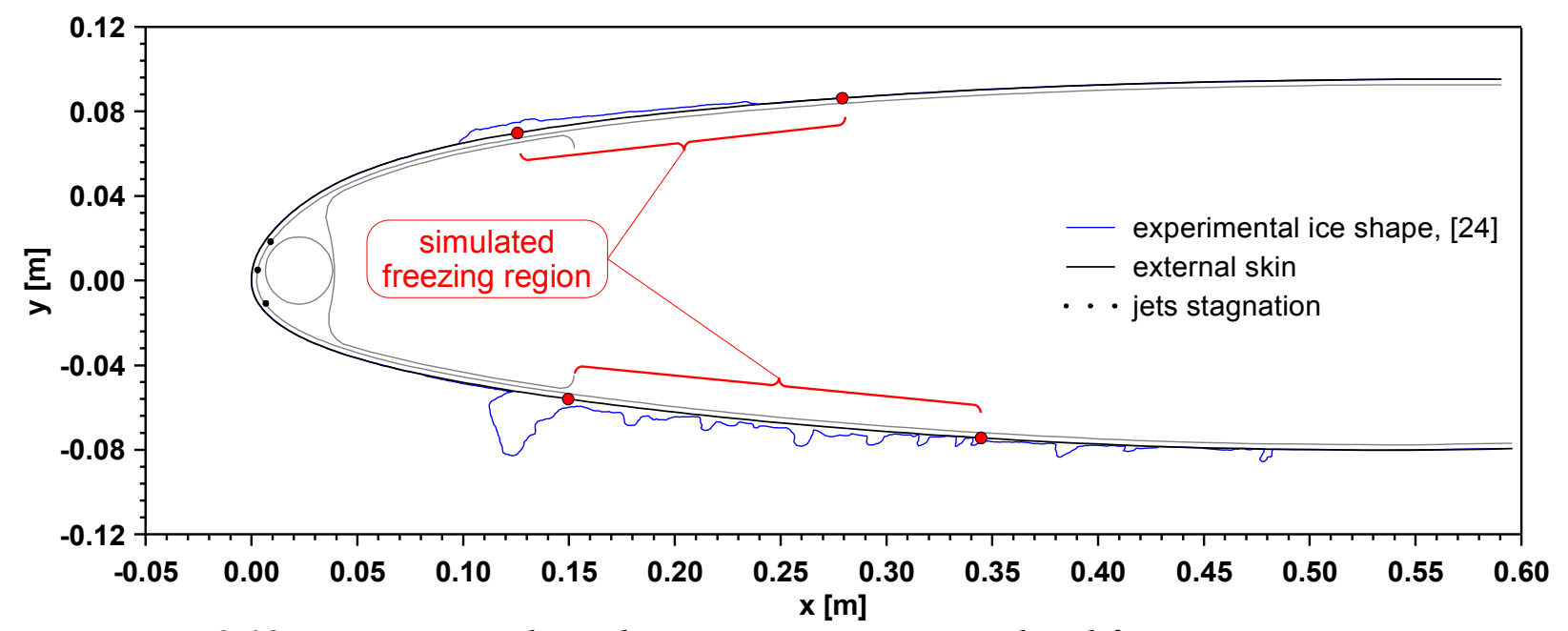

3.18a. Experimental ice shape tracing versus simulated freezing region.

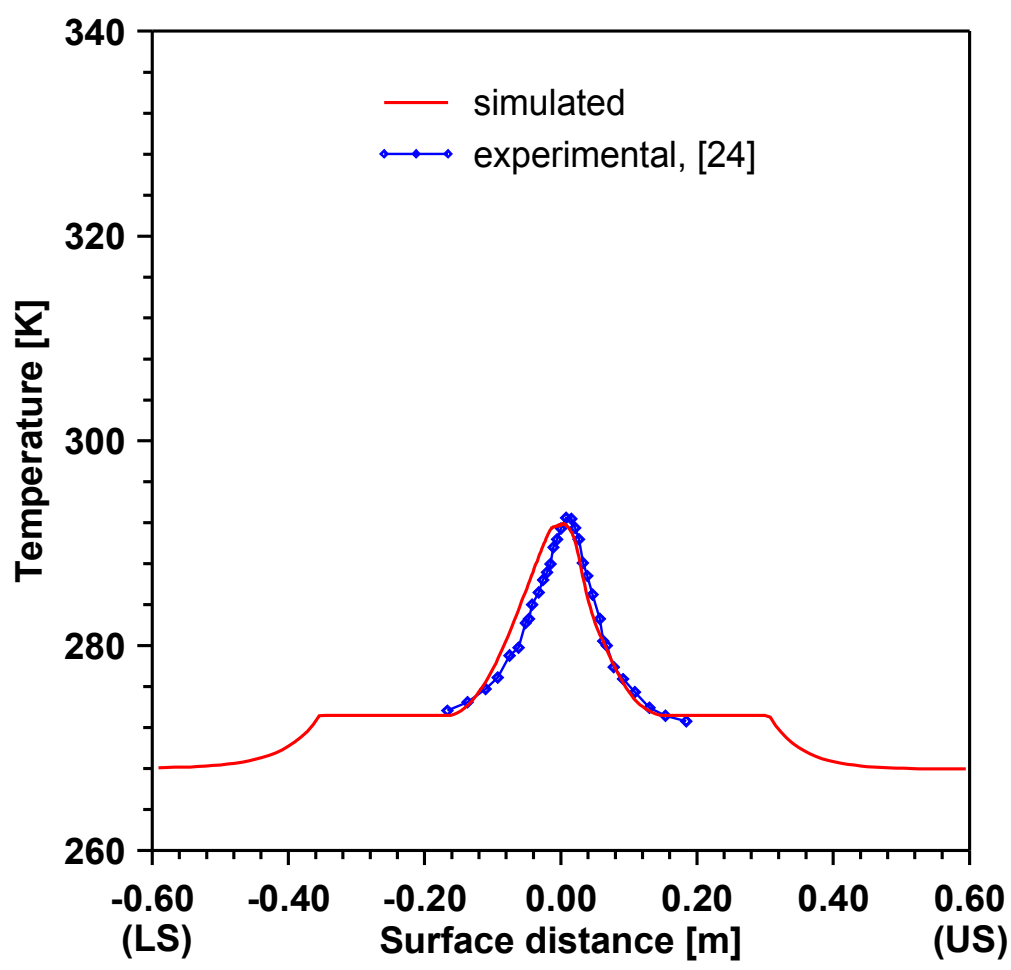

3.18b. Experimental versus simulated skin temperature distribution, Station B.

Figure 3.18. LE skin temperature and freezing location, warm hold, wet air condition; $V_{\infty}=59.2[\mathrm{~m} / \mathrm{s}], \alpha=3\left[^{\circ}\right], L W C=0.87\left[\mathrm{~g} / \mathrm{m}^{3}\right], M V D=29[\mu \mathrm{m}], \overline{\dot{m}^{\prime}}=0.0080[\mathrm{~kg} / \mathrm{s}-\mathrm{m}]$, $\overline{T_{p}}=391.05[\mathrm{~K}], T_{\infty}=266.48[\mathrm{~K}]$, piccolo configuration: P45-0-M45 (Run 48). 


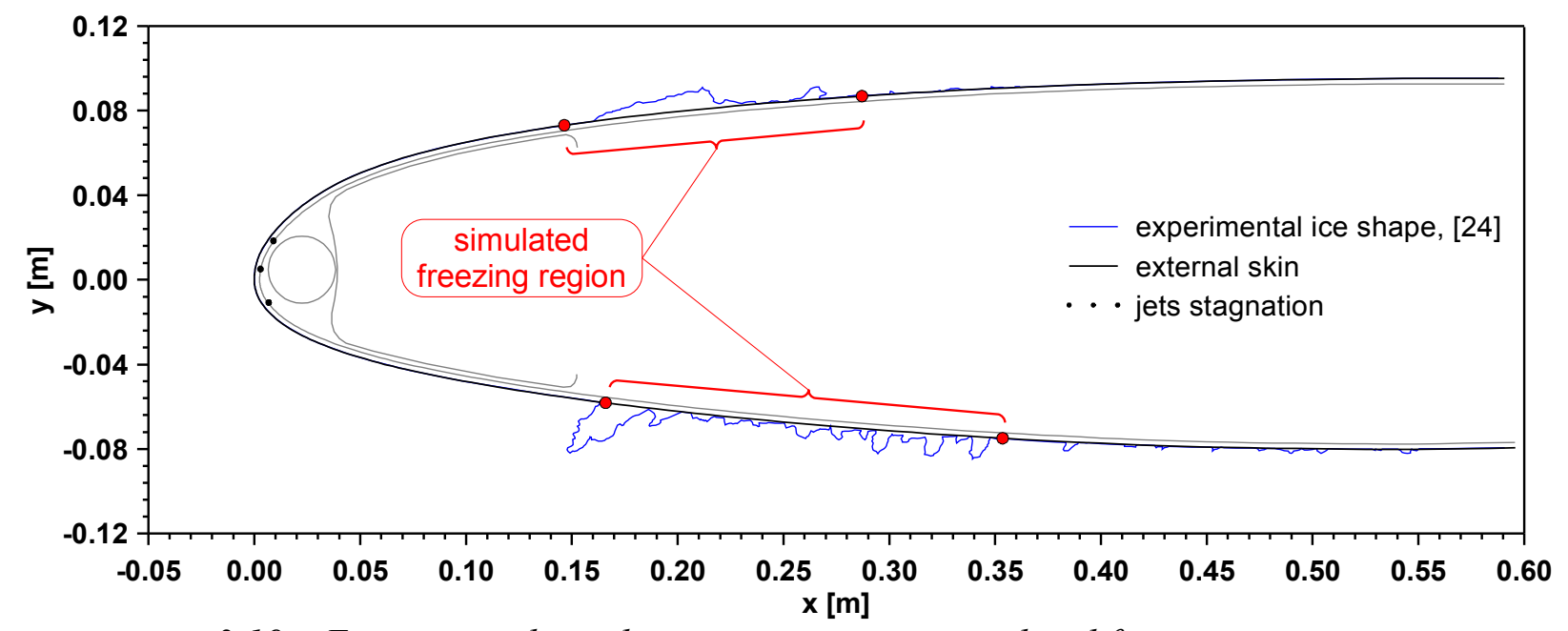

3.19a. Experimental ice shape tracing versus simulated freezing region.

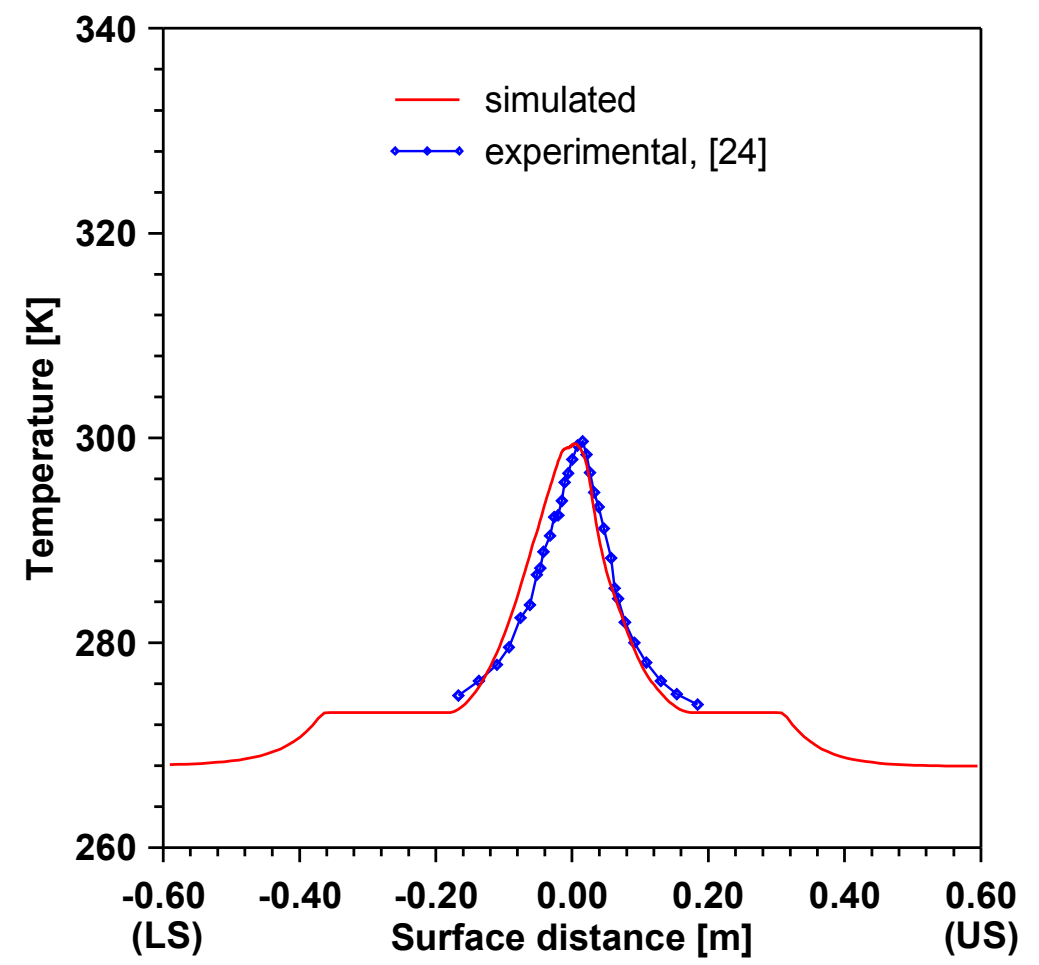

3.19b. Experimental versus simulated skin temperature distribution, Station B.

Figure 3.19. LE skin temperature and freezing location, warm hold, wet air condition; $V_{\infty}=59.2[\mathrm{~m} / \mathrm{s}], \alpha=3\left[^{\circ}\right], L W C=0.87\left[\mathrm{~g} / \mathrm{m}^{3}\right], M V D=29[\mu \mathrm{m}], \overline{\dot{m}^{\prime}}=0.0081[\mathrm{~kg} / \mathrm{s}-\mathrm{m}]$, $\overline{T_{p}}=432.35[\mathrm{~K}], T_{\infty}=266.48[\mathrm{~K}]$, piccolo configuration: P45-0-M45 (Run 67). 


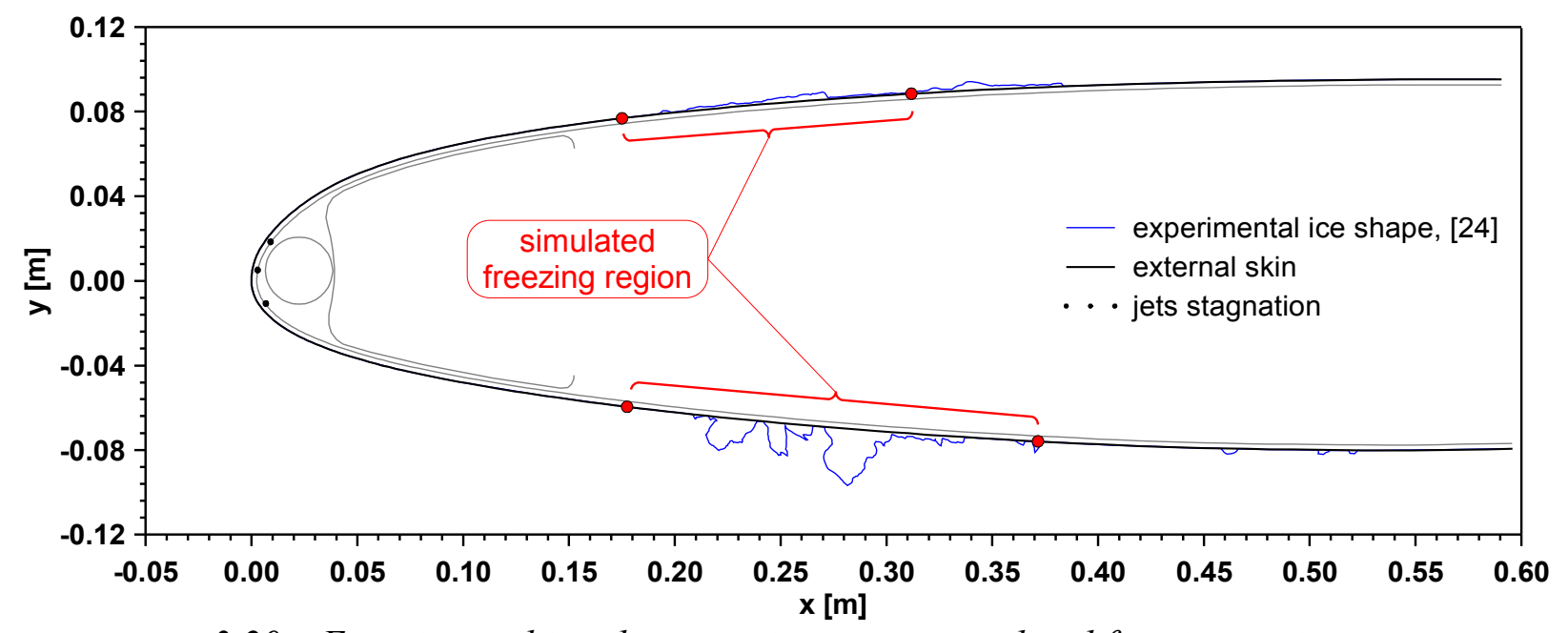

3.20a. Experimental ice shape tracing versus simulated freezing region.

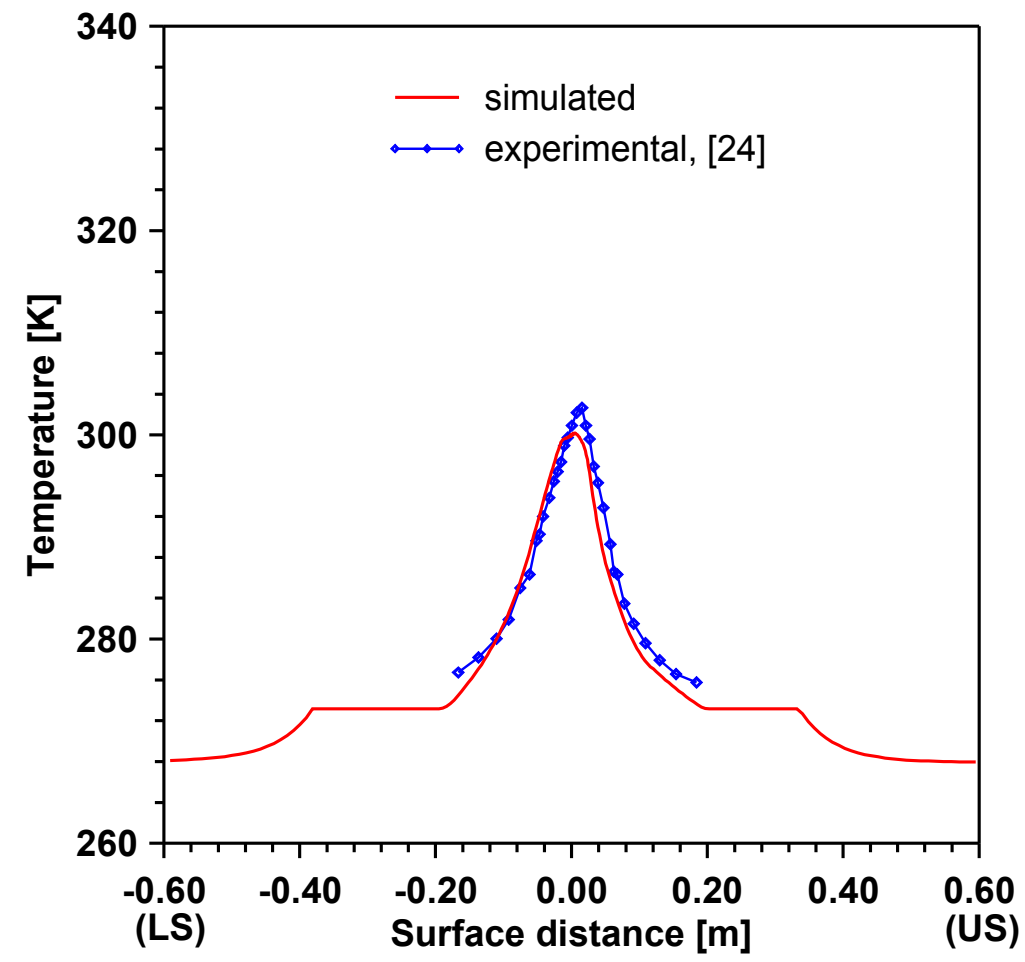

3.20b. Experimental versus simulated skin temperature distribution, Station B.

Figure 3.20. LE skin temperature and freezing location, warm hold, wet air condition; $V_{\infty}=59.2[\mathrm{~m} / \mathrm{s}], \alpha=3\left[^{\circ}\right], L W C=0.87\left[\mathrm{~g} / \mathrm{m}^{3}\right], M V D=29[\mu \mathrm{m}], \overline{\dot{m}^{\prime}}=0.0171[\mathrm{~kg} / \mathrm{s}-\mathrm{m}]$, $\overline{T_{p}}=388.25[\mathrm{~K}], T_{\infty}=266.48$ [K], piccolo configuration: P45-0-M45 (Run 73). 


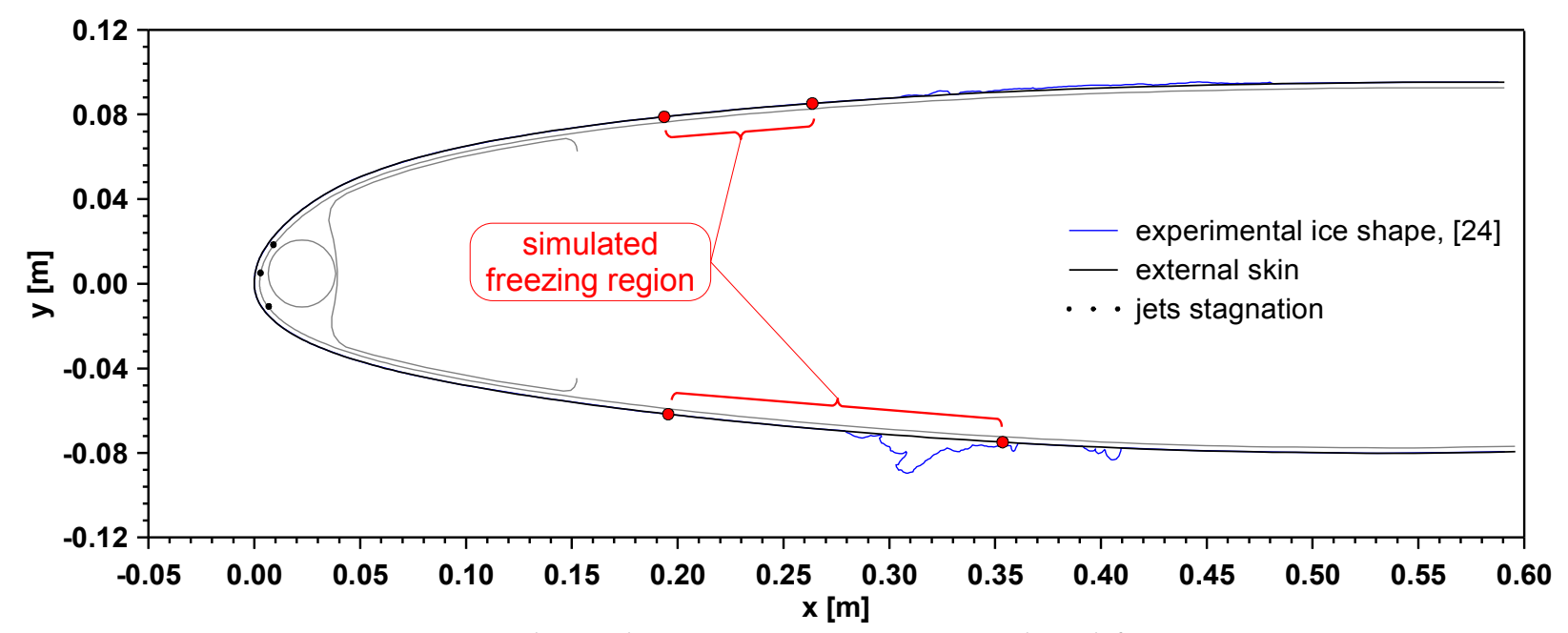

3.21a. Experimental ice shape tracing versus simulated freezing region.

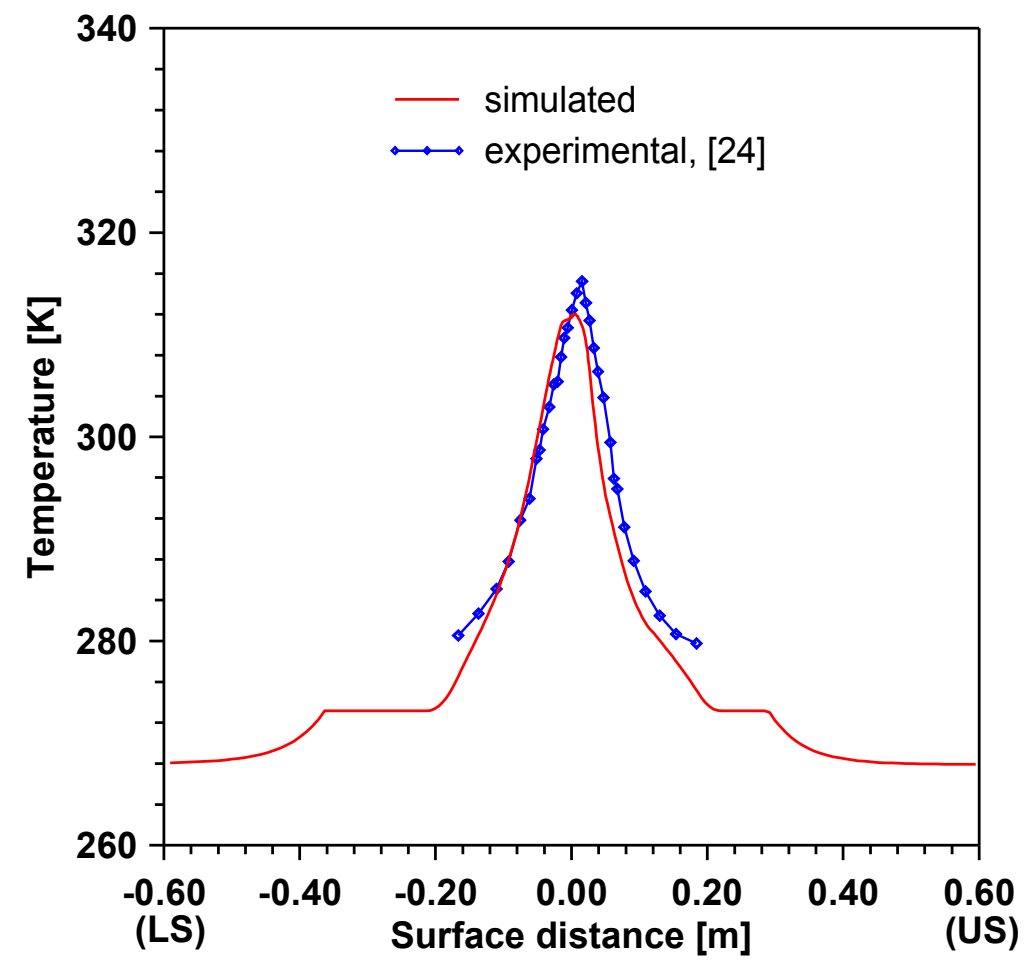

3.21b. Experimental versus simulated skin temperature distribution, Station B.

Figure 3.21. LE skin temperature and freezing location, warm hold, wet air condition; $V_{\infty}=59.2[\mathrm{~m} / \mathrm{s}], \alpha=3\left[^{\circ}\right], L W C=0.87\left[\mathrm{~g} / \mathrm{m}^{3}\right], M V D=29[\mu \mathrm{m}], \overline{\dot{m}^{\prime}}=0.0191[\mathrm{~kg} / \mathrm{s}-\mathrm{m}]$, $\overline{T_{p}}=437.75[\mathrm{~K}], T_{\infty}=266.48$ [K], piccolo configuration: P45-0-M45 (Run 39). 


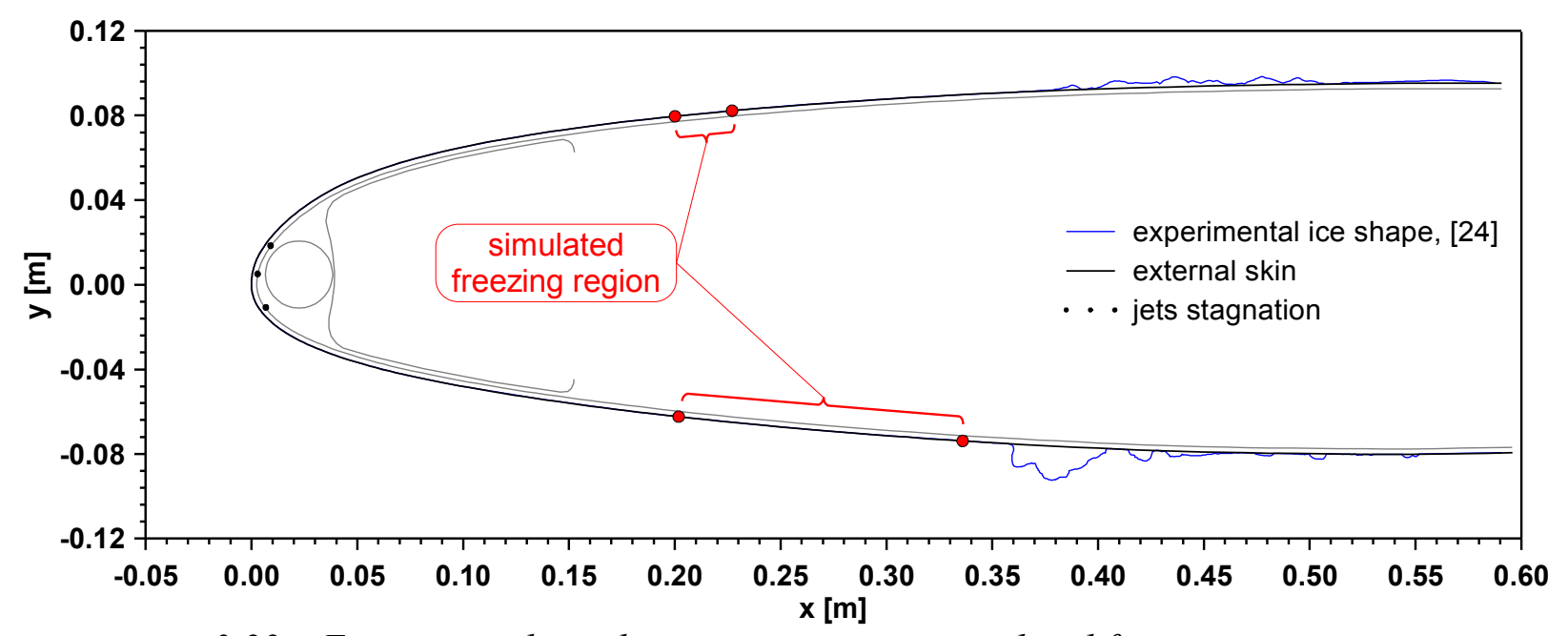

3.22a. Experimental ice shape tracing versus simulated freezing region.

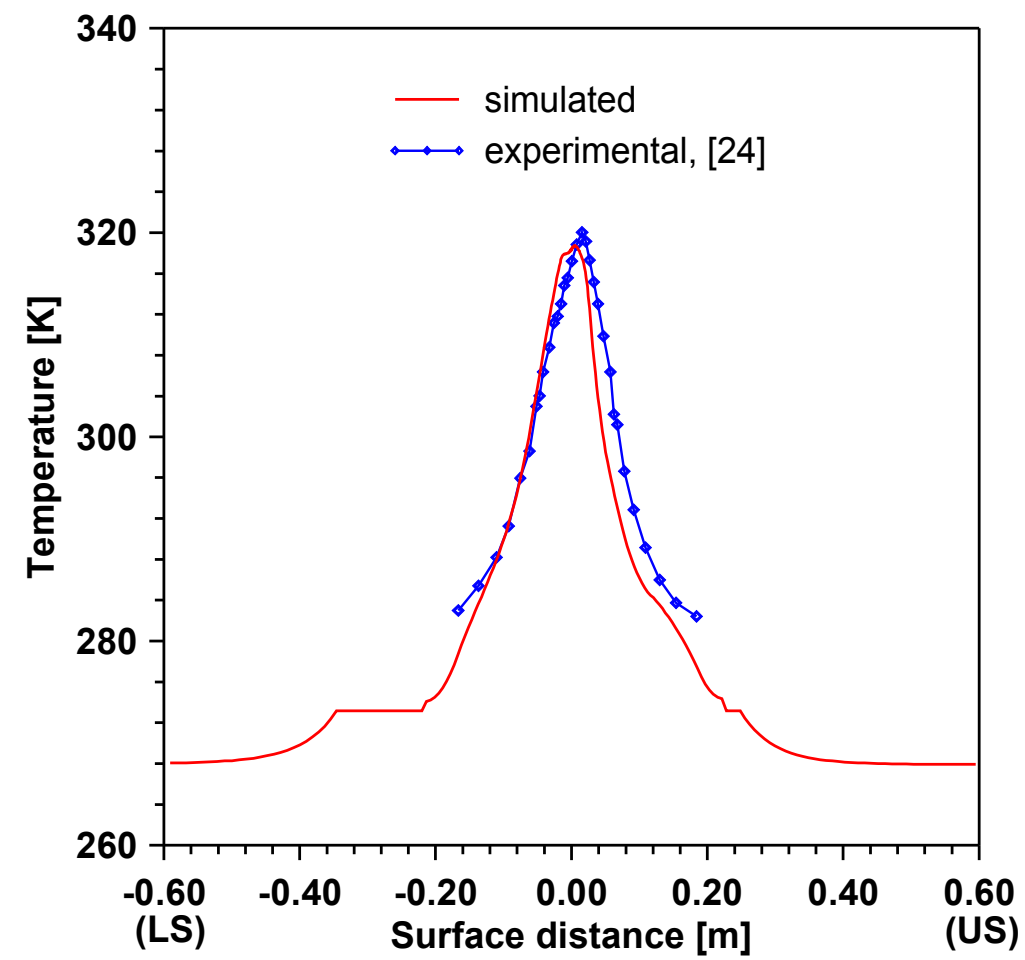

3.22b. Experimental versus simulated skin temperature distribution, Station B.

Figure 3.22. LE skin temperature and freezing location, warm hold, wet air condition; $V_{\infty}=59.2[\mathrm{~m} / \mathrm{s}], \alpha=3\left[^{\circ}\right], L W C=0.87\left[\mathrm{~g} / \mathrm{m}^{3}\right], M V D=29[\mu \mathrm{m}], \overline{\dot{m}^{\prime}}=0.0243[\mathrm{~kg} / \mathrm{s}-\mathrm{m}]$, $\overline{T_{p}}=452.65[\mathrm{~K}], T_{\infty}=266.48[\mathrm{~K}]$, piccolo configuration: P45-0-M45 (Run 43). 


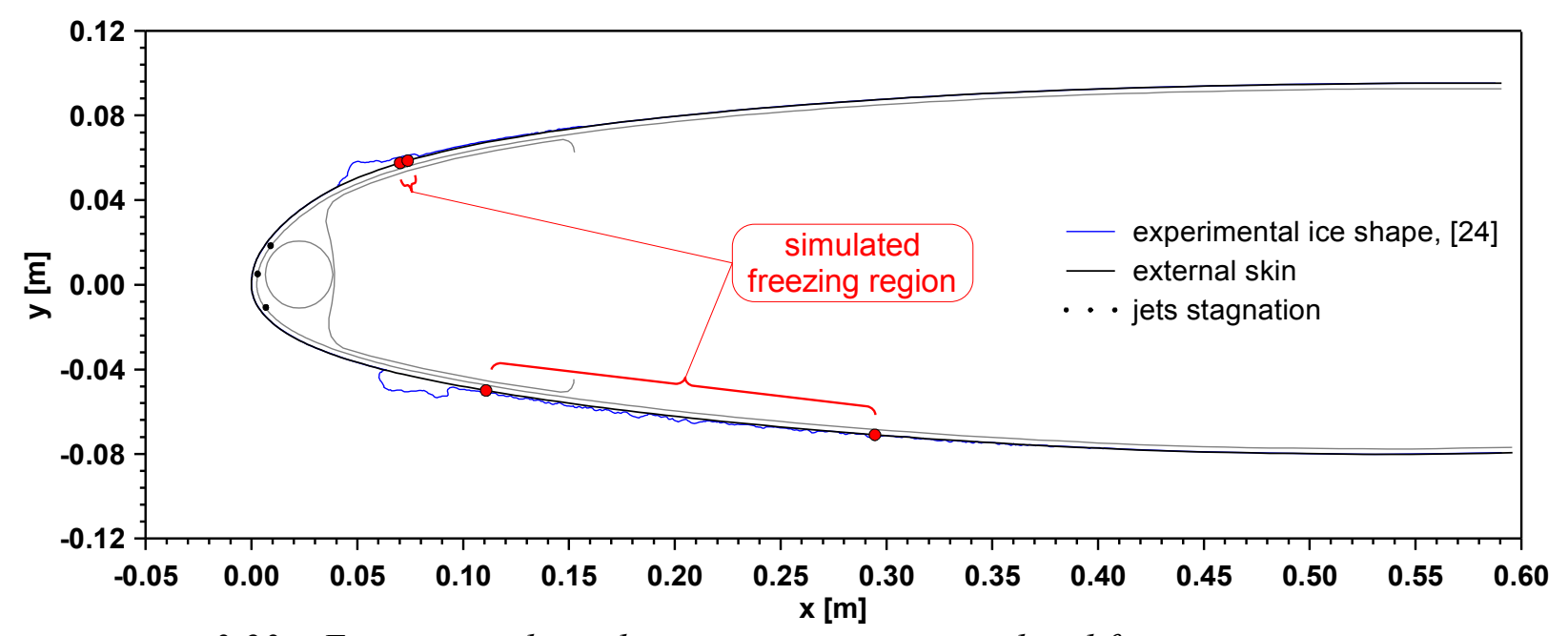

3.23a. Experimental ice shape tracing versus simulated freezing region.

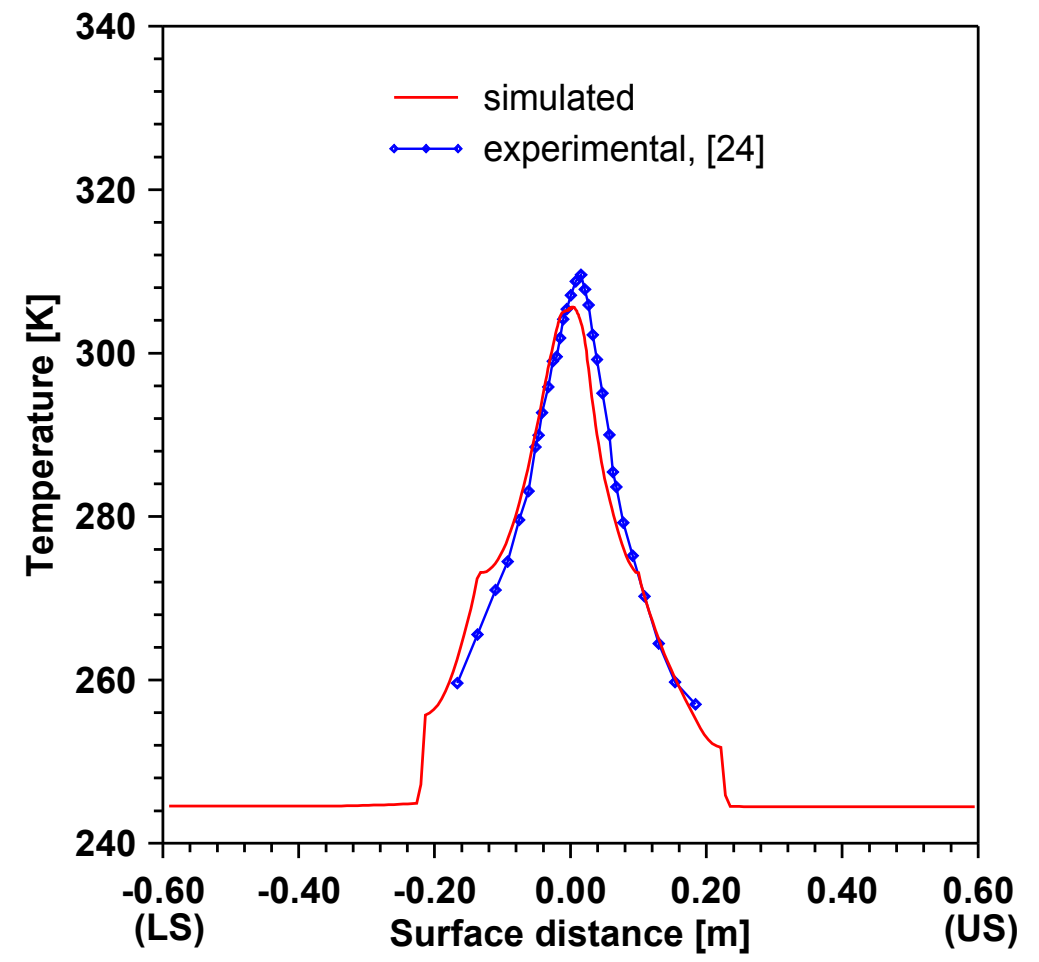

3.23b. Experimental versus simulated skin temperature distribution, Station B.

Figure 3.23. LE skin temperature and freezing location, cold hold, wet air condition; $V_{\infty}=59.2[\mathrm{~m} / \mathrm{s}], \alpha=3\left[^{\circ}\right], L W C=0.69\left[\mathrm{~g} / \mathrm{m}^{3}\right], M V D=29[\mu \mathrm{m}], \overline{\dot{m}^{\prime}}=0.0195[\mathrm{~kg} / \mathrm{s}-\mathrm{m}]$, $\overline{T_{p}}=435.46[\mathrm{~K}], T_{\infty}=243.15$ [K], piccolo configuration: P45-0-M45 (Run 59).

For preliminary analysis and design purposes, the results show good qualitative agreement with the experimental data published in [24] for both glaze and rime runback ice 
formed during warm and cold hold conditions, respectively. As it can be observed from Figs. 3.18-3.23 (Runs 48, 67, 73, 39, 43, and 59), the difference in the location of the freezing region between analysis and experiment was smaller for the cases with a relatively lower heat input (i.e., Runs 48,67 , and 59, where runback ice formed closer to the leading edge). This is attributed to the difference in the airfoil wall temperatures between experiment and simulation and to the uniform water film model used to simulate water runback. Most of the computed wall temperatures near the freezing front for Runs 48 and 59 were higher than the experiment, thus the computed ice front was downstream of the experimental one for both test runs. For Runs 67, 73,39 , and 43 , however, the computed wall temperatures near the freezing region were lower than the experiment, therefore the computed ice front was clearly upstream of the experimental one (except to Run 67, where the experimental and simulated ice front on the wing lower surface are approximately at the same position). Furthermore, for Runs 73,39 , and 43 the difference in wall temperatures between analysis and experiment near the freezing region was even greater than for Runs 48,67, and 59, thus the difference in computed and experimental ice fronts was also greater. Regarding the water runback effects, for the range of LWC studied, the accumulated water streamed over the airfoil surface in the form of beads and rivulets, which typically have a smaller surface area-to-volume ratio than a uniform film, and thus take longer to freeze. Therefore, for runback ice formations that tend to occur further downstream (i.e., for relatively high heat inputs) the difference between the experimental and predicted freezing regions tends to increase, as observed in Figs. 3.20-3.22 (Runs 73, 39, and 43). In such cases, the ice front of the ice shapes computed with the simulation tool developed is upstream of the experimental front.

Table 3.8 provides the percentage difference in peak leading edge temperature between analysis and experiment computed from Equation (3.4), and the percentage difference in the 
chordwise location of the runback ice front computed from Equation (3.5) below,

$$
\Delta\left(x_{\text {ice-start }}\right)[\%]=\frac{\left(x_{\text {ice-start }}\right)_{\text {simulated }}-\left(x_{\text {ice-start }}\right)_{\text {experimental }}}{C} \times 100
$$

where $x_{\text {ice-start }}$ is the $x$ component of the residual ice starting location (in [m]), and $\mathrm{C}$ is the airfoil chord (in $[\mathrm{m}])$.

Table 3.8. Percentage difference between simulated and experimental [24] skin peak temperature and ice starting point, wet air condition.

\begin{tabular}{|c|c|c|c|}
\hline \multirow{2}{*}{ Run \# } & $\Delta\left(T_{\text {e-max }}\right)[\%]$ & \multicolumn{2}{|c|}{$\Delta\left(x_{\text {ice-start }}\right)[\%]$} \\
\cline { 3 - 4 } & & Pressure Side & Suction Side \\
\hline \hline 48 & -0.20 & 1.82 & 1.75 \\
\hline 67 & -0.08 & -0.89 & 0.20 \\
\hline 73 & -0.83 & -1.11 & -2.00 \\
\hline 39 & -1.02 & -7.31 & -5.48 \\
\hline 43 & -0.40 & -10.8 & -10.2 \\
\hline 59 & -1.27 & 1.92 & 3.07 \\
\hline
\end{tabular}

The performance of the impinging jet Nusselt number correlation beyond its calibration range was evaluated with the P45-0-M45 and P70-P10-M40 piccolo tubes, using the conditions of Runs 43 and 106 (see Fig. 3.24). The P45-0-M45 piccolo tube was the one used in the calibration of the correlation. The P70-P10-M40 piccolo tube had a different circumferential hole placement as shown in Figures 3.1b and 3.1c. The experimental and simulated results are provided separately in Fig. 3.24 to avoid clutter.

As shown in Fig. 3.24b, the change in the airfoil skin temperature near the region of jet impingement due to the change in the piccolo tube hole pattern was well captured by the computational model. On the thin passages region, however, the skin temperature remained practically unchanged, as opposed to the experimental results where a noticeable change was 
observed. This behavior can be attributed to the thin passage inlet Reynolds number $\left(\operatorname{Re}_{t}\right)$ used in the two simulations (Runs 43 and 106), which was equal for both upper and lower passages. Although an equal flow share between the two passages might be reasonable for the P45-0-M45 piccolo tube case, the same is probably not true for the P70-P10-M40 configuration, because the jets are further inclined upwards, tending to increase the fraction of total hot-air flow passing through the upper passage. The importance of the specification of $R e_{t}$ becomes evident by repeating Run 106 with an arbitrarily determined flow share of $60-40 \%$ to the upper and lower passages, respectively, as shown in Fig. 3.25. This exploratory analysis showed that further studies are necessary for a proper specification of the flow share between the upper and lower passage flows.
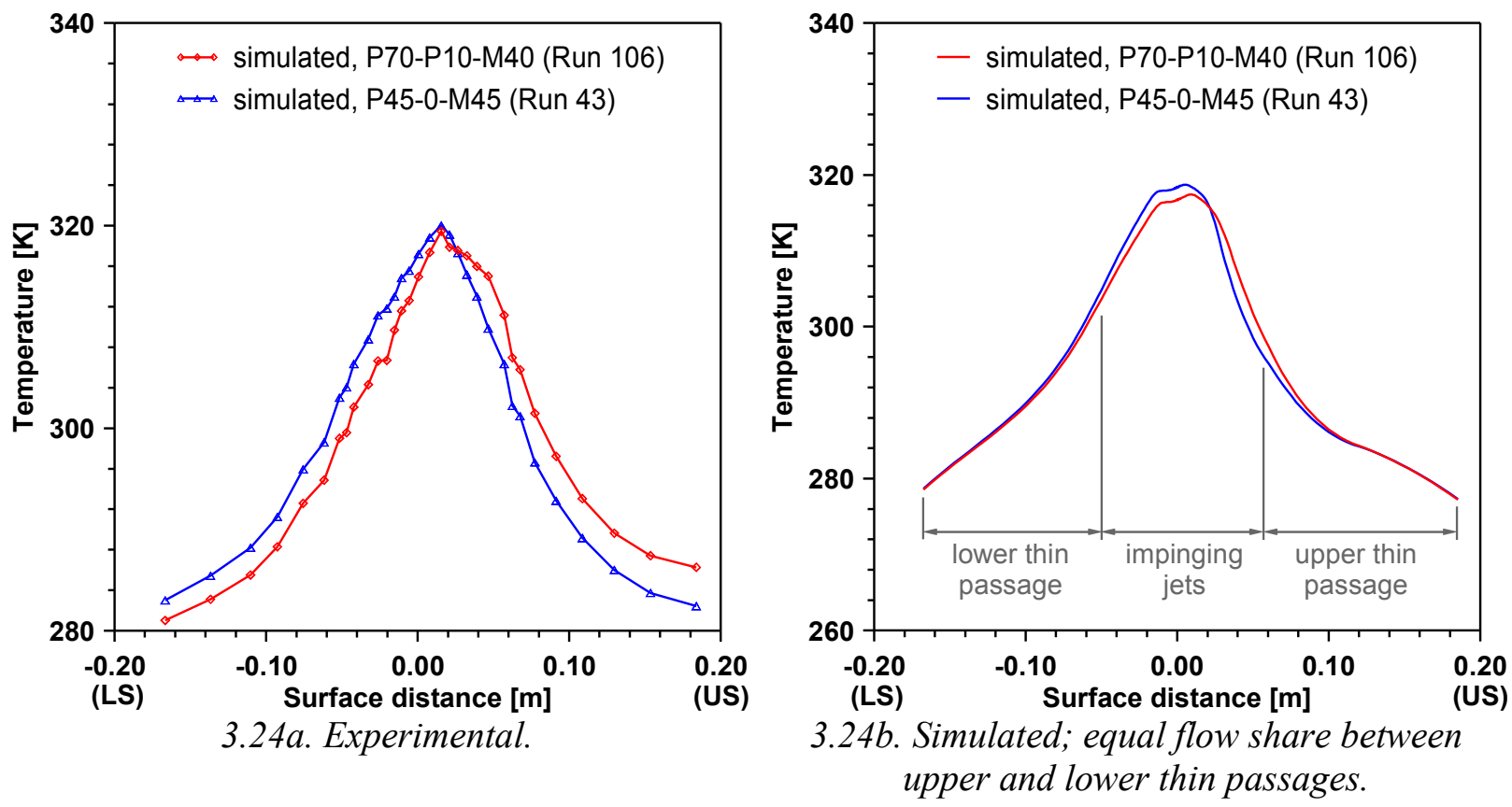

Figure 3.24. Effect of piccolo hole pattern, warm hold, wet air condition; $V_{\infty}=59.2[\mathrm{~m} / \mathrm{s}]$, $\alpha=3\left[^{\circ}\right], L W C=0.87\left[\mathrm{~g} / \mathrm{m}^{3}\right], M V D=29[\mu \mathrm{m}], T_{\infty}=266.48[\mathrm{~K}], \overline{\dot{m}^{\prime}}=0.0243[\mathrm{~kg} / \mathrm{s}-\mathrm{m}]$, $\overline{T_{p}}=452.65[K]$ (Run 43), $\overline{T_{p}}=449.35$ [K] (Run 106), Station B. 


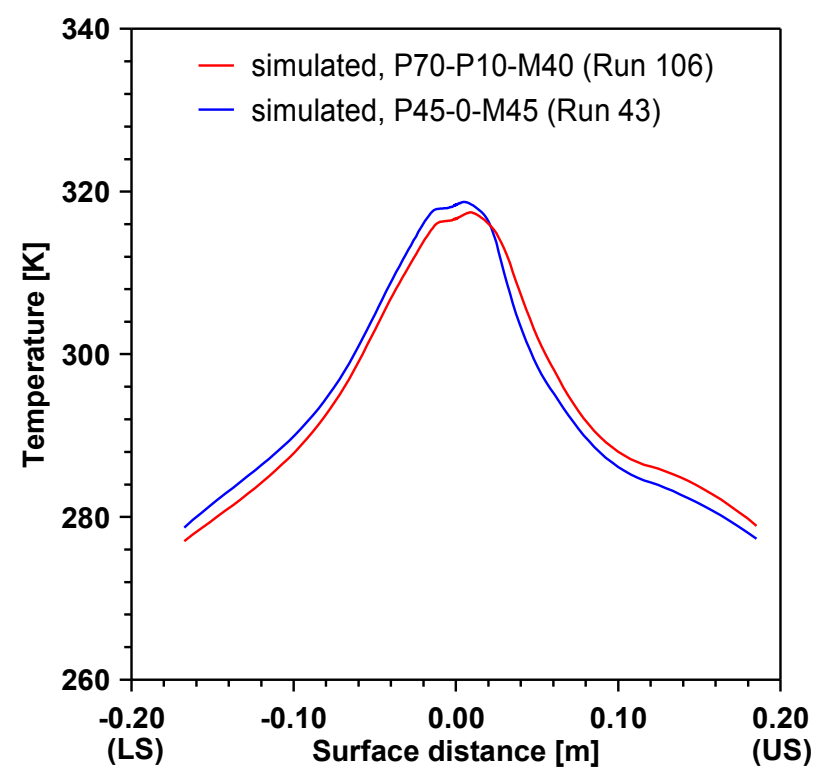

Figure 3.25. Effect of piccolo hole pattern and thin passages flow share (60\% to the upper passage and $40 \%$ to the lower passage), warm hold, wet air condition; $V_{\infty}=59.2[\mathrm{~m} / \mathrm{s}], \alpha=3\left[^{\circ}\right]$, $L W C=0.87\left[\mathrm{~g} / \mathrm{m}^{3}\right], M V D=29[\mu \mathrm{m}], T_{\infty}=266.48[\mathrm{~K}], \overline{\dot{m}^{\prime}}=0.0243[\mathrm{~kg} / \mathrm{s}-\mathrm{m}], \overline{T_{p}}=452.65[\mathrm{~K}]$ (Run 43), $\overline{T_{p}}=449.35$ [K] (Run 106), Station B.

\subsection{Application to System Development}

This section illustrates how the 2-d simulation methodology presented in this thesis can be applied to assess bleed air system performance as a function of selected design variables. Two examples are provided where only one parameter is varied at a time so that the respective influence can be evaluated. In the first example, the LE temperature and runback ice location are computed as functions of freestream temperature. The second example investigates the influence of piccolo tube hole pattern on LE temperature.

Results from the first example study are presented in Fig. 3.26 and show that the skin temperature decreases as the freestream temperature is decreased, as expected. The results also demonstrate that the drop in temperature causes the runback ice formation to advance upstream towards the airfoil leading edge as shown in Fig. 3.27.

Figure 3.28 provides the computed LE temperature distributions for four piccolo tube 
hole patterns. In all cases, the center hole was kept at the same location while the upper and lower hole circumferential spacing was varied. Note that the in all cases the hole spacing was symmetric with respect to the single hole to ensure that equal amounts of hot-air mass flow entered the upper and lower thin passages. The results demonstrate that the LE peak temperature tends to decrease and spread over a wider area as the hole circumferential spacing is increased. The computed runback ice front locations practically did not change, as indicated by the regions of the LE where the computed temperature was equal to the freezing point of water (see Fig. 3.28).

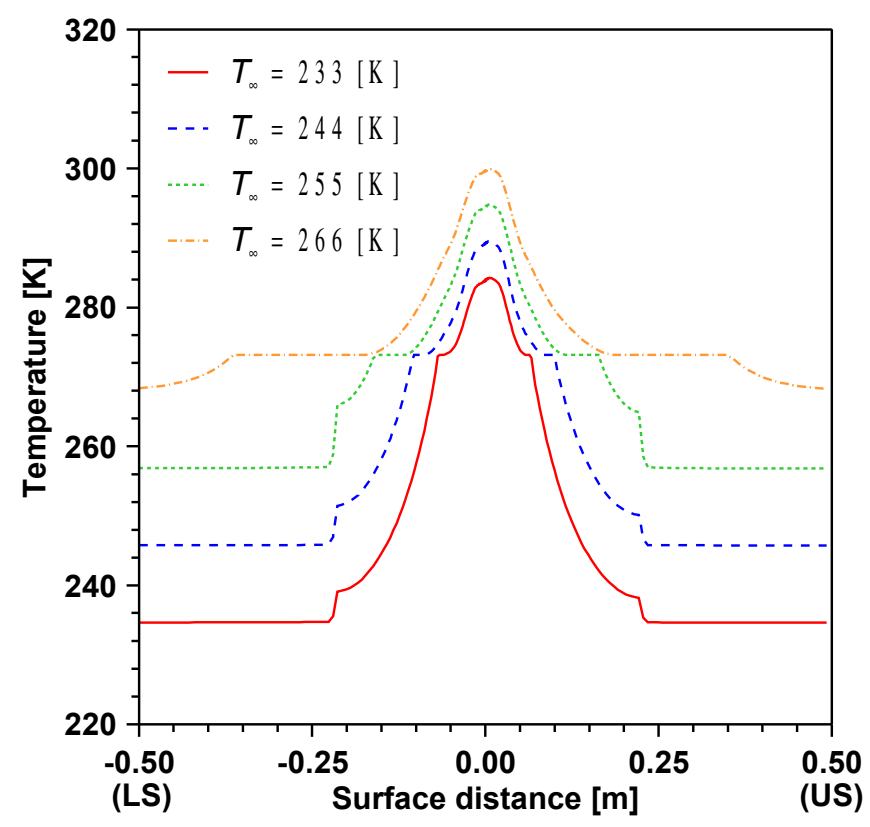

Figure 3.26. Simulation of the effect of freestream temperature on LE skin temperature, warm hold, wet air condition; $V=59.2[\mathrm{~m} / \mathrm{s}], \alpha=3\left[^{\circ}\right], L W C=0.87\left[\mathrm{~g} / \mathrm{m}^{3}\right], M V D=29[\mu \mathrm{m}]$, $\overline{\dot{m}^{\prime}}=0.0081[\mathrm{~kg} / \mathrm{s}-\mathrm{m}], \overline{T_{p}}=432.35[\mathrm{~K}]$, piccolo configuration: P45-0-M45. 


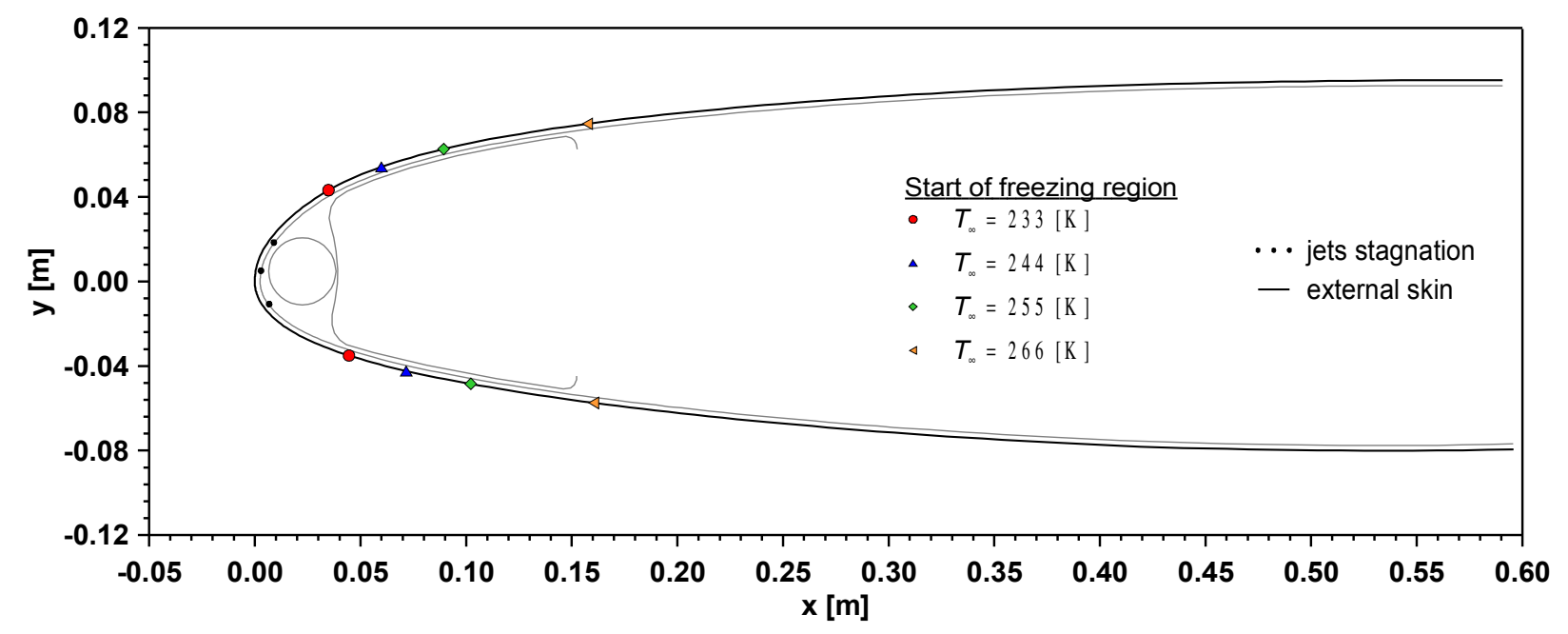

Figure 3.27. Simulation of the effect of freestream temperature on freezing starting point location, warm hold, wet air condition; $V=59.2[\mathrm{~m} / \mathrm{s}], \alpha=3\left[^{\circ}\right], L W C=0.87\left[\mathrm{~g} / \mathrm{m}^{3}\right]$, $M V D=29[\mu \mathrm{m}], \overline{\dot{m}}^{\prime}=0.0081[\mathrm{~kg} / \mathrm{s}-\mathrm{m}], \overline{T_{p}}=432.35[\mathrm{~K}]$, piccolo configuration: P45-0-M45.

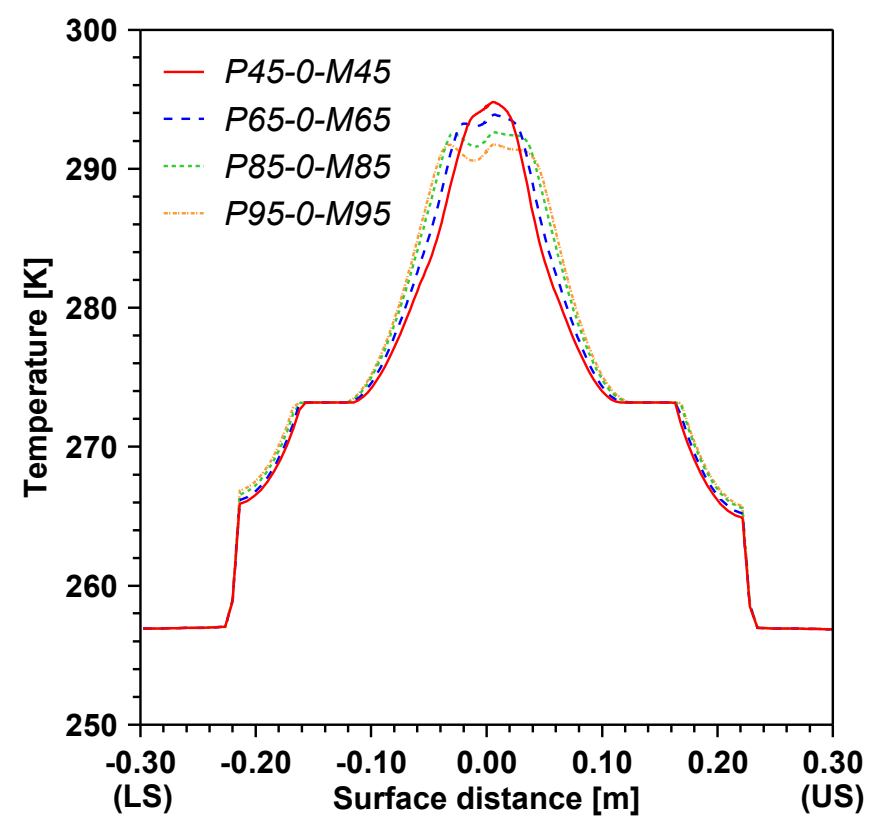

Figure 3.28. Effect of hole positioning on LE skin temperature, warm hold, wet air condition; $V=59.2[\mathrm{~m} / \mathrm{s}], \alpha=3\left[^{\circ}\right], L W C=0.87\left[\mathrm{~g} / \mathrm{m}^{3}\right], M V D=29[\mu \mathrm{m}], \overline{\dot{m}^{\prime}}=0.0081[\mathrm{~kg} / \mathrm{s}-\mathrm{m}]$, $\overline{T_{p}}=432.35[K], T_{\infty}=255[K]$. 


\section{CHAPTER 4}

\section{CONCLUSIONS AND RECOMMENDATIONS}

\subsection{Conclusions}

An efficient and low cost 2-d methodology was developed that combines CFD analysis with Nusselt number correlations, and an anti-icing thermodynamic model developed during the course of this research to support parametric analysis of hot-air anti-icing systems. The methodology was implemented in a computer code, in a fully automated process that requires as inputs only the airfoil profile, piccolo tube configuration, and flight, icing and hot-airflow conditions. The simulation tool developed was tested using a business jet wing equipped with a piccolo tube anti-icing system. Test cases involved a range of internal hot-air and external cold-air flow conditions. Results from experiments performed with the business jet wing at the NASA icing research tunnel were used to assess the performance of the simulation tool developed.

The results presented demonstrate that the use of Nusselt number correlations for impinging jet is highly efficient for computing the distribution of heat transfer coefficient on the airfoil internal skin. However, the correlations require calibration against experimental and or analytical data. The use of a span-weighted average of the convective heat transfer coefficient for the region of the impinging jets proved valid for converting a 2-d (as a function of $c$ and $s$ ) heat transfer coefficient field into an equivalent 1-d (as a functions of $c$ ) profile.

The decoupling of the external flow solution from the internal hot-air flow proved effective in allowing the solution of the external flow to be obtained without prior knowledge of the airfoil skin temperature. This was accomplished by applying an isothermal wall boundary 
condition to the airfoil external skin. Studies showed that an acceptable level of accuracy was reached without the necessity of coupling the external and internal flows.

The hot-air anti-icing model developed was based on steady state energy and mass balance analysis using 2-d control volumes for the heat conduction within the airfoil wall and 1-d control volumes for the runback water flow. The comparisons with experiments showed that the 1-d film model is capable of capturing the cooling and heating effects of water phase change over the airfoil wall external surface.

The developed model successfully reproduced airfoil skin temperature distributions for the wing model with the hot-air anti-icing system used in this study. The percentage error in the wing LE peak temperature in all test cases, which included dry and wet air and warm and cold hold conditions, was within $2.44 \%$.

For the dry air test cases (Runs 66, 26, and 76), the agreement between the computed and experimental wing LE temperature distributions improved as the hot-air mass flow was increased, suggesting that more accuracy can be achieved by further refining the current calibration of the Nusselt number correlation for impinging jet. The overprediction of the heat transfer coefficient over the turbulent region of the external flow was due to the isothermal boundary condition applied on the airfoil wall. This boundary condition caused the airfoil wall temperature to be underestimated in the turbulent zone of the external flow.

For the warm hold wet air cases with lower anti-icing thermal energy supply (Runs 48, 67, and 73), the performance of the simulation tool developed was in good agreement with the experiments, in terms of both wing LE temperature distribution and runback ice front location. For the warm hold wet air cases with higher energy supply (Runs 39 and 43), the accuracy of the wing LE peak temperature computations remained approximately the same, while the 
performance in predicting the runback ice front location decreased, although the percentage error (based on the airfoil chord length) was no larger than $10.8 \%$, which is acceptable for parametric studies. For the cold hold wet air condition test case (Run 59), computed wing LE skin temperatures and runback ice locations were in good agreement with the experimental data.

The Nusselt number heat transfer correlation developed for impinging jet performed well for a piccolo tube with a hole circumferential spacing that was different from the configuration used in the calibration of the correlation. However, the use of this correlation for piccolo tubes beyond the calibration range is not recommended.

The Nusselt number correlation (based on 6th degree polynomials) developed for the inner liner flow performed satisfactorily for the cases tested. Nevertheless, the results presented indicate that further studies are necessary to improve the overall performance of this correlation.

Extensive testing of the computer code developed showed that 20 to 30 seconds are needed to perform a single bleed air analysis on a desktop computer. Thus the objective of developing an efficient and sufficiently accurate tool for bleed air system parametric design studies was met.

\subsection{Recommendations}

The calibration of the Nusselt number correlation for hot-air impinging jet was based on heat transfer data from one single piccolo tube configuration. This limited calibration was used to demonstrate the applicability of the method developed. The simulation of hot-air anti-icing systems with different configurations is now dependent on the expansion of heat transfer data base for more piccolo tube configurations, considering parameters like the distance to the impingement wall, incidence angle of the impinging jet, piccolo tube diameter, diffuser bay 
volume, etc.

For the thin passage Nusselt number correlation, the influence of the passage inlet radius (on the inner liner wall) could be further investigated with CFD simulations. Larger inlet radii could possibly rid the passage of the separation bubble that was present in some cases. This would improve the prediction of the local heat transfer coefficient.

An important aspect of the thin passage flow, for systems with two passages, is the determination of the flow share between the upper and lower channels. It was demonstrated that the external skin temperature is a function of the passages flow share, and therefore further studies should be conducted so that a correct specification method can be developed.

If necessary, the performance of the simulation tool in predicting the freezing location can be improved by replacing some of the assumptions of the current model with more representative physical models, such as:

$\rightarrow$ solving the energy equation for the runback flow in order to obtain the film temperature distribution (instead of assuming it equal to the airfoil external skin)

$\rightarrow$ implementing a runback flow model based on a force balance (due to shear stress, surface tension, gravity, pressure gradient, etc) to govern the water film motion over the airfoil surface

$\rightarrow$ coupling the external flow solution with the actual external skin temperature through an iterative solution based on a successive transfer of heat flux and skin temperature boundary conditions between the anti-icing and external flow modules 


\section{LIST OF REFERENCES}

1 Manual of Scaling Methods, NASA CR 2004-212875, March 2004.

2 Gent, R.W., Dart, N. P., and Cansdale, J.T., "Aircraft Icing”, Transactions Mathematical Physical and Engineering Sciences, Vol. 358, No. 1776, Ice and Snow Accretion on Structures, Nov. 2000, pp. 2873-2911.

3 Fisher, J. B., "Future Rulemaking, Policy and Guidance -Engine Icing", SAE presentation 07ICE-80, Sept. 2007.

4 Cebeci, T., and Kafyeke, F., “Aircraft Icing”, Annual Review of Fluid Mechanics, Vol. 35, Jan. 2003, pp. 11-21.

5 An Experimental Method for Measuring Water Droplet Impingement Efficiency on Twoand Three-Dimensional Bodies, NASA CR 4257, Nov. 1989.

6 Lynch, F.T., and Khodadoust, A., "Effects of Ice Accretions on Aircraft Aerodynamics", Progress in Aerospace Sciences, Vol. 37, 2001, pp. 669-767.

7 Addy, HE Jr., "A wind tunnel study of icing effects on a natural laminar flow airfoil”,,AIAA paper 2000-0095, Jan. 2000.

8 Szilder, K., "Numerical Simulation of Ice Formation on a Helicopter Fuselage", SAE paper 2007-01-3308, Sept. 2007.

9 Green, S.D., “A Study of U. S. Inflight Icing Accidents and Incidents, 1978 to 2002”, AIAA paper 2006-82, Jan. 2006.

10 Cao, Y., Zhang, and Q., Sheridan, J.,"Numerical Simulation Of Ice Accretion On Airfoils”, XXII ICTAM, 2008.

11 Paraschivoiu, I., and Saeed, F., Aircraft Icing, New York: John Willy \& Sons, Inc., 1984.

12 Bourgault, Y., Boutanios, Z., and Habashi, W. G., "An Eulerian Approach to 3-D Droplet Impingement Simulation Using FENSAP-ICE. Part I: Model, Algorithm and Validation", Journal of Aircraft, No. 37, 2000, pp.95-103.

13 Wirogo, S., Srirambhatla, S., An Eulerian Method to Calculate the Collection Efficiency on Two and Three Dimensional Bodies, , AIAA paper 2003-1073, Jan. 2003.

14 Wright, W.B., “An Evaluation of Jet Impingement Heat Transfer Correlations for Piccolo Tube Application”, AIAA paper 2004-0062, Jan. 2004.

15 Zamora, A.O., Numerical Investigation of a Wing Hot air Ice Protection System, M.Sc. Thesis, Department of Aerospace Engineering, Wichita State University, Wichita, KS, 
2007.

16 Santos, L.C.C., Tobaldini Neto, L., Papa, R., Silva, D.B.V.F., and Wirogo, S., "A Grid Refinement Strategy for Impingement Limits Computation in an Eulerian Collection Approach", AIAA paper 2005-1247, 2005.

17 Santos, L.C.C., Tobaldini Neto, L., Papa, R., Oliveira, G.L., and Jesus, A.B., "Grid Sensitivity Effects in Collection Efficiency Computation”, AIAA paper 2006-0566, Jan. 2006.

18 Pueyo, A., Brette, C, Vafa, S., and Akel, I., "A Comparison Exercise of Ice Accretion Simulations with 2D and 3D Solvers", SAE paper 2007-01-3338, Sept. 2007.

19 Riley, J.T., McDowall, R., Hughes, W.J., and Flemming, R.J., “A Quantitative Method For Assessing Agreement Between Experimental And Calculated Ice Shapes”, AIAA paper 2002-0384, Jan. 2002.

20 SAE Recommended Practice for Droplet Impingement and Ice Accretion Computer Codes, ARP5903, 2003.

21 Kind, R.J., "Ice Accretion Simulation Evaluation Test”, NATO RTO-TR-038, Nov. 2001.

22 Papadakis, M. and Wong, S-H.J., "Parametric Investigation of a Bleed Air Ice Protection System", AIAA paper 2006-1013, Jan. 2006.

23 Papadakis, M., Wong, S.-H., Yeong, H.-W., Wong, S.-C., and Vu, G.T., "Experimental Investigation of a Bleed Air Ice Protection System”, SAE paper 2007-01-3313, Sept. 2007.

24 Papadakis, M., Wong, S.-H., Yeong, H.-W., Wong, S.-C., and Vu, G.T., "Icing Tunnel Experiments with a Hot-air Anti-Icing System”, AIAA paper 2008-444, Jan. 2008.

25 Messinger, B.L., "Equilibrium Temperature of an Unheated Icing Surface as a Function of Air Speed", Journal of the Aeronautical Sciences, 1953, pp. 29-42.

26 Wright, W.B., Al-Khalil, and K., Miller, D., "Validation of NASA Thermal Ice Protection Computer Codes Part 2 - LEWICE/Thermal”, AIAA paper 1997-50, Jan. 1997.

27 Al-Khalil, K.M., Miller, D.R., and Wright, W.B."Validation of NASA Thermal Ice Protection Computer Codes Part 3: The Validation of Antice”, AIAA paper 1997-51, Jan. 1997.

28 Wright, W.B., "Users Manual for the Improved NASA Lewis Ice Accretion Code LEWICE 1.6”, NASA CR-198355, Jun. 1995.

29 Wright, W., "LEWICE 2.2 Capabilities and Thermal Validation”, SAE paper 01-2134, June 2003. 
30 Wright, W.B., "User Manual for the NASA Glenn Ice Accretion Code LEWICE Version 2.2.2”, NASA CR-211793, Aug. 2002.

31 Potapczuk, M.G., Al-Khalil, K.M., and Velazquez, M.T., "Ice Accretion and Performance Degradation Calculations With LEWICE/NS", AIAA paper 0173, Jan. 1993.

32 Bidwell, C.S., D.P., and Garrison, P.,'Ice Accretion Calculations for a Commercial Transport Using the LEWICE3D, ICEGRID3D and CMARC Programs", NASA TM208895, Jan. 1999.

33 Addy Jr.,H.E., Potapczuk, M.G., and Sheldon, D.W., "Modern Airfoil Ice Accretions", AIAA paper 0174, Jan. 1997.

34 Wright, W.B., and Potapczuk, M.G., "Comparison of LEWICE 1.6 and LEWICE/NS with IRT Experimental Data from Modern Airfoil Tests", AIAA paper 0175, Jan. 1997.

35 Wright, W.B., and Potapczuk, M.G., "Semi-Empirical Modeling of SLD Physics", AIAA paper 2004-0412, Apr. 2004.

36 Wright, W.B., "Validation Results for LEWICE 3.0", AIAA paper 1243, Jan. 2005.

37 Guffond, D., and Brunet, L., "Validation du Programme Bidimensionnel de Captation", ONERA RP 20/5146 SY, 1988.

38 Gent, R.W., "TRAJICE2 - A Combined Water Droplet Trajectory and Ice Accretion Prediction Program for Aerofoils", RAE TR-90054, Nov. 1990.

39 Hedde, T., and Guffond, D., "ONERA Three-Dimensional Icing Model”, AIAA Journal, Vol. 33, No. 6, 1995, pp. 1038-1045.

40 Gent, R.W., Guffond, D., and Reinmann, J., "DRA/NASA/ONERA Collaboration on Icing Research: Part I - Prediction of Water Droplet Trajectories," DRA/MS/TR93085/1, Dec. 1993.

41 Wright, W.B., Gent, R.W., and Guffond, D., "DRA/NASA/ONERA Collaboration on Icing Research Part II - Prediction of Airfoil Ice Accretion. Cleveland, National Aeronautics and Space Administration, NASA CR-202349, May 1997.

42 Guffond, D., Reinmann, J., and Gent, R.W., "DRA/NASA/ONERA Collaboration on Icing Research: Part III - Prediction of Thermal Deicer Simulations," ONERA T.R. 2/7766 PN, June 1993.

43 Al-Khalil, K.M., Numerical Simulation of an Aircraft Anti-Icing System Incorporating a Rivulet Model for the Runback Water, Ph.D. Thesis, University of Toledo, Toledo, OH, 1991. 
44 Croce, G., Habashi, W.G., Guevremont, G., and Tezok, F., "3D thermal Analysis of an Anti-Icing Device Using FENSAP-ICE”, AIAA paper 1998-0193, 1998.

45 Bourgault, Y., Beaugendre, H., and Habashi, W.G., "Development of a Shallow Water Icing Model in FENSAP-ICE", Journal of Aircraft, Vol. 37, No. 4, 2000, pp. 640, 646.

46 Beaugendre, H., Morency, F., and Habashi, W.G., "Development of a Second Generation In-Flight Icing Simulation Code", Journal of Fluids Eng., Vol. 128, Issue 2, 2006, pp. 378387.

47 H. Beaugendre, F. Morency, and W.G. Habashi, "ICE3D, FENSAP-ICE's 3D In-Flight Ice Accretion Module”, AIAA paper 2002-0385, Jan. 2002.

48 Croce, G., Beaugendre, H., and Habashi, W.G., "CHT3D: FENSAP-ICE Conjugate Heat Transfer Computations With Droplet Impingement And Runback Effects", AIAA paper 2002-0386, Jan. 2002.

49 Morency, F.,Tezok, F., and Paraschivoiu, I., "Anti-Icing System Simulation Using CANICE", Journal of Aircraft, Vol. 36, No. 6, 1999, pp. 999, 1006.

50 Saeed, F, Gouttebroze, S, and Paraschivoiu, I., "Modified CANICE For Improved Prediction of Airfoil Ice Accretion”, CASI 8th Aerodynamic Symposium, May, 2001, pp. 283-289.

51 Pueyo, A., Simulation Numérique de la Formation de la Glace Pour des Écoulements Tridimensionnels, M.Sc.A. Thesis, École Polytechnique de Montreal, 1992.

52 Silveira, R.A., Simulação Numérica da Formação de Gelo na Borda de Ataque de Perfis Aerodinâmicos, M.Sc. Dissertation, Universidade Federal de Santa Catarina, Florianópolis, SC, 2001.

53 Domingos, R.H., Pustelnik, M., Trapp, L.G., Silva, G.A.L., Campo, W., and Santos, L.C.C., "Development of an Engine Anti-Ice Protection System using Experimental and Numerical Approaches", SAE paper 2007-01-3355, Sept. 2007.

54 Donatti, C.N., Simulação Numérica da Formação de Gelo com Modelo de Rugosidade em Perfis Aerodinâmicos, M.Sc. Dissertation, Universidade Federal de Santa Catarina, Florianópolis, SC, 2007.

55 Federal Aviation Administration Advisory Circular AC 20-73A, “Aircraft Ice Protection", April 2006.

56 Poling, B.E., et al., The Properties of Gases and Liquids, McGraw-Hill, 5th ed., 2001, pp.11.5-11.6, B.1.

57 Gau, C., and Chung, C. M., "Surface Curvature Effect on Slot-Air-Jet Impingement Cooling Flow and Heat Transfer Process", Trans. of the ASME, Vol. 113, pp. 858-864, 
Nov. 1991.

58 Myers, T.G., "Extension to the Messinger Model for Aircraft Icing", AIAA Journal, Vol. 39, No. 2, Feb. 2001, pp. 211-218.

59 Menter, F.R., "Two-Equation Eddy-Viscosity Turbulence Models for Engineering Applications", AIAA Journal, Vol. 32, No. 8, 1994, pp. 1598-1605.

60 Menter, F.R., "Improved Two-Equation $k$ - $\omega$ Turbulence Model for Aerodynamic Flows", NASA TM-103975, 1992.

61 Wilcox, D.C., Turbulence Modeling for CFD, DCW Industries, Inc. La Canada, California, 1998.

62 Fluent Incorporated, FLUENT 6.3 User's Guide, Lebanon, NH, 2007.

63 Remfry. J., Heat Transference and Pressure Loss for Air Flowing in Passages of Small Dimensions, Ph.D Dissertation, University of London, London, UK, 1947.

64 Wright, W.B., "Users Manual for the NASA Glenn Ice Accretion Code LEWICE Version 3.0", available on the NASA LEWICE 3.0 release CD, Apr. 2003.

65 Croce, G., De Candido, E., Habashi, W.G., Aubé, M. S., and Baruzzi, G.S., "FENSAPICE: Numerical Prediction of In-flight Icing Roughness Evolution", AIAA paper 20904126, Jun. 2009.

66 Montreuil, E., Chazottes, A., Guffond, D., Murrone, A., Caminade, F., and Catris, S., "Enhancement of Prediction Capability in Icing Accretion and related Performance Penalties Part I: Three-dimensional CFD Prediction of the Ice Accretion".

67 Fortin, G., Perron, J., Mingione, G., and Luliano, E., "CIRAAMIL Ice Accretion Code Improvement”, AIAA paper 2090-3968, Jun. 2009.

68 Brown, J.M., Watterson, J.K., Raghunathan, S., Linton, A. J., "Heat Transfer Correlation for De-icing Systems", AIAA paper 2001-0837, Jan. 2001.

69 Martin, H., "Heat and Mass Transfer between Impinging Gas Jets and Solid Surfaces", Advances in Heat Transfer, Vol. 13, Academic Press, 1977, pp. 1-60.

70 Fregeau, M., Saeed, F., Paraschivoiu, I., "Numerical Correlation of Heat Transfer From an Array of Hot-Air Jets Impinging on 3D Concave Surface", AIAA paper 2003-3403, Jun. 2003.

71 Pellissier, M., Habashi, W.G., Pueyo, A., "Design optimization of hot-air anti-icing systems by FENSAP-ICE”, AIAA paper 2010-1238, Jan. 2010. 
72 Weiss, J. M., Maruszewski, J.P., and Smith, W.A., "Implicit Solution of the Navier-Stokes Equations on Unstructured Meshes", AIAA paper 1997-32420, 1997.

73 Weiss, J. M., Maruszewski, J.P., and Smith, W.A., "Implicit Solution of Preconditioned Navier-Stokes Equations using Algebraic Multigrid", AIAA Journal, Vol. 37, No. 1, pp. 29-36, 1999.

74 Issa, R.I., "Solution of Implicitly Discretized Fluid Flow Equations by Operator-Splitting", Journal of Computational Physics, Vol. 62, 1985, pp. 40-65.

75 Stueben, K. "Introduction to Algebraic Multigrid". In C. W. Oosterlee, U. Trottenberg, and A. Schuller, editors, Multigrid, Academic Press, New York, 2001, pp. 413-532.

76 de Mattos, B. and Oliveira, G., "Three-dimensional Coupled Analysis of a Wing Slice Slat with a Piccolo Tube", AIAA paper 2000-39841.

77 Morsi, S.A., and Alexander, A.J., 1972. "An Investigation of Droplet Trajectories in TwoPhase Flow Systems.” J. Fluid Mech., 55(2): pp 193-208.

78 Wong, S.H., Papadakis, M., Zamora, A.O., "Computational Investigation of a Bleed Air Ice Protection System”, AIAA paper 2009-3966, Jun. 2009.

79 Gelder, T.F., and J.P. Lewis, "Comparison of Heat Transfer from Airfoil in Natural and Simulated Icing Conditions", NACA TN 2480, Sept. 1951. 
APPENDIX 


\section{BINARY MASS DIFFUSION COEFFICIENT FOR AIR-WATER VAPOR MIXTURES}

The binary mass diffusion coefficient for air-water vapor mixture $D_{a w}$ (in $\left[\mathrm{cm}^{2} / \mathrm{s}\right]$ ) is computed according to [56], as shown in Equation (A.1),

$$
D_{a w}=\frac{0.00266 T^{3 / 2}}{P(M W)_{a w}^{1 / 2} \sigma_{a w}^{2} \Omega_{D}}
$$

where:

$\rightarrow \mathrm{T}$ is temperature of the mixture (in $[\mathrm{K}]$ )

$\rightarrow \mathrm{P}$ is the pressure (in [bar])

$\rightarrow \sigma_{a w}$ is the average of the effective collision diameters of air $\sigma_{a}=3.711[\AA]$ and water $\sigma_{w}=2.641[\AA]$

$\rightarrow(M W)_{a w}$ is defined as $2 /\left[(M W)_{a}^{-1}+(M W)_{w}^{-1}\right]$, where $(M W)_{a}$ is the molecular weight of air, $28.965[\mathrm{~kg} / \mathrm{kg}-\mathrm{mol}]$, and $(M W)_{w}$ is the molecular weight of water, 18.01056 $[\mathrm{kg} / \mathrm{kg}-\mathrm{mol}]$

$\rightarrow \Omega_{D}$ is the dimensionless collision integral for diffusion, which is given by:

$$
\Omega_{D}=\frac{1.06036}{\left(T^{*}\right)^{0.15610}}+\frac{0.19300}{\exp \left(0.47635 T^{*}\right)}+\frac{1.03587}{\exp \left(1.52996 T^{*}\right)}+\frac{1.76474}{\exp \left(3.89411 T^{*}\right)}
$$

In Equation (A.2), $T^{*}$ is defined as:

$$
T^{\cdot}=\left(\frac{T}{\left(\varepsilon_{a} \varepsilon_{w}\right)^{1 / 2}}\right)
$$

The terms $\varepsilon_{a}$ and $\varepsilon_{w}$ in Equation (A.3) are the Lennard-Jones "12-6" characteristic energies normalized by Boltzmann's constant, for air and water respectively (in $[\mathrm{K}]$ ). 